NBSIR 85-3136

\title{
Summaries of Center for Fire Research Grants and In-House Programs - 1984
}

Sonya M. Cherry, Editor

U.S. DEPARTMENT OF COMMERCE

National Bureau of Standards

National Engineering Laboratory

Center for Fire Research

Gaithersburg, MD 20899

April 1985

Final Report

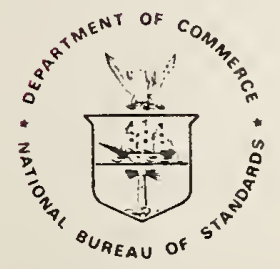

U.S. DEPARTMENT OF COMMERCE

- QC - ATIONAL BUREAU OF STANDARDS

100

.456

$85-3136$

1985 



\section{SUMMARIES OF CENTER FOR FIRE} RESEARCH GRANTS AND IN-HOUSE PROGRAMS - 1984

Sonya M. Cherry, Editor

U.S. DEPARTMENT OF COMMERCE

National Bureau of Standards National Engineering Laboratory

Center for Fire Research

Gaithersburg, MD 20899

April 1985

Final Report 

TABLE OF CONTENTS

$\underline{\text { Page }}$

ABSTRACT. . . . . . . . . . . . . . . . . . . . . 1

CENTER FOR FIRE RESEARCH PROGRAMS

Ad Hoc Working Group of Mathematical Fire Modeling. . . . . . . . . . . . 2

Compartment Fire Modeling . . . . . . . . . . . . . . . . . 3

Exploratory Fire Research . . . . . . . . . . . . . . . . 8

Fire Growth and Extinction. . . . . . . . . . . . . . . . . 14

Fire Performance and Validation . . . . . . . . . . . . . . 20

Fire Safety Performance . . . . . . . . . . . . . . . . 24

Fire Toxicology . . . . . . . . . . . . . . . . . . 28

Furnishings Flammability. . . . . . . . . . . . . . . . . 34

Smoke Hazard. . . . . . . . . . . . . . . . . . . . 37

GRANTS AND CONTRACTS

American Institute of Architects

A Computerized Model for the Simulation of

General Fire Emergency Evacuations . . . . . . . . . . . . . 40

Brown University

Soot Dynamics in Flames. . . . . . . . . . . . . . . . . 43

Brown University

Study of Effects of Material Properties on

Flaming Combustion of Charring Fuels . . . . . . . . . . . . 47

California Institute of Technology

Experimental Study of Environment and

Heat Transfer in a Room Fire . . . . . . . . . . . . . . 51

Case Western Reserve University

Experimental and Analytical Study of

Fire Sprinkler Scaling Laws. . . . . . . . . . . . . . 55

Case Western Reserve University

Flame Spread and Spread Limits . . . . . . . . . . . . 58 
Clemson University

Ternary Reactions Among Polymer Substrate-

Organohalogen-Antimony Oxides in the Condensed

Phase Under Pyrolytic, Oxidative and Flaming

Conditions. . . . . . . . . . . . . . . . . . . . . 60

Colorado School of Mines

Characterization of Aerosols from Fires . . . . . . . . . . . 63

Factory Mutual Research Corp.

Calculated Interaction of Water Droplet Sprays

with Fire Plumes in Compartments. . . . . . . . . . . . . . 66

Factory Mutual Research Corp.

Determination of Fuel Parameters for Fire

Modeling. . . . . . . . . . . . . . . . . . . 70

Factory Mutual Research Corp.

Effects of Water Discharge Rate and Drop Size

on Spray Cooling in Residential Fires . . . . . . . . . . . . . 72

Factory Mutual Research Corp.

Experimental Fire and Smoke Verification Data

for Multiroom and Corridor Conditions . . . . . . . . . . . 75

Factory Mutual Research Corp.

Prediction of Fire Dynamics . . . . . . . . . . . . . . . 78

Harvard University

Prediction of Upper Layer Composition in

Transient Compartment Fires . . . . . . . . . . . . . . 87

The Pennsylvania State University

An Investigation of Turbulent Fires on

Vertical and Inclined Walls . . . . . . . . . . . . . 90

Princeton University

Flow Field Effects on the Sooting Structure

of Diffusion Flames . . . . . . . . . . . . . . . 9 95

Rutgers, The State University of New Jersey

Negatively Buoyant Flows Generated in

Enclosure Fires .......................

Southwest Research Institute

Analysis of Hazards to Life Safety in Fires:

A Comprehensive Multi-Dimensional Research

Program . . . . . . . . . . . . . . . . . 100

Stanford University

The Behavior of Furniture Frames During Fire. . . . . . . . . . . 104 
TRW

Modeling of Wind-Aided Flame Spread. . . . . . . . . . . . 109

University of California, Berkeley

Fire Propagation in Concurrent Flows . . . . . . . . . . . . . 113

University of California, Berkeley

Flame Radiation. . . . . . . . . . . . . . . . . . . 117

University of California, Berkeley

Fire Modeling. . . . . . . . . . . . . . . . . . 120

University of Dayton Research Institute

Mathematical Modeling of Furniture Fires . . . . . . . . . . . . . 124

University of Florida

Network Models of Building Evacuation:

Development of Software System - Year

Three. . . . . . . . . . . . . . . . . . . 127

University of Minnesota

Method and Apparatus for Quantitative

Fit Test of Respirators. . . . . . . . . . . . . . . 131

University of Montana

Chemistry of Smoldering Combustion . . . . . . . . . . . . 133

University of Notre Dame

Scaling Correlations of Flashover

Experiments. . . . . . . . . . . . . . . . . 137

University of Pittsburgh

Toxicity of Plastic Combustion Products. . . . . . . . . . . . 141

APPENDIX A, AGENDA, 1984 ANNUAL CONFERENCE ON FIRE RESEARCH . . . . . . . 143 APPENDIX B, LIST OF PARTICIPANTS. . . . . . . . . . . . . . . 149 



\title{
Summaries of Center for Fire Research Grants and In-House Programs - 1984
}

October 1984

\begin{abstract}
This report was prepared for distribution at the 1984 Annual Conference on Fire Research, October 17-19, 1984. It contains extended abstracts of grants and contracts for fire research sponsored by the Center for Fire Research, National Bureau of Standards, as well as descriptions of the internal programs of the Center for Fire Research.

Key words: Evacuation; combustion; extinction; fire models; flame spread; ignition; polymers; smoke; soot; toxicity.
\end{abstract}


AD HOC WORKING GROUP OF MATHEMATICAL FIRE MODELING

CENTER FOR FIRE RESEARCH

FY 84

\section{Professional Personnel}

Robert S. Levine, Chairman of Steering Committee

John A. Rockett, Chairman of Computer Committee

James G. Quintiere, Chairman of Models Subcommittee

NOTE: The Modeling Committee is chaired by Professor Howard Emmons of Harvard University, the Subprogram Committee by John de Ris of Factory Mutual, and the User's Needs Committee by Irwin Benjamin of Benjamin-Clarke.

A number of CFR personnel are members of the technical committees.

\section{Program Objectives}

The objectives of this committee are to facilitate the development and use of mathematical models of fire and to coordinate and facilitate research needed to improve the models. The Steering Committee includes members from other government agencies who have influence on their agencies' research and development in this field. The coordination, of course, is voluntary.

\section{Project Areas}

Each applicable area is included in another program abstract. The major portion of the CFR effort is in the Fire Modeling Program.

\section{Associated Grants}

Several grants as listed elsewhere. 


\section{COMPARTMENT FIRE MODELING \\ FIRE SAFETY TECHNOLOGY DIVISION \\ CENTER FOR FIRE RESEARCH \\ FY 84}

\section{Professional Personnel}

Leonard Y. Cooper, Head

John A. Rockett, Senior Research Scientist

Henri E. Mitler, Physicist

David W. Stroup, Fire Protection Engineer

Masahiro Morita, Guest Worker (Tokyo Science University)

Anne Woodhouse, Guest Worker (University of Maryland)

\section{Program Objectives}

(1) Develop, maintain, improve and provide assistance in the use of benchmark Compartment Fire Model computer codes. Provide assistance in the improvement of applications-oriented compartment fire simulation models, and measure their performance against the benchmark codes.

(2) Develop and maintain a library of submodel algorithms for general use in compartment fire models.

(3) Formulate, develop, and establish the validity of new and improved analytic/computational compartment-fire-phenomena submodel algorithms for use in compartment fire simulations.

\section{Scope}

The work focuses on the development of benchmark computer codes(s) which would be useful in simulating the phenomena which occur in compartment fire scenarios. The term "benchmark computer code" is intended to connote a welldocumented computer code which: a) is based on physics and numerics of proven reliability; b) is numerically robust; and c) is user-friendly in the sense that it can be used with relative ease by researchers and professional fire safety practitioners, and that it can be transferred to and used with computer hardware facilities readily available to the fire science/technology community.

While the benchmark computer code(s) would be up-to-date in the sense of including algorithms which describe the details of fire phenomena currently under investigation in the Fire Research Community, they would not be responsive to forecasts of future research thrusts. In terms of the complexity of compartment configurations, the capability of the new generation of benchmark code(s) would be limited to the simulation of fire-generated environments only in those compartment spaces which affect actual fire development, e.g., in rooms of fire involvement and "freely connected" adjacent spaces. In terms of the level of "user-friendliness", the code(s) would be useful to researchers and practitioners with relatively high levels of commitment and technical skill. 
1. Compartment Fire Models

Single-Room Fire Simulations. The Harvard single-room fire model has been operational at NBS for some years. It has been used both for demonstration calculations and as a test bed for new modeling concepts. The "official" Harvard V, model has been enriched successfully. The results of this have led to two new and different versions of the model; namely, versions 5.2 and 5.3. The enrichments include:

- restructuring of the physical subroutines so that they are interchangeable with other compartment fire simulation computer codes (5.2).

- restructuring the code in a way that facilitates the incorporation of new or different equation solvers (5.2).

o the ability to include the dynamics of forced ventilation in the simulation (5.3).

NBS/Harvard 5.2 has been applied in two practical problem areas. The first of these involves the simulation of full-scale fire tests carried out at NBS for the U.S. Park Service. In this study, physically reasonable input parameters resulted in a good simulation of the experimental data. Using the same input parameters, the simulation was then used to predict fire behavior in rooms of different sizes from that included in the test program. This allowed the experimental data base to be extended to cases which would have been very expensive, and perhaps impractical to have tested.

The other application of NBS/Harvard 5.2 was to a design problem associated with sizing the ventilation fans of a proposed new Navy firefighter training facility. A series of simulations of the facility were run with different ventilation conditions. Results included predicted temperatures and gas compositions in the training facility as the amount and location of fire gas extraction were varied. From this, a rational choice of ventilating fans was possible.

Harvard 5.3 was used to simulate the fire environments generated during tests in the full-scale, ventilated, fire test facility of the Lawrence Livermore National Laboratory.

Additional progress was made in making the ASET (Available Safe Egress Time) computer program more user-friendly. This work is now continuing as a joint activity with the Fire Safety Performance Group of CFR. ASET has found much application over the course of the last year.

In a special study for the FAA a model of the external-fuel-spill-fire - generated environment in aircraft cabins was developed and used to establish an analytic methodology for simulating the thermal response of cabin ceiling materials. The analysis was developed in conjunction with experimental data available from FAA fire tests on a full-scale, wide-body, aircraft fuselage.

In another special study for the U.S. Park Service a simple graphical method for designing smoke control systems in atrium-like configurations was developed. 
Mult1-Room Fire Simulation (based on Harvard VI). Harvard VI was brought to NBS in usable form during the summer of 1983. It was made operational on the CFR computer, made to conform strictly to the ANSII FORTRAN 77 standard, and a series of minor errors were corrected. After adding several enrichments, it has been "calibrated" against some avallable NBS multi-room fire test data. The agreement between the tests and the simulations was very good. As a part of this effort, an extensive debugging capability was also added to the computer code. A separate plot package, originally developed for NBS/Harvard 5.2, has been adapted to the more general demands of the new NBS/Harvard VI. Further enrichments suggested by the calibration simulations are being added at this writting.

Cooper, L.Y., "Smoke Movement in Rooms for Fire Involvement and Adjacent Spaces", presented at 1983 SFPE Symposium on Smoke-Its Chemistry, Physics and Control Through Engineering, Fire Safety Journal, 7, 1 (1983).

Cooper, L.Y., "The Development of Hazardous Conditions in Enclosures with Growing Fires", Combustion Science and Technology, 33, (1983).

Cooper, L.Y., "Methods of Designing and Evaluating Facilities for Fire Safety", presented at the 7 th Joint Meeting of the UJNR Panel on Fire Research and Safety (1983), and to appear in the Proceedings of the Meeting.

Cooper, L.Y., "The Need and Availability of Test Methods for Measuring the Leakage Characteristics of Door Assemb1lies", NBSIR 84-2876, presented at the 1984 ASTM/FSPE Symposium on Applications for Fire Science to Fire Engineering, to appear in Fire Sclence.

Cooper, L.Y., Nelson, H.E., and Thorne, S., "National Park Service Full-Scale Burns: Analysis and Insights Gained", a video tape report to the U.S. National Park Service (1984).

Cooper, L.Y., and Stroup, D.W., "ASET: A Computer Program for Calculating Available Safe Egress Time", presented at 1984 SFPE Symposium on Computer Applications in Fire Protection: Analysis, Modeling and Design, to appear in Fire Safety Journal.

Cooper, L.Y., "The Thermal Response of Aircraft Cabin Ceiling Materials During a Post-Crash, External Fuel-Sp111, Fire Scenar1o", to appear as an NBSIR 842912 and as Chapter 2 in a NBS report to the FAA: "The Role of Aircraft Pane1 Materials in Cabin Fires and Their Properties," presented to the FAA, to be presented at the 23rd AIAA Aerospace Sclences Meeting (1985), to be submitted for publication.

Cooper, L.Y., "An Interim Buoyancy Smoke Control Approach (for Atrium-like Arrangements", Appendix B of NBSIR under review: Fire Safety Evaluation System for National Park Service Accommodations, H.E. Welson, et al.

Rockett, J.A., "Park Service Room Fire Test Simulations, Using the Harvard Level 5.2 Computer Fire Model", NBSIR 83-2805.

Baum, H., and Rockett, J.A., "Analysis of Forced Ventilation in Container Ship Holds", Journal of Flu1d Mechanics 142, pp. 309-342 (1984). 
Rockett, J.A., "Data for Room Fire Models", to appear in Combustion Science and Technology.

Rockett, J.A., "Two Approaches to the Analysis of Actual Fires", presented at 1984 SFPE Symposium on Computer Applications in Fire Protection: Analysis, Modeling and Design, to appear in Fire Safety Journal.

Mitler, H.E., "Zone Modeling of Forced Ventilation Fires", Combustion Science and Technology, 39, 88 (1984).

Mitler, H.E., "The Harvard Fire Model", presented at 1984 SFPE Symposium on Computer Applications in Fire Protection: Analysis, Modeling and Design, to appear in Fire Safety Journal.

Stroup, D.W., "Heat-Transfer-Related Calculations for the Jefferson National Memorial Historical Site", Appendix A of NBSIR under review: Jefferson National Memorial Historical Site Analysis of Impact of Fire, H.E. Nelson, et al.

2. Compartment Fire Model Library of Submodel Algorithms and Associated Computer Subroutines

This project involves a series of short- and long-term activities. These will be initiated by: a) merging the physical subroutines of the NBS/Harvard computer codes into a single, portable, subroutine library; b) reviewing the subroutine algorithms of the NBS/harvard computer codes, and identifying those which are of "benchmark" quality (the term "benchmark quality algorithm is intended to suggest an algorithm which would generally be considered to provide reliable physical simulations, and an algorithm which would not likely be substantially improved as a result of indepth review and analysis of existing fire-science-related literature); c) developing and proposing a format for a Catalogue of Compartment Fire Submodel Algorithms. Developing and proposing a mechanism for publication, distribution and revision of the Catalogue. The Catalogue will be for general use in zone comparment fire models.

The project has only recently been initiated and products have not yet been generated.

3. Compartment-Fire-Generated Flow Dynamics, Flame Spread/Growth and Heat Transfer: Submodel/Algorithm Development and Ventilation

NBS/Harvard 5.2 was used to evaluate each of five different published plume entrainment models when used in single-room fire simulations. A series of simulations were run for both small fires, for which experimental room gas flow measurements were available, and for larger fires where experimental data is not now available. The fire plume models led to simulations which were in moderate agreement with the small fire test data. There was a wide disparity in the predicted results for the large fire. To select from among these several models additional experimental data for large area and heat-release-rate fires will be needed.

The dynamics of forced ventilation in the context of a two-layer compartment fire model has been analyzed, and an algorithm for simulating the phenomenon 
was developed. This was used to enrich Harvard 5.3. An algorithm for simulating the effect of roof venting under natural convection conditions was also developed. This latter algorithm has not yet been incorporated into the full compartment fire model(s).

Work has been recently initiated on a new, reduced-scale, experimental program where the thermal response of different ceiling constructions positioned above fires of different strengths and fire-ceiling separations will be measured. This experimental program will complement continuing theoretical activities which are being carried out to formulate, develop and validate algorithms for simulating compartment-fire-generated flow dynamics and heat transfer.

A theoretical study of the structure of wall fires has been undertaken from the point of view that the results be consistent with available experimental data, and useful in an algorithm which is simple enough for use in full compartment fire models.

Cooper, L.Y., "On the Significance of a Wall Effect in Enclosures with Growing Fires", to appear in Combustion Science and Technology.

Cooper, L. Y., "A Buoyant Source in the Lower of Two, Homogeneous, Stably Stratified Layers - A Problem of Fire in an Enclosure", presented at 1983 ASME Symposium on Modeling at Environmental Flow Systems, and at the 20th International Symposium on Combustion (1984), to appear in the Proceedings of the latter Symposium.

Cooper., L. Y., "The Thermal Response of Unconfined Ceilings Above Growing Fires and the Importance of Convective Heat Transfer", NBSIR 84-2856, presented at 22nd National Heat Transfer Conference (1984), and at the 1984 CFR Annual Conference on Fire Research, to be submitted for publication.

Rockett, J.A., "A Comparison of Plume Entrainment Models", manuscript under review.

Mitler, H. E., "On Roof Vents", manuscript under review.

\section{Associated Grants and Contracts}

1. Yogesh Jaluria - Rutgers - The State University of New Jersey, "Negatively-Buoyant and Penetrative Flows Generated in Enclosure Fires."

2. Colin H. Marks - University of Maryland, "Transient Heat Transfer in Ceiling Jets." 


\section{EXPLORATORY FIRE RESEARCH \\ FIRE MEASUREMENT AND RESEARCH DIVISION \\ CENTER FOR FIRE RESEARCH \\ FY 84}

\section{Professional Personnel}

Walter M. Shaub, Head

James E. Brown, Research Chemist

George W. Mulholland, Research Chemist

Takashi Kashiwagi, Materials Research Engineer

W. Gary Mallard, Research Chemist

William J. Parker, Physicist

Thomas J. Ohlemiller, General Engineer

William M. Pitts, Research Chemist

Kathleen E. Werner, Chemist

Kermit C. Smyth, Research Chemist

Atsushi Inaba, Guest Worker

J. Houston Miller, Faculty Research Associate

\section{Program Objectives}

(1) Improve the understanding of the chemical and physical processes which underline macroscopic fire phenomena. The research embraces broad areas covering both solid and gas phase processes, with particular attention to polymer degradation, the effect of thermal radiation, and the hot gas chemistry and physics leading to incomplete combustion.

(2) Devise new techniques and methods for studying these phenomena.

(3) Furnish fundamental scientific information to support the other activities within the Center for Fire Research.

\section{$\underline{\text { Scope }}$}

This work is scientific not empirical. It embraces broad areas underpinning CFR programs with focussed study in the areas of materials degradation, hot gas physics and chemistry, and thermal radiation. Efforts are directed toward improved understanding of the chemical and physical processes which underlie macroscopic fire phenomena and include development of new techniques and methods for studying these processes.

\section{$\underline{\text { Project }}$}

\section{Polymer Gasification and Ignition}

The mechanisms of thermal degradation and thermal oxidation of poly (methyl methacrylate) (PMMA) are being studied by measuring the molecular weight of rapidly quenched samples thermally degraded in nitrogen and air in the range of temperatures between $200^{\circ} \mathrm{C}$ and $325^{\circ} \mathrm{C}$. Present work shows that thermal oxidation reduces the degree of polymerization much faster than does thermal 
degradation. Random scission has been found to be the initiation step for both thermal degradation and oxidative degradation. The activation energy for the random scission initiation is $233 \mathrm{kj} / \mathrm{mole}$ for thermal degradation and $64 \mathrm{kj} /$ mole for oxidative degradation. The average zip length decreases from 2620 to 1340 with an increase in temperature from $258^{\circ} \mathrm{C}$ to $324^{\circ} \mathrm{C}$ for thermal degradation. The average $z$ ip length increases from 20 to 102 with an increase in temperature from $205^{\circ} \mathrm{C}$ to $251^{\circ} \mathrm{C}$ for thermal oxidative degradation. A reasonable value of activation energy for the termination reaction in nitrogen, 104 $\mathrm{kj} / \mathrm{mole}$, is obtained only for the assumption of first order termination.

Weight loss rates and surface temperature of Lucite and Plexiglas $G$ have been measured in air and nitrogen at a radiant flux of $2.2 \mathrm{~W} / \mathrm{cm}^{2}$ from the blackbody radiant source. Results show that the change in surface temperature with time is almost the same for both samples either in nitrogen or in air, there is no difference in surface temperature between the two samples. However, the rates of weight loss are significantly different for the samples degraded in nitrogen: Lucite degrades with much faster rates than Plexiglas G. Plexiglas G shows a two step type degradation pattern which was recognized by thermal analysis of a small sample. The weight loss of Plexiglas but not Lucite shows a strong oxygen dependency in the gas phase. This trend is consistent with that observed by a thermal analysis study. These observations indicate that the chemical degradation mechanism does not change from slow heating rates of $0.5 \sim 5^{\circ} \mathrm{C} / \mathrm{m}$ in the thermal study to typical heating rates of $\mathrm{N}$ tens ${ }^{\circ} \mathrm{C} / \mathrm{S}$. of degrees per second in fire conditions.

A theoretical model is being developed to calculate changes in weight loss and in the molecular weight distribution of a polymer, including random scission initiation, depropagation and termination reactions without any transport processes. This calculation simulates results of thermal analysis of the polymer. The model uses about 40,000 ordinary differential equations. Each differential equation is written with respect to an individual degree of polymerization. In addition, work on the theoretical description of the pyrolysis of (certain) polymers is nearly complete.

Experiments are being carried out to investigate the effect of terminal vinyl groups on the stability (thermal) of PMMA. GPC chromatograms of thermally stressed or non-stressed samples have been made. A glass apparatus has been designed in which hydrogenation of the PMMA terminal vinyl groups will be made in preparation for further studies.

Kashiwagi, T., Hirata, T. and Brown, J.E., "Thermal and Oxidative Degradation of Poly(methyl methacrylate) - Molecular Weight", submitted to Macromolecules (1984).

Kashiwagi, T. and Hirata, T., "Thermal and Oxidative Degradation of Poly (methyl methacrylate) II. Weight Loss", submitted to J. Poly. Sci. Macromolecules (1984).

\section{Smoldering Combustion of Cellulosics}

The propensity for smoldering exhibited by cellulosic materials continues to be a subject of major concern. Smoldering combustion is driven by exothermic oxygen attack on the surface of organic materials; wood-based materials such as cellulosic insulation are particularly prone to this attack. The process is slow but self-sustaining once initiated. It poses a life threat as a copious 
source of toxic gases. Also, it provides a relatively easy pathway to flaming combustion that is not precluded by flame retardants. It is this latter aspect-smoldering as an initiator of flaming--which is of greatest concern with cellulosic insulation materials. Smolder to flaming tests are presently being conducted using unretarded cellulosic insulation material. Though it comes from the same manufacturer, a batch may exhibit somewhat differing behavior from the last batch. This is probably a consequence of a different composition of inorganic ions in the insulation stock.

The study of the low temperature $\left(295-315^{\circ} \mathrm{C}\right)$ pyrolysis and oxidation of cellulose continues. Our present goal is to "come up" with some sort of mechanism to account for the endo and exothermic heats of reaction observed in DSC experiments with $\mathrm{N}_{2}$ and $\mathrm{O}_{2}$ respectively. We are analyzing for $\mathrm{CO}, \mathrm{CO}_{2}$ methyl alcohol, $\mathrm{H}_{2} \mathrm{O}$ and levoglucosan, the compounds we believe account for nost of the weight loss. Since we are interested in solid phase reactions, the role of gas phase reactions in the distribution of products had to be ascertained. This was accomplished by varying the flow rate $(0.24-1.41 / \mathrm{min})$. of the carrier gas in our tube furnace. Our present work suggests gas phase oxidation is not affecting product distributions for experiments with flow rates greater than $1.01 / \mathrm{min}$. We are now performing experiments with $\mathrm{N}_{2}$ and air at 295,305 and $315^{\circ} \mathrm{C}$ with the expectation that the product distribution will provide insights as to a mechanism.

Physical property data for char forming materials are being carefully developed to support an effort to be able to predict the heat release rate of wood. A new pyrolyzer is being constructed for this purpose. This will be used to obtain mass generation rate data and heats of combustion of the volatile pyrolysis products from wood components (cellulose, hemicellulose and lignin) using the new pyrolyzer and the gas sampling system in the cone calorimeter. The thermal property data for various soft and hardwoods will be obtained as a function of temperature and fractional mass loss. A model will be used to predict the heat release rates of woods in a vertical orientation as a function of incident flux and specimen thickness. The predictions of the model will be compared against cone calorimeter results.

Parker, W.J., "Calculations of the Heat Release Rate By Oxygen Consumption for Various Applications", submitted to Journal of Fire Sciences (1984).

Ohlemiller, T., "Modeling of Smoldering Combustion Propagation", submitted to Progress in Energy and Combustion Science.

Ohlemiller, T., "Structure of a Smoldering Combustion Wave in a Permeable Horizontal Fuel Layer", in preparation.

Ohlemiller, T., "Modeling of Smoldering Combustion Propagation", NBSIR 84-2895, National Bureau of Standards, Washington, D.C., June 1984

\section{Products of Wood Combustion}

The objective of this research is to understand degradation processes of wood under fire conditions and the formation and evolution of the combustion

products. Major support for this work comes from the Department of Energy under 
its residential alternate fuels program. Our studies elucidate the chemical processes occurring in the fuel itself under controlled pyrolysis. High resolution nuclear magnetic resonance spectra clearly show the evolution from a cellulosic/lignin structure to a highly aromatic structure. Gaseous samples from various locations in the stack of a wood stove show no chemical change once they leave the firebox.

Radiative heating tests on various woods are being conducted. We are studying the effects of flux, oxygen, grain orientation, water level, wood type, wood thickness and exposure time effects on emitted products. Major organic species are being primarily identified by GC-MS. We plan to utilize as many as five thermocouples to characterize the evolving thermal wave in the wood. This information and the time dependent mass flux will be compared with the predictions of a theoretical model (for non-oxidative atmospheres first).

\section{Soot Formation Chemistry and Physics}

Flame radiation from incandescent soot dominates flame spread and heat transfer in large fires. Escaping particulates hinder vision and impair breathing, as well as being a sensitive signature for fire detection. Despite this importance, there is little understanding at the molecular level of the soot formation process; i.e., how small molecules grow rapidly to become soot particles. We are now in the fifth year of a long-term study of the fundamental chemistry and physics of soot formation, carried out jointly with the NBS Thermal Processes Division in the Center for Chemical Engineering.

A series of optical and mass spectrometric profile measurements have been completed for methane/air diffusion flames on our Wolfhard-Parker burner. We have used fluorescence to monitor $\mathrm{OH}, \mathrm{C}_{2}$, and polycyclic hydrocarbons (three ways), multiphoton ionization to detect polycyclics and small soot particles and Rayleigh-mie scattering to observe the emergence of large soot particles. In addition, mass spectrometric profiles of $\mathrm{CO}_{2}, \mathrm{H}_{2} \mathrm{O}$, methane, acetylene, butadiene, benzene, toluene, diacetylene, triacetylene, vinyl acetylene, methylacetylene, and allene have been taken. These results clearly delineate the region of soot nucleation: soot particles, first appear on the high temperature, radical-rich side of a zone containing numerous pyrolysis products. Velocity measurements using laser doppler velocimetry for the same flame conditions are being planned.

In addition to species characterization studies, physical properties of soot are being investigated. The kenetics of cluster aggregation and structure of the resulting clusters have been studied using a "Brownian dynamics" computer simulation of conditions appropriate for soot growth. A free radical soot growth model has been extended to account for the pyrolysis of the fuel in a more realistic manner. The flow pattern of a starting plume in an enclosure has been measured using an aerosol tracer. The heat loss to the walls and ceiling in the smoke dynamics facility has been measured as a function of time as the smoke fills the enclosure. A study of smoke detector sensitivity to a dioctylsebacate aerosol indicated one of three tested to have adequate sensitivity for use in a quantitative test for respirator face mask fit.

Dobbins, R.A. and Mulholland, G.W., "Interpretation of Optical Measurements of Flame Generated Particles," Comb. Sci. and Tech., 40, 175 (1984). 
Mountain, R. and Mulholland, G.W., "Stochastic Dynamics Simulation of Particle Aggregation," Proc. of First International Conference on Kinetics of Aggregation and Gelation, D.P. Landar Editor, (1984).

Marx, E. Mulholland, G.W., Size and Refractive Index Determination of Single Polystyrene Spheres," J. of Research NBS, 88, 321 (1983).

Baum, H.R., Rehn, R.G., Mulholland, G.W., "Prediction of Heat and Smoke Movement in Enclosure Fires," Fire Safety Journal 6, 193 (1983).

Miller, J.H., Mallard, W.G., and Smyth, K.C., "Intermolecular Potential Calculations for Polycyclic Aromatic Hydrocarbons," J. Phys. Chem. (in press).

Miller, J.H., Smyth, K.C., and Mallard, W.G., "Calculations of the Dimerization of Aromatic Hydrocarbons; Implications for Soot Formation," Twentieth Symposium (International) on Combustion (accepted).

Smyth, K.C., Mallard, K.C., and Miller, J.H., "Multiphoton Ionization Detection of Molecules in Flames," SPIE Symposium on Laser Chemistry and Diagnostic (in press).

\section{Turbulent Chemically-Reacting Flow}

In a large fire plume, the combustion region is turbulent and is characterized by highly variable (both spatial and temporal) distributions of temperature and species concentration. In such cases the flame properties are dominated by the substantial temperature and species concentration fluctuations. Due to the scarcity of measurements on such systems and the complexity of the phenomena, the understanding of turbulent fire plumes is poor. This project is designed to study chemically reacting turbulent flows by systematically investigating the effects of density differences, temperature differences, and heat release on turbulent mixing.

Our research has shown that hot-wire and film anemometry can be applied to mixtures if the mixture compositon is known. However, despite the wide spread use of these instruments and a great deal of previous research, it has been necessary to undertake a fairly detailed investigation of their response in different gases and mixtures in order to be confident of their behavior. Calibration measurements have been made in binary gas mixtures. The heat transfer in these mixtures is not predicted well by the extrapolated pure gas results. We have postulated that these differences are due to thermal diffusion effects in the mixtures and are using theories especially developed for this study in an attempt to quantitatively predict the magnitude of such effects. The results of our calibration studies have highlighted the complexity and poorly understood nature of the response of heated filament anemometers. Such problems were not evident as we began our investigation. The results of this study have enabled us to understand hot-wire and film response in different gases much better. Such an understanding is necessary for accurate velocity measurements using our new technique.

There has been a great deal of recent interest in making line and two-dimensional measurements of concentration in turbulent flow fields. These measurements 
combine laser based optical probes with the use of new and powerful solid state detector arrays.

The studies done thus far have yielded a great deal of information about turbulent flow fields and have demonstrated the vast potential of these techniques for contributing to an improved understanding of chemically reacting turbulent flow fields. However, it is fair to say that the technique is still severely limited by laser, detector, and computer constraints. For example, the measurements reported thus far have been single shot and measurement accuracy has been poor. We are currently developing an experiment in which line measurements of concentration are to be made in a turbulent flow of two gases. The design goals of this experiment are (1) a $0.2 \mathrm{~ms}$ time resolution, (2) a $0.2 \mathrm{~mm}$ spatial resolution, and (3) a concentration accuracy of $4 \%$ for each individual measurement. A system has been designed which should meet these goals and we have begun purchasing the necessary components for its construction. This new experiment will allow much more detailed studies of density effects on turbulent mixing.

Pitts, W.M. and Kashiwagi, T., "The Application of Laser-Induced Rayleigh Light Scattering to the Study of Turbulent Mixing", NBSIR 83-2641 and Journal of Fluid Mechanics 141, 391 (1984).

Pitts, W.M., McCaffrey, B.J., and Kashiwagi, T., "A New Diagnostic Technique for Simultaneous, Time-Resolved Measurements of Concentration and Velocity in Simple Turbulent Flow Systems", Fourth Symposium on Turbulent Shear Flows, Karlsruhe, Germany, Sept. 1983.

\section{Associated Grants and Contracts}

1. Joseph Flynn and Emanuel Horowitz - The Johns Hopkins University, "Thermal and Material Transport and the Solubility of Oxygen and Other Gases in Oxidizing Polymer."

2. Michael J. Drews and Christine W. Jarvis - Clemson University, "Ternary Reactions Among Polymer Substrate-Organohalogen-Antimony Oxides in the Condensed Phase Under Pyrolytic, Oxidative and Flaming Conditions."

3. Irvin Glassman, Ian M. Kennedy, and Frederick L. Dryer - Princeton University, "Flow Field Effects on the Sooting Structure of Diffusion Flames."

4. Patrick Pagni - Lawrence Berkeley Labratory, "Fire Modeling."

5. Eric M. Suuberg - Brown University, "A Study of the Effects of Oxygen Transport, and Temperature History on the Chemistry of Polymethyl Methacrylate and Cellulose Pyrolysis."

6. Chang-Lin Tien - Lawrence Berkeley Laboratory, "Flame Radiation."

7. Richard A. Dobbins - Brown University, "Soot Dynamics in Flames." 


\section{Professional Personnel}

James Quintiere, Head

Howard Baum, Research Physicist

Dan Corley, Physicist

David Evans, Mechanical Engineer

Margaret Harkleroad, Physicist

Warren Hayes, Fire Protection Engineer

Randy Lawson, General Physical Scientist

James Milke, Fire Protection Engineer

Bernard McCaffrey, Mechanical Engineer

Alex Robertson, Senior Scientist

Ken Steckler, Physicist

Alex Calderas-Flores, Coop Student

Claire Carpentier, Guest Worker, URBAT (France)

Michel Curtat, Guest Worker, CSTB (France)

Yuji Hasemi, Guest Worker, BRI (Japan)

Hiroshi Koseki, Guest Worker, FRI (Japan)

Matt1 Kokkala, Guest Worker, (Finland)

Anil Kulkarni, Summer Faculty, Penn. State

Hi sahiro Takeda, Guest Worker, Univ. of Tokyo (Japan)

\section{Program Objectives}

Through research we aim to develop predictive methods to describe the processes of growth and extinction related to natural fires and fire safety.

\section{Scope}

The work addresses the processes of fire growth and decay associated with fires within structures and with free burning fires. It examines the overall dynamics of fire growth and its suppression in order to identify and understand the significant underlying processes: ignition, flame spread, burning rate, extinction, and the related transport processes. It utilizes mathematical techniques, experimental studies and correlations, and similitude methods to develop accurate predictions for realistic configurations and materials. As appropriate, it formulates and demonstrates its predictive methods for specific applications.

\section{Introduction}

In February 1984 the group expanded its scope to address suppression and extinction by the addition of staff in that area. Also, the activity in "zone" modeling was set apart in a newly created Compartment Fire Modeling group. Several foreign guest workers have since come and gone, each making a distinct contribution to our efforts. Also we should acknowledge the technical and clerical support of Bill Rinkinen, Henry Wheelock, Dorna Williams, and Wanda Duffin. 


\section{Fire Generated Enclosure Phenomena}

Progress continues to be made (in collaboration with the Center for Applied Mathematics) on the computations of three-dimensional unsteady, inviscid, buoyancy generated flows within enclosures. The ability to include vents at the boundary and to address combustion phenomena are under development. Al though computations have been made for long horizontal and vertical ductenclosures, large-scale computer resources have limited our exploration of this capability.

Previously derived experimental data on natural convection wall vent flows due to enclosure fires have been analyzed with two contributions. The first shows the accuracy of current "zone" vent-plume models relative to data on vent flows. This study addressed the phenomena of wall flows and vent mixing effects on the compartment flows. Also it demonstrated the accuracy of predicting natural convection vent flow rates solely from temperature data.

The second analysis showed the relative constancy of the vent (orifice) flow coefficient - 0.68 to 0.73 . A theoretical potential flow solution predicts a value of 0.62 against the data, but the theory indicates a slow increase with vent to room width ratio with a rapid rise to 1 at an aspect ratio of 1 .

A formulation of a one-dimensional unsteady model of counter-current corridor flows induced by a fire has been completed. This work complements external experimental and theoretical elaboration on this class of problems.

In addition, a project to enhance a probabilistic fire growth model for $n$ aval vessels with deterministic formulae is underway. The identification of a decoupled set of algebraic fire growth sub-models offers a useful methodology without heavy computer demands.

"A Perspective on Compartment Fire Growth" by J. Quintiere, Comb. Sc1. and Technol., 40, 1984.

"Finite Difference Calculations of Buoyant Convection in an Enclosure, I. The Basic Algorith" by H. R. Baum, R. G. Rehm, P. D. Barnett, D. M. Corley, S.I.A.M. J. Sci. Stat. Comp. 4, p. 117, (1983).

"Accuracy of Finite Difference Methods in Recirculating Flows" by R. A. Beier, J. deRis, H. R. Baum, Numer. Heat Transfer 6, p. 283, (1983).

"Calculations of Three-Dimensional Buoyant Plumes in Enclosures" by H. R. Baum, R. G. Rehm, Comb. Sci. and Technol., 40, p. 55, (1984).

"Finite Difference Solutions for Internal Waves in Enclosures" by H. R. Baum, R. G. Rehm, S.I.A.M. J. Sci. Stat. Comp., 5, (1984).

"An Investigation of the Forced Ventilation in Containership Holds" by H. R. Baum, J. A. Rockett, J. Fluid Mech., 142, p. 309, (1984). 
"An Assessment of Flre Induced Flows in Compartments" by

J. G. Quintiere, K. Steckler, D. Corley, Fire Sci. and Technol., 4 ,

No. 1, 1984.

"Fire Induced Flows Through Room Openings - Flow Coefficients" by

K. D. Steckler, H. R. Baum, J. G. Quintiere, NBSIR 83-2801, 20th

Int. Symp. on Combustion (to be pub. 1985).

"Numerical Computation of 3-Dimensional Fire Induced Flows and Smoke Coagulation", R. G. Rehm and H. R. Baum, Ninth Int. Conf. on

Numerical Methods in Fluid Dynamics (to be published 1985).

"Prediction of Corridor Smoke Filling Models" by W. W. Jones,

J. G. Quintiere, Comb. Sci. and Technol., 35, 1984.

"Air Flows Induced by Sparse Clouds of Droplets" by D. S. Bright, R. A. Fletcher, H. R. Baum, Aerosol Science and Techology, 3 , p. $187,(1984)$.

"Buoyancy-Induced Wall Flow Due to Fire in a Room" by Y. Jaluria, NBS IR 84-2841, May 1984.

\section{Flame Spread on Materials}

From data taken with a radiant panel apparatus, observations of ignition and lateral flame spread on a vertically oriented material have led to a practical procedure for determining general property data. Relying on a known relationship for the surface heat loss and heat transfer theories for ignition and flame spread, the following effective properties can be determined.

$$
\begin{aligned}
& \text { kpc product of conductivity, density, specific heat } \\
& \begin{aligned}
\mathrm{T}_{\mathbf{i g}} & \sim \text { ignition temperature } \\
\mathrm{T}_{\mathrm{S}, \mathrm{m}} & \sim \text { minimum temperature required for spread }
\end{aligned} \\
& \Phi \sim \text { flame heat transfer parameter so that for ignition by thermal } \\
& \text { radiation }\left(\dot{q}_{e}^{\prime \prime}\right) \text { under natural convection cooling, the time to } \\
& \text { ignite is } \\
& t \sim(k \rho c)\left[\left(T_{i g}-T_{i}\right) / \dot{q}_{e}^{*}\right]^{2}
\end{aligned}
$$

and for opposed flow spread velocity under natural convection

$$
\mathrm{V}=\frac{\Phi}{k \rho c\left(\mathrm{~T}_{i g}-\mathrm{T}_{\mathrm{s}}\right)^{2}}, \mathrm{~T}_{\mathrm{s}} \geq \mathrm{T}_{\mathrm{s}, \mathrm{m}}
$$

for a specified surface temperature $T_{S}$. Over forty materials have been successfully analyzed.

Progress to develop a counterpart procedure for upward flame spread has also been made. The basic premise here is that the spread velocity can be derived from an expression of the form: 


$$
V=\frac{\dot{q}^{\prime 2} \delta_{f}}{k \rho c\left(T_{i g}-T_{s}\right)^{2}}
$$

where $\dot{q} "$ is the flame heat flux and $\delta_{f}$ is the flame extinction length beyond the pyrolysis zone. In general the numerator parameters are not constant: both vary with position and time. From static experiments on a vertical heat transfer surface $(2.5 \mathrm{~m})$ wall slabs and line burner sources ( $Y$. Hasemi) have ylelded total heat flux distributions which can be roughly correlated for all cases into a function only of position normalized with the flame length measured from the base of the test sample. Although radiation and convection have not been separated, the total maximum heat $f l u x$ is generally found to be between 2 to $3 \mathrm{~W} / \mathrm{cm}^{2}$ in the flame zone and in accordance with the data of Ahmad and Faeth overall. Current measurements are attempting to determine the radiative and convective components.

Dynamic experiments of upward flame spread have been conducted ( $K$. Saito) for PMMA and wood samples. The effect of sample width, height and the ignition energy supplied by a line burner source were studled. Surface temperature measurements, along with a parallel radiative piloted ignition study, have been used to define an ignition temperature to define the pyrolysis front and its speed. Although bubbles are observed in the PMMA near $290^{\circ} \mathrm{C}$, ignition appears to occur near $360^{\circ} \mathrm{C}$. For wood, interpretations are more difficult and propagation could not be sustained for our conditions. Analysis and theoretical approaches are in progress.

More work in this area is planned and a study of fire plume ignition of a ceiling surface will be initiated.

"New Concepts for Measuring Flame Spread Properties" by

J. G. Quintiere, M. Harkleroad, ASTM/SFPE Symp. on Appl. of Fire

Sc1. to Fire Eng., Denver, June 1984 (ASTM STP to be published).

"Some Factors Influencing Fire Spread Over Room Linings and in the ASTM E-84 Tunnel Test". by J. Quintiere, Fire and Materials, to be published.

"Wall Flames and Implications for Upward Flame Spread" by

J. Quintiere, M. Harkleroad, Y. Haseni (in review).

"Heat Feedback and Flame Height Measurements on Burning Vertical

Surfaces" by A. Kulkarni, M. Harkleroad and J. Quintiere, Fall

Technical Meeting, Eastern Section, The Comb. Inst., (1983).

\section{Dynamics of Compartment Wall Fires}

This project has concentrated on an experimental study of the burning of a wall slab of PMMA in a $1 \mathrm{~m}$ scale enclosure. A technique has been developed to monitor the mass loss of the PMMA over the fire development phase to "flashover." Instrumentation is used to monitor gas temperatures, wall convective and radiative heat flux, and oxygen concentration. Other more extensive gas analysis equipment has been assembled for more complete measurements subsequently. The objectives of the current experiments are to record the PMMA mass loss rate as a function of the changing compartment conditions, and then 
to investigate the capability of existing theoretical nodels to predict the mass loss rate. This problem, devoid of surface flame spread, is a first step at developing a sound predictive strategy for wall lining materials. A parallel effort is underway to incorporate a complete wall fire growth model into the "Harvard Compartment Fire Code."

Related studies (H. Takeda) included a small scale ( $1 / 3 \mathrm{~m}$-scale) compartment fire experiment in which floor slabs of PMMA were burned. An unusual feature of these experiments showed pulsations in the burning behavior for particular conditions and subsequent extinction in some cases.

Another study, sponsored by the Federal Aviation Administration, involved the assessment of aircraft cabin lining materials subject to post-crash fire conditions. This was a coordinated effort with other groups. It combined the quantitative interpretation of full-scale experiments, an attempt to predict ceiling ignition in this scenario, and an extensive series of measurements on six candidate aircraft panel materials in several flammability apparatuses.

"The Role of Aircraft Panel Materials in Cabin Fires as Their Properties" by J. G. Quintiere (ed), V. Babrauskas, L. Cooper, M. Harkleroad, A. Tewarson, FAA Report in review.

"Some Aspects of Flashover and Pre-Flashover Behavior in Compartment Wall Fires" by H. Takeda, Fall Technical Meeting, Eastern Section, The Combustion Institute, (1983).

\section{Suppression Dynamics}

This project area extends from the former Suppression and Extinguishment Group. Our initial concerns have been with research on the extinguishment of oil-well blow-out fires for the Minerals Management Service of DoI, and a new experimental investigation of fully-developed compartment fire suppression by idealized fire fighting water applications. In the former study several experimental scales and water injection techniques for high speed fuel jets have been examined. The most dramatic results demonstrated that suppression of 5 to 10 MW gas jet $\mathrm{flames}$ was feasible with a 50 per cent decrease in flame radiation and complete extinction of water to gas flow rate ratios greater than 2 (or about $10 \mathrm{gal}$. of water was required).

The latter study of compartment fires is currently underway and utilizes wood crib fires and horizontal water sprays of various flows and drop size distributions. The goal is to better understand and possibly predict fire fighting tactics.

"Thermal Activation of Extinguishing Systems" by D. D. Evans, Comb. Sci. and Technol., 40, p. 79, (1984).

"Suppressing of Gas Well Blowout Fires Using Water Sprays: Large and Small Scale Studies" by D. D. Evans, D. Pfenning, American Petroleum Institute, Fire and Safety Protection Meeting, San Antonio, September 11-13, 1984. 
"Control of Blowout Fires with Water Sprays", by D. Evans and B. McCaffrey, Technology Assessment and Research Program for Offshore Minerals Operations, $\propto S$ Report MMS 84-0001, (1984).

"Jet Diffusion Flame Suppression Using Water Sprays" by

B. J. McCaffrey, NBSIR 84-2812, al so in Comb. Sc1. and Technol., 40, (1984).

\section{Grant Research}

1. Fire Dynamics - flame radiation and pool fires, R. Friedman, FMRC.

2. Wind-Aided Flame Spread, A. C. Fernandez-Pello, U.C.B.

3. Theory of Flamespread with Charring, F. Fendell, TRW and G. Carrier, Harvard.

4. Upward Laminar Flame Spread Limits, J. THen, Case-Western Reserve.

5. Turbulent Combustion, G. M. Faeth, Penn. St.

6. Stratified Combustion and Mixing, E. E. Zukoski, Cal. Tech.

7. Wall Burning in a Stratified Atmosphere, A. Kulkarni, Penn. St.

8. Drop-size Distribution in Sprays, J. Prahl, Case-Western Reserve.

9. Spray-Plume Interactions, R. Al pert, FMRC.

10. Residential Sprinklers, H. C. Kung, FMRC. 
FIRE PERFORMANCE AND VALIDATION

FIRE MEASUREMENT AND RESEARCH DIVISION

CENTER FOR FIRE RESEARCH

FY 84

\section{Professional Personnel}

Sanford Davis, Head

Billy T. Lee, Fire Prevention Engineer

Richard D. Peacock, Chemical Engineer

J. Samuel Steel, Physicist

J. Newton Breese, Computer Programmer

\section{Program Objectives}

The objectives are to develop the generic methodology for assessing the accuracy and limitations of fire models and measurement methods and to design and conduct tests to evaluate the fire performance of components, systems, and structures.

\section{Scope}

This work includes two important efforts: first, the conduct of unique, highly instrumented experiments to establish fire behavior on a realistic scale in order to contribute to model development and second, the evaluation and validation of fire models by providing expertise in facility fire test experimental design, instrumentation, and data processing and analysis.

\section{$\underline{\text { Projects }}$}

1. Validation of Fire Models

The fire model validation project, initiated in FY 83, moved into high gear during the past year. One of the primary subtasks of the toxic hazard assessment project has involved the development of efficient and accurate models to predict the spread of smoke and gases in a building. Because the smoke transport model was well advanced in its development, it was chosen as the first major effort of the validation project.

A room/corridor facility was constructed and instrumented for carrying out full-scale experiments designed to evaluate the model. Replicate experiments were carried out using an idealized fire (gas diffusion burner) in which several of the model input parameters were varied. Jointly with the Center for Applied Mathematics, analysis and presentation of the data have been under development. Although this work has been associated with a specific model, the development of the generic methodology for model evaluation has been started and will be refined during the coming year.

In order to further support the toxic hazard assessment project, the program for the coming year will include the study of "real" fuels. This will enable us to test the model for growing fires, as well as to evaluate 
the $\mathrm{N}$-gas model for toxic effect of combustion products. A target room has been instrumented for gas analysis and for animal exposure experiments. In addition to the study of horizontal smoke movement, work will be initiated to evaluate the model for predictions of smoke transport in a vertical mode between floors in a two-story residential type facility.

\section{Large-Scale Fire Test Facilities Development}

An existing two story fire test facility in the large-scale fire research laboratory is being modified to simulate the interior of a residential townhouse. This structure, exclusive of kitchen and bathroom facilities, will be typical of the smaller townhouses being built in the 1980 's. The main features of this modification are to provide an open stairway connecting the two levels and an external exhaust collection system for measuring rate of energy release.

A new computer based data acquisition system is being installed in the full scale fire test facilities that will dramatically increase our data collection capabilities. The new system will double the data collection rate currently available and increase the number of channels that can be dedicated to a single test. Two computers, two hard disk drives, a full color interactive graphics display, and the data collection equipment form the nucleus of the system.

In addition to the improved data collection capabilities, an interactive color graphics display is included in the system that will allow display of test data and calculations based on test data while the test is underway.

The burn room and room/corridor test facilities at Building 205 are located adjacent to an exhaust hood which collects the combustion products from fire tests conducted in these facilities. The hood has been instrumented to measure heat, smoke, and combustion products from these tests as a function of time. The burn room can be used to quantify the fire hazard contribution from interior finish and furnishing materials. It has been used to analyze the thermal environment in the room for various ignition exposures and fuel loadings, to study flame spread on room surfaces, and to evaluate the room effect on burning furnishings. The room/corridor test facility permits measurement of the fire environment along the corridor and in adjoining side rooms as a function of fires of various types and intensities in the test room.

Reconstruction of the NBS furniture calorimeter is complete, resulting in improved instrumentation, control, and methods for data collection and reduction. Mass flow rate through the system was doubled, and a variable speed exhaust fan allows improved measurement sensitivity by providing variable mass flow rates. Each of these improvements results in better control and more accurate data.

3. Flame Spread on Walls

The objective of this project is to study fire spread and growth involving wall and ceiling finish materials when exposed to different 
ignition scenario and to provide a data base for the development and refinement of mathematical models which might be used to predict the performance of materials in the standard room fire test. Another objective is to use the data from these studies to help further develop the standard room fire test for use by ASTM.

Room fire tests of several materials having a wide range of fire properties have been conducted under three different ignition exposures. In these tests, the test material either lines the walls or the ceiling or fully lines both walls and ceiling. For some materials, the surface fire spread rate was found to be a strong function of the ignition exposures considered. Heat transfer characteristics and fire spread from full-scale plume impingement of ceiling finish materials will be performed next. A study on flame spread along a single wall surface using a line burner ignition source will also be conducted to obtain a more detailed understanding of the phenomenon.

Lee, B. T. Standard Room Fire Test Development at the National Bureau of Standards, ASTM/SFPE Symposium on Application of Fire Science to Fire Engineering, Denver, CO, June 26 and 27, 1984.

\section{Fire Safety Aspects of Solid Fuels}

The objective of this continuing project is to study the hazards associated with the installation, operation, and maintenance of wood burning appliances used for space heating in single family dwellings and similar small scale applications. The overall research program included the evaluation of a number of different protection systems designed to shield combustible wall and ceiling surfaces from the effects of radiant energy from hot stove and chimney connector surfaces. Acceptable systems will be those found capable of maintaining the surface temperatures of walls and ceilings at or below code recommended temperature rise limitations throughout the exposure period. Another aspect of the program included the evaluation of a number of different types of thimbles or wall pass-through systems which will, in effect, help maintain the surface temperature of combustibles in the walls within code acceptable temperature rise limitations throughout the exposure.

Loftus, J. J. and Peacock, R. D., An Evaluation of Wall Protection Systems for Wood Burning Appliances, Fire Journal, September 1983.

Loftus, J. J. and Peacock, R. D., Clearances and Methods of Protection for Wall and Ceiling Surfaces Exposed to Radiant Heating Appliances, Nat. Bur. Stand. NBSIR in preparation.

Loftus, J. J. and Peacock, R. D., Evaluation of Thimble-Chimney Connector, Wall Pass Through Systems for Solid Fuel Heating Appliances, Nat. Bur. Stand. NBSIR in preparation. 
5. Fire Performance of Walk-On Platforms of the VA Hospital Building System

The objective of this project is to develop and evaluate test data on the fire performance of unique construction systems proposed for use in VA medical facilities. The building concept incorporates a suspended walk-on deck system which forms an interstitial space between functional floors. These systems are designed to provide a fire endurance of two hours between functional floors when exposed to a heat environment which follows the ASTM E119 time-temperature curve. Tests were conducted in a three level steel frame structure which represents a portion of a mid-rise building. Two different suspended walk-on deck systems were constructed in the test structure and evaluated. More than 130 thermocouples throughout the structure measured temperature rise on critical building components. Deflection measurements were made on the walk-on deck systems.

A computer model was used to simulate fire performance of the walk-on deck systems and results were compared with test data. This was done to further validate the computer model. Computer model predictions were typically within 15 percent of actual test values. The test data showed that both walk-on deck systems performed well during the two hour fire exposures. It also showed that fireproofing on structural steel members can be of major importance.

Lawson, J. R., Fire Performance of Interstitial Space Construction Systems, Nat. Bur. Stands., NBSIR in preparation.

\section{Fire Safety of Amtrak Passenger Car Interior Furnishings}

A series of fire tests was conducted to assess the burning behavior of the interior of passenger rail vehicles. Three types of tests were performed: (1) small-scale laboratory tests to study the flammability and smoke generation characteristics of the individual materials, (2) full-scale calorimeter tests on the seats to determine the rate of heat release from burning seat assemblies, and (3) full-scale tests on mock-ups of the interior of the cars to investigate the potential for fire hazard in the fully furnished vehicles. A comparison of the results of the selected small-scale laboratory tests with the full-scale mock-up tests shows that while the small-scale tests can be used to screen individual materials, the geometry of the full-scale mock-up tests are critically important in predicting the potential for fire inside the vehicle.

Peacock, R. D. and Braun, E., Fire Tests of Amtrak Passenger Rail Vehicle Interiors, Nat. Bur. Stands., NBS Technical Note 1193, May 1984. 
Fire Safety Performance

Center for Fire Research

FY 84

\section{Professional Personnel}

Harold E. Nelson, Head

Bernard M. Levin, Research Psychologist

Edward K. Budnick, Research Fire Protection Engineer

A. Jeffrey Shibe, Research Protection Engineer

S. Wayne Stiefel, Operations Research Analyst

W. Douglas Walton, Research Fire Protection Engineer

Eric Rosenbaum, Coop Student-Fire Protection Engineer

Steven Thorne, Coop Student-Fire Protection Engineer

Steven Baer, Coop Student-Fire Protection Engineer

Program Objectives

The objectives of the Fire Safety Performance thrust encompass the development of a system of methods for use in predicting the performance of facilities and people in response to the potential fire threats.

\section{Scope}

This thrust focuses on development of a wide range of fire protection systems, models, and other tools targeted for the practicing fire protection engineering, design, or regulatory professional. It utilizes the state of the art in scientific knowledge, physical property data, empirical results from tests, fire experience, and sound engineering judgment. It involves development of a framework of macro models and other systems for evaluating active and passive systems for facility fire protection and use. It draws heavily on closely related activities in the area of fire growth processes, suppression and extinguishment, smoke and toxic gases, building response, and human response. It also addresses factors related to the likelihood of fire incidents, the varibility of parameters, and quantitative measurement of fire risk.

\section{Project Areas}

\section{Engineering Methodologies for Predicting Facility Fire Safety}

Development of systems of deterministic models and procedures for predicting the performance of facilities, the response of fire protection systems, the ability of occupants to cope, and the resultant impact in case of fire. Tasks will include the assembly, development and combination of existing, emerging and new systems, models, and other computational approaches that can be incorporated into design and/or hazard evaluation systems for use by fire protection engineers and others. Extensive use will be made of the outputs (e.g. models) of other CFR thrusts. The approach is to develop an overall integration "model" workable at various levels of sophistication; obtain or develop the 
necessary sub-routines; merge and adopt these, as appropriate, to obtain the problem solving methods; and establish confidence guidance on its use. Currently the project is addressing computational means to:

a. Estimate hazard growth in rooms and corridors.

b. Predict performance of fire protection devices.

c. Calculate horizontal and vertical perimeter smoke leakage.

d. Evaluate agreement of above with test results.

e. Appraise the evacuation time required.

f. Develop a model of human behavior, decisions, actions in flux.

\section{Fire Risk Measurement Methodologies}

Continued development of methods for the quantitative measurement of fire risk -- the probability and magnitude of fire caused harm to life, property, or operational capabilities. The overall risk measurement structure developed for the residential setting in FY 84 is being used to integrate probabilistic functions into both the key variables of the emerging deterministic models and the choice and weighting of individual simulations executed by those models. The risk measurement form of the models will apply the deterministic models in the stochastic environment of reality to predict the likelihood of selected types of harmful impact (e.g., death, injury, property loss) of a given entity (e.g., building, operation, use) and the change in this likelihood caused by selected mitigation measure implementation. The development of the structure will require attention to each element within the overall model (e.g., ignition, spread, growth, human reaction, tolerances, damageabilities, etc.). The inclusion of stochastic considerations will require the development of a process for assigning values to critical variables according to fire scenario and a process for weighting each scenario. This process may involve Monte Carlo techniques.

\section{Engineering Methods for Calculating Thermal Activation}

Development of generalized method for determining response of thermally activated devices to typical growing compartment fires; output in form satisfactory for engineering problem solving (eg. microcomputers, hand calculators, charts \& tables).

Candidate methods for detector spacing and sprinkler activation have been under development. Current versions include limited geometry and fire growth effects. A benchmark tested, generalized model is necessary in order to address variations in design problems.

A comparative analysis of current methods will be performed to identify limitations, and assess accuracy of the calculation methods. Based on this analysis and experimental data, a candidate method will be developed, extending the scope of the existing methods to include localized conditions appropriate for sidewall sprinkler and ceiling locations in adjacent spaces. The accuracy of these modifications will be assessed based on experimental work by Evans, and from data collected under the Kung grant at FMRC. Where demonstrated feasible, methods will be generalized and put in user friendly format. 


\section{Aircraft Fire Risk}

Development and exercise of a risk assessement modeling approach for aircraft cabin fire safety analysis. Continued risk assessment development efforts with special emphasis on in-flight fires and evaluation of multiple mitigation strategies--involving fire prevention, earlier detection, smoke control, fire spread limitation, or improved suppression. The approach will require enlargement of the data base of historical fires to include nonfatal fires; development of a generic structure capable of determining the risk (for different classes of fire scenario (e.g. concealed space fire, gasoline fires, etc.)) associated with multiple mitigation strategies; exercise of the methods on a selected sample of strategies to demonstrate the application of the methods, and refinement of the generic cost model developed in the first phase effort to specify the cost parameters in sufficient detail to permit data collection.

\section{Pragmatic Fire Safety Evaluation}

To develop grading systems needed by various agencies to judge the hazard of facilities and the impact of parametric changes.

Complete development of the FSES's for Board and Care Homes, NASA Operations Buildings, and Detention and Correctional Occupancies. The major work yet to be accomplished relates to the evaluation systems for coal mines and operations buildings.

\section{Associated Grants and Agreements}

1. Factory Mutual Research Corporation, Gunnar Heskestad, Experimental Fire and Smoke Verification Data for Multi-room and Corridor Conditions.

2. University of Washington, John Keating, Post Fire Interviews: Development and Field Validation.

3. AIA Research Corporation, Earle Kennett and Daniel Alvord, Fire Safety Evaluation System for Board and Care Homes (Escape and Rescue Model).

4. University of Washington, Norman Groner and John Keating, A Fire Emergency Planning and Training Manual for National Park Residential Buildings.

5. University of Florida, R.L. Francis and T.M. Kisco, Network Models of Building Evacuation: Development of Software System.

6. SRI International, Fred L. Offensend, Continuation of Decision Analysis Studies in Fire Hazard Analysis.

7. Center for Applied Mathematics, National Bureau of Standards, Economic Analysis of Residential Automatic Sprinkler Systems.

8. University of Maryland, Kwan-nan Yeh (IPA), Ignition Risk Analysis. 


\section{Publications and Other Products}

Budnick, E.K., Estimating Effectiveness of State-of-the-Art Detectors and Automatic Sprinklers on Life Safety in Residential Occupancies, National Bureau of Standards Report NBSIR 84-2819 (1984).

Nelson, H.E., Credible Engineering Methodologies (as a solution to bridging the fire safety technology gap). Conference on communications between the fire research community and the owner-operators of buildings. Session on "Possible ways of bridging the communications gap" November 10, 1983, Washington, D.C.

Nelson, H.E., How close are we to scientifically based fire protection engineering? IFPEL - IV International Fire Protection Engineering Institute; February 26-March 10, 1983: Brunnen, Switzerland.

Alvord, D.M., Escape and Rescue Model: A simulation model for the emergency evacuation of board and care homes, National Bureau of Standards Report NBS-GCR-83-453(1983).

Alvord, D.M., Status report of Escape and Rescue model; National Bureau of Standards Report NBS-GCR-83-432(1983).

Kahn, M.J., Detection times to fire-related stimuli by sleeping subjects. National Bureau of Standards Report NBS-GCR-83-435(1983).

Nober, E.H., Peirce, H., Wells, A., Waking effectiveness of household smoke and fire detection devices, National Bureau of Standards Report NBS-GCR83-439(1983).

Hall, Jr., J.R., Bukowski, R. and Gomberg, A., Analysis of Electrical Fire Investigations in Ten Cities; Final Report; National Bureau of Standards Report NBSIR 83-2803(1983).

Hall, Jr., J.R. and Helzer, S.G., Civilian Residential Fire Fatality Rates: Six High-Rate Versus Six Low-Rate States, National Bureau of Standards Report NBSIR 83-2754 (1983).

Hall, Jr., J.R. and Stiefel, S.W., Decision Analysis Model for PassengerAircraft Fire Safety with Application to Fire-Blocking of Seats, National Bureau of Standards Report NBSIR 84-2817(1984).

Kisco, T.M., Francis, R.L., Network Models of Building Evacuation: Development of Sof tware System. National Bureau of Standards Report NBS-GCR-84-457.

Chapman, R.E., Hall, W.G., User's Manual for the Fire Safety Evaluation System Cost Minimizer Computer Program. National Bureau of Standards Report NBSIR 83-2797.

Nelson, H.E., Shibe, A.J., Levin, B.M. and Thorne, S.D., Cooper, L.Y., Fire Safety Evaluation System for National Park Service Overnight Accommodations, NBS Report No. NBSIR 84-2896. 


\section{FIRE TOXICOLOGY \\ FIRE MEASUREMENT AND RESEARCH DIVISION \\ CENTER FOR FIRE RESEARCH \\ FY 84}

\section{Professional Personne1}

Barbara C. Levin, Research Biologist and Head

Laura L. Baier, Biologist

Chery1 S. Bailey, Research Chemist

Emil Braun, Physicist

Steven E. Harris, Guest Worker, University of Pittsburgh

Joshua L. Gurman, Research Associate, American Iron and Steel Institute

Maya Paabo, Research Chemist

\section{Program Objectives}

To identify potentially harmful combustion products and measure their effect on living organisms.

$\underline{\text { Scope }}$

This thrust determines composition of potentially toxic combustion products under different fire exposures, establishes the physiological effects of such products, and provides measurement methods.

\section{Projects}

\section{Toxicity Measurement Method Development}

The Center for Fire Research has developed a test method to assess the acute inhalation toxicity of combustion products from materials thermally decomposed under specific laboratory conditions. Although this test screens materials under presumed worst case (but still realistic) flaming and non-flaming conditions, it does not subject materials to all fire conditions. The objective of this study is to determine the extent to which the toxicity of a material's combustion products is sensitive to changes in combustion conditions. Therefore, a new combustion system has been designed, a modification of the cone calorimeter developed by the Center for Fire Research to measure the rate of heat release. This new radiant energy system will permit the evaluation of materials under a variety of combustion conditions and measure the effects of these conditions on toxicity. For example, early smoldering conditions will be simulated by exposing the materials to low radiant fluxes and high oxygen concentrations; preflashover conditions will be simulated by using higher radiant fluxes and oxygen concentrations greater than $16 \%$; and flashover conditions will be examined by using high radiant fluxes and very low oxygen concentrations. Materials will also be tested in both vertical and horizontal orientations, and the surface of composite materials normally exposed to the fire will be exposed to the heat source first. In addition, the new system is designed to provide continuous mass loss measurements and to allow square wave exposures of the animals. 
Levin, B. C., Paabo, M., Birky, M. M., "An Interlaboratory Evaluation of the 1980 Version of the National Bureau of Standards Test Method for Assessing the Acute Inhalation Toxicity of Combustion Products," National Bureau of St.andards, Washington, DC, NBSIR 83-2678, 1983. 88p.

Levin, B. C., "The National Bureau of Standards Toxicity Test Method," Proceedings of the Flame Retardant Chemical Association Meeting, 1983, Baltimore, Maryland. In press.

Gann, R. G., "Predicting Fire Hazard," Proceedings of the National Conference on Fire Toxicity, sponsored by the Consumer Product Safety Commission and the National Aeronautics and Space Administration, Arlington, VA, June 26, 1984.

2. Determination of the Toxicological Effects of Fire Gases, Alone and In Various Combinations for. Use in Toxic Hazard Assessment Computer Models.

Experimental research is being conducted to characterize the toxic gases produced in fires and their specific effects on living organisms. The two main purposes of these studies are: (1) to accumulate baseline data to determine the extent to which the toxicity of a material's combustion products can be explained by the interactions of the major gases produced in fires or if it is necessary to account for the minor and more obscure thermal decomposition products; and (2) to predict the toxicological effects of combinations of fire gases on humans for use in the computer modeling of toxic hazard.

To date, $\mathrm{IC}_{50}$ values have been determined for carbon monoxide (CO) in air for $10,20,30^{5}$ and 60 minute experiments using rats exposed in the head-only mode in the chamber designed for use in the NBS Toxicity Test Method (NBSIR 82-2532). Similar $\mathrm{I}_{50}$ values have been obtained for hydrogen cyanide (HCN) in air. Thirty minute experiments on the effect of combinations of $\mathrm{CO}$ and HCN in air have shown that these two gases appear to act in an additive manner such that if :

$$
\frac{[\mathrm{CO}]}{\mathrm{LC}_{50} \mathrm{CO}(30 \mathrm{~min})}+\frac{[\mathrm{HCN}]}{\mathrm{LC}_{50} \mathrm{HCN}(30 \mathrm{~min})} \geq 3
$$

the animals will die. If the above equation is lower than 1 , the animals wi]l live.

Carbon dioxide $\left(\mathrm{CO}_{2}\right)$ is relatively non-toxic. Yet, in 30 minute experiments, sublethal levels of $\mathrm{CO}_{2}$ in combination with sublethal levels of $\mathrm{CO}$ caused deaths of the rats. The most toxic combination of these two gases was found to be $5 \% \mathrm{CO}_{2}$ and $2500 \mathrm{ppm} \mathrm{CO}$. Experiments have also been conducted with reduced oxygen $\left(\mathrm{O}_{2}\right)$ concentrations. The 30 minute $\mathrm{LC}_{50}$ value is $7.5 \% 0_{2}$. As expected, the toxicity of the exposures increased as the animals inhaled combinations of additional toxic gases, e.g., low $\mathrm{O}_{2}$ and $\mathrm{CO}_{2}$ or low $\mathrm{O}_{2}, \mathrm{CO}$ and $\mathrm{CO}_{2}$ : Preliminary examination of the toxic gases evolved from some materials indicates that the interactions of the primary toxic gases, $\mathrm{CO}, \mathrm{CO}_{2}$ and $\mathrm{HCN}$, appear to explain the toxicity of the combustion products.

Levin, B. C., Paabo, M., Bailey, C. S., Harris, S. E. and Gurman, J. I.., "Toxicological Interactions of the Primary Gases Produced in Fires."

Manuscript, in preparation. 
Fowe11, A. J., "An Approach to Hazard Assessment of the Combustion Products in Bujlding Fires." Proceedings of the 4th International Fire Protection Engineering Institute, Switzerland, 1984.

3. Conditions Conducive to Hydrogen Cyanide Generation From Flexible Polyurethane Foam (GM-21).

In Fiscal Year 1983, we identified a set of combustion conditions under which increased concentrations of hydrogen cyanide (HCN) are generated from flexible polyurethane foam. A two-stage decomposition process is necessary. First, the flexible polyurethane foam is heated at a relatively low temperature $\left(25^{\circ} \mathrm{C}\right.$ helow its autoignition temperature) and a char is formed. In the second step, this char is heated to higher temperatures (approximately $500-600^{\circ} \mathrm{C}$ ), during which approximately ten times more HCN is produced than when the virgin foam is thermally decomposed in a single step process regardless of temperature or whether the material is in a non-flaming or flaming mode. The two-stage decomposition simulates a real. fire scenario in which a cigarette dropped in a crevice of a polyurethane chair causes the chair to smolder for some undefined period of time during which a char is formed. At some point the chair will burst into flames, heating the char and releasing the cyanide. Validation studies with polyurethane chairs have shown that significant quantities of cyanide are generated at the time that the chairs burst into flames.

In Fiscal Year 1984, much effort was expended to determine the molecular mechanisms for the increased cyanide production from this two step decomposition process. We found that the HCN levels were related to the amount of char formed. A fire retarded polyurethane foam (GM-24) produced twice as much char and twice as much $\mathrm{HCN}$ as the non-fire retarded foam (GM-21) even though elemental analysis of the two chars indicated that both contained the same amount of nitrogen.

Ion chromatographic analysis of both basic and acidic extracts of the chars showed very little HCN indicating that cyanide was not physically adsorbed to the char, but more likely was produced by the thermal degradation of a nitrogen-containing compound. That this compound is probably highly crosslinked and insoluble was indicated from elemental analysis studies showing that the nitrogen content of the chars was not reduced after extraction with a variety of organic solvents.

Additional analysis by ESCA (electron spectroscopy for chemical analyşis), FTIR (Fourier transform infrared), pyrolysis/mass spectrometry, and ${ }^{13} \mathrm{C}$ solid-state NMR (nuclear magnetic resonance) provided little additional information as to the molecular structure of the nitrogen-containing compounds. These results did provide evidence that the charred residues contained more than one nitrogen-containing compound and suggested the presence of amine, amide, imine, and nitrile functional groups.

For these studies, we acknowledge the help of W. F. Koch, T. J. Jack, J. Strassburger, K. J. Voorhees, and W. Manders.

Levin, B. C., Paabo, M., Fu]tz, M. I.., and Bailey, C., "Conditions Conducive to the Generation of Hydrogen Cyanide from Flexible Polyurethane Foam." Proceedings of the 7 th Joint Meeting of the U.S.-Japan Panel on Fire Research and Safety, UJNR, National Bureau of Standards, Washington, D. C., October 1983. In press. 
Levin, B. C., Paabo, M., Ful.tz, M. J. Bailey, C., Yin, W., and Harris, S. E., "An Acute Inhalation Toxicological Evaluation of Combustion Products from Fire Retarded and Non-Fire Retarded Flexible Polyurethane Foam and Polyester." National Bureau of Standards, Washington, D.C., NBSIR 83-2791, November, 1983. $70 \mathrm{p}$.

4. An Acute Inhalation Toxicological Evaluation of Combustion Products From Fire Retarded and Non-Fire Retarded Flexible Polyurethane Foam and Polyester.

The acute inhalation toxicity of the combustion products from selected upholstered furniture filling materials with and without fire retardants was evaluated by the NBS toxicity test method (NBSIR 82-2532). The five materials that were evaluated consisted of two different formulations of flexible polyurethane foam (each formulation was supplied in both a fire retarded and non-fire retarded form) and a polyester fiberfill (not fire retarded). Atmospheric concentrations of carbon monoxide, carbon dioxide, oxygen, and hydrogen cyanide in the exposure chamber were monitored throughout the themal decomposition of the materials. In addition, time-toignition, rate of heat release, hydrogen cyanide generation via a two step decomposition procedure and $\mathrm{x}$-ray fluorescense measurements were performed. The $\mathrm{LC}_{50}$ (30 minute and 14 day) values did not distinguish any of the materials as being significantly more toxic than the others. In the worst case, one of the fire retarded polyurethane foams was only a factor of two more toxic than its untreated counterpart. Only the fire retarded foams and the polyester caused deaths of the Fischer 344 rats durjing the 30 minute exposures. Extensive weight loss and post-exposure deaths occurred after exposure to the combustion products from all the materials. Animal deaths during or following exposure to the polyurethane cannot be attributed to carbon monoxide or hydrogen cyanide alone. Deaths during exposure to the polyester combustion products appear to be more directly related to the concentrations of carbon monoxide.

Levin, B. C., Paabo, M., Fultz, M. L., Bailey, C., Yin, W., and Harris, S. E., "An Acute Inhalation Toxicological Evaluation of Combustion Products From Fire Retarded and Non-Fire Retarded Flexible Polyurethane Foam and Polyester." National Bureau of Standards, Washington, D.C., NBSIR 83-2791, November, 1983. $70 \mathrm{p}$.

\section{Measurement of $\mathrm{NO}_{\mathrm{x}}$ During Large-Scale Room Fire Tests}

The objective of this study was to determine whether significant concentrations of $\mathrm{NO}_{\mathrm{x}}$ are generated in large-scale fire tests from either nitrogencontaining materials or from atmospheric nitrogen fixation. In the latter case, polystyrene, a material without nitrogen, was tested. The measurement technique was based on the principle of chemiluminescence in which NO reacts with $\mathrm{O}_{3}$ and the photoemission of the excited $\mathrm{NO}_{2}^{*}$ is measured. A stainless steel converter is used to reduce the $\mathrm{NO}_{2}$ to $\mathrm{NO}^{2}$ so that all $\mathrm{NO}_{2}$ generated in the fire is detected and treated as NO. 'At high temperatures, the stainless steel converter will also convert other nitrogen-containing compounds, such as $\mathrm{HCN}, \mathrm{NH}_{3}$, acetonitrile, and phenylisocyanate, to NO. This interference thus produces results which may be higher than the actual concentration levels of the $\mathrm{NO}_{\mathrm{x}}$. 
Using this technique, the No from a number of large-scale room tests has been measured. Atmospheric nitrogen fixation appears to be of little concern as the maximum concentration of $\mathrm{NO}_{\mathrm{x}}$ observed from tests involving polystyrene (no nitrogen) was $25 \mathrm{ppm}$. ' In other tests involving polyisocyanurate foam (containing nitrogen), a maximum of 60-110 ppm No was detected after accounting for HCN interference by separately measuring the HCN and subtracting that amount. The instrumental reading attributed to $\mathrm{NO}_{\mathrm{x}}$ may still be high due to the interference of some other unknown nitrogen containing compound. These experimental studies are continuing.

\section{Blood Cyanide Measurements}

The objective of this project has been to review, assess, and improve currently available procedures for measuring the concentration of cyanide in blood. In addition, we also evaluated the handling and storage techniques for blood to ensure both precision and accuracy of results. During the first year of this study, Valentour's electron capture gas chromatographic analytical technique in conjunction with the Conway diffusion procedure for separating the cyanide from the blood was used extensively. This system has two major limitations. First, it requires large volumes of blood (1-2 m1) and secondly, it is a very time consuming procedure requiring a minimum of four hours for the diffusion step. The within and between sample variability was also higher than desired. The Naval Submarine Medical Research Laboratory technique by R. M. Bell et al. was also examined. Only slightly faster than the Conway Diffusion technique, it required the same large quantities of blood and showed poor reproducibility.

We are currently evaluating a new semi-automated head gas system which looks very promising. The volume of blood required is approximately $0.25 \mathrm{ml}$ and the time from sampling to final result is about 30 minutes. Initial tests indicate good reproducibility. We also plan to investigate the feasibility of a technique developed by the U.S. Army Medical Command Unit, Aberdeen Proving Ground. They have loaned us some of the necessary equipment and we are trying to obtain the other pieces. This system also has the advantages of using small samples and requiring only 15 minutes from sampling to final results.

\section{Review of the Toxicology and Combustion Products from Ten Synthetic} Materials

A survey and a detailed critical review of the literature on the thermal decomposition products and inhalation toxicity of ten plastics commonly found in residential homes are being done under contract for the Consumer Product Safety Commission. The materials being examined are poly (vinyl chloride), polystyrene, nylon, polyethylene, phenolics, acrylics, ABS, polypropylene, polyester, and rigid polyurethane. The computer data bases that were searched included Toxline, Medlars, RTECS, Environmental Abstracts, NTIS, TRIS, Excerptica Medica, RAPRA and Chemical Abstracts. Over 1,000 pertinent articles were identified and collected from the Fire Research Information Services (FRIS) of the Center for Fire Research or through interlibrary loan. The first three materials - rigid polyurethane foam, nylon, and polyester are being reviewed at the present time. 


\section{Associated Grants}

J. University of Pittsburgh, Yves Alarie, "Toxicity of Plastic Combustion Products."

2. Colorado School of Mines, Kent Voorhees, "Characterization of Aerosols from Fires."

3. Southwest Research Institute, Gordon Hartze1.1, "Analysis of Hazards to Life Safety in Fires." 


\section{FURNISHINGS FLAMMABILITY \\ FIRE MEASUREMENT AND RESEARCH DIVISION \\ CENTER FOR FIRE RESEARCH \\ FY 84}

Professional Personnel

Vytenis Babrauskas, Fire Protection Engineer, Head

John Krasny, Textile Technologist

Joseph Loftus, Research Chemist

Richard Dipert, Fire Protection Engineer

\section{Program Objectives}

The objectives are to develop and validate measurement methods and to generate data necessary to characterize the fire performance of furnishings and other combustible occupant items.

\section{$\underline{\text { Scope }}$}

Current understanding of building fires places a major emphas is on the burning properties of the combustibles involved, which are generally furniture or other occupant combustibles. Both mathematical fire modeling and engineering applications require that flammability properties--heat release rates, mass loss rates, smoke and gas product production rates--and also ignition and flame spread properties be known. The research necessary to develop this data base falls into two categories: (1) full-scale burning behavior studies of furniture items under realistic fire scenario conditions, and (2) development of bench-scale laboratory tests suitable to the prediction of the full-scale behavior. For maximum generality and validity the benchscale tests should not be arbitrary, but rather should be configured to represent, as much as possible, physical or chemical properties of the materials being tested.

\section{Projects}

1. Development of the cone calorimeter

During the past year two separate smoke measurement devices were implemented on the cone calorimeter. An optical extinction beam was designed, using a small He-Ne laser, which can be used to make direct readings of the extinction coefficient of the smoke. Also implemented was a soot mass gravimetric sampling technique, whereby a flow stream proportional to the main exhaust duct flow is sampled on filter discs. When validated, these cone calorimeterbased smoke measurements will allow the NBS smoke chamber to be obsoleted. Also being implemented are real-time measurement capabilities for a number of additional product gases, including $\mathrm{HCl}$ and $\mathrm{HCN}$.

Significant progress was also made during the year in standardization activities. The working group on heat release rate in ISO selected the corie calorimeter for standardization. Within ASTM a first ballot was taken; also, a new working group is being formed for cone calorimeter operators (laboratories). 
An investigation of the suitability of the use of the cone calorimeter for predicting room flashover was made. For rooms with walls and ceilings lined with a single, combustible lining type, it was found that flashover velocities could be predicted by the use of a function (peak heat release rate)/ (time to ignition), with both the measurements being made in the cone calorimeter.

Babrauskas, V., Development of the Cone Calorimeter--A Bench-scale Heat Release Rate Apparatus Based on Oxygen Consumption, Fire \& Materials. 8, $81-95$ (1984).

\section{Upholstered furniture burning rates}

Based on data available to this point (furniture calorimeter burns of both actual furniture and mockups), a unified engineering calculation scheme was developed, allowing both the peak heat release rate to be predicted, and release rate curve to be represented by the use of a triangular representation. The method allows various frame materials to be treated; however, experimental data in this area are thin, and additional experimental work is planned for next year.

Other activities included a cooperative program with the California state Bureau of Home Furnishings, where NBS tested in the cone calorimeter specimens of institutional chairs which were burned in full-scale by the California state BHF. Also, a monograph was prepared, intended to serve as an engineering guide for the flammability design of upholstered furniture and beds.

The results of a validation testing program were published, which compared the behavior of upholstered furniture burning rates in the furniture calorimeter and in room fires--pre-flashover and post-flashover--but not in the ventilation-limited regime of post-flashover fires. The behavior was seen to be, to within experimental error, identical. Also examined were several simplified theories for flashover prediction.

The data enabled the theory of P. H. Thomas to be identified as the most useful.

Furniture and bed fires often involve pillow burning. Since there existed no available data, experimental measurements were made in the furniture calorimeter of a number of common pillow types.

Babrauskas, V., Upholstered Furniture Room Fires--Measurements, Comparison with Furniture Calorimeter Data, and Flashover Predictions, J. of Fire Sciences. 2, 5-19 (1984).

\section{Flame spread over furniture items}

The role of flame spread over upholstered furniture items was further clarified by analysis of the mockup test data. This showed that a substantial fraction of the variance in the full-scale (furniture calorimeter heat release rate) vs. bench-scale (cone calorimeter data) could be accounted for by flame spread differences. This is in contrast to ignitability measurements, whose effects were seen to be negligible. 
Investigations in a special apparatus for the measurement of flame spread over upholstered furniture were made with calibration specimens and showed a significant dependence on specimen width.

Dipert, R., Applications of Flame Spread Modeling to Flame Spread on Horizontal Samples. (M.S. Thesis). Worcester Polytechnic Institute (July 1984).

4. Protective Garments

A review was made summarizing both the flammability and the heat transfer aspects of protective garments, for firefighters and other workers.

Krasny, J. F., Some Characteristics of Eabrics for Heat Protective Garments, presented at the ASTM International Symp. on Protective Clothing (July 1984).

\section{Associated Grants}

1. Brown University, Merwin Sibulkin - Study of Effects of Material Properties on Flaming Combustion of Charring Fuels.

2. Factory Mutual, Archibald Tewarson - Development of a Model to Provide Comprehensive Eire Property Data.

3. Stanford University, George Springer - The Behavior of Furniture Frames during Fire.

4. University of Dayton Research Institute, Mark Dietenberger - Mathematical Modeling of Furniture Fires. 


\section{SMOKE HAZARD \\ FIRE SAFETY TECHNOLOGY DIVISION \\ CENTER FOR FIRE RESEARCH \\ FY 84}

\section{Professional Personnel}

Richard W. Bukowski, Head

Dan Gross, Senior Research Engineer

Walter Jones, General Physical Scientist

John Klote, Mechanical Engineer

\section{Program Objectives}

To provide an understanding of the rate of production, properties and spread of smoke and toxic gases from fires and the technical basis for control of these products to enable reduction of their impacts particularly on people in fire situations.

\section{Scope}

The predictive methods being developed are based on numerical modeling but, also include hand calculation methods for estimating hazards and production of design curves/tables for use by architects and engineers. To ensure use, necessary data must be readily available and data input and presentation must be in terms readily understandable by the average professional. Thus, the projects include a strong emphasis on state-of-the-art computer graphics and computer aided design techniques.

\section{Projects}

\section{Toxic Hazard Assessment Methods}

The predictive methods currently under development are being applied to the evaluation of the hazards of combustion product toxicity relative to the other hazards to occupants from fire, i.e. thermal, smoke obscuration. The goal is to produce a model which can make hazard predictions for speclfic fires (materials in their context of use) in specific, multi-story buildings. To date, a zone model which can produce predictions for multiple compartments on a single floor and spread to other floors through open shafts or openings in the ceilings (but not stairwells) has been produced. This model can display its results on a color computer graphic system in a two dimensional format using a color coded hazard display and histograms for selected parameters. The model tracks temperature, smoke density, interface heights, and eight individual gas species through all compartments.

Bukowski, R., "Development of a Method for Assessing Toxic Hazard", to be published in NFPA Fire Command.

Bukowski, R., "NFPA Toxicity Advisory Committee Strawman Procedure for Estimating Smoke Toxicity Hazard", to be published in proceedings of the NFPA Toxicity Workshop. 
Bukowski, R., "Toxic Hazard Evaluation of Plenum Cables", to be published in NFPA Fire Journal.

\section{Smoke Transport Modeling}

This work connects various modeling efforts in CFR. The model work itself revolves around a robust zone model which can predict the transport of smoke, species and fire from compartment to compartment in an arbitrary structure. At one end it will use the fire models which are being developed and at the other end provide output for building design consideration and personnel evacuation models.

A great deal of effort has gone into fast, stable numerical routines and data presentation that is edsy to use. By retaining the conservation equations in differential form we retain the ability to do the calculations for pressurized systems, flame puffing and related phenomena.

Verification of this model is an ongoing process. The first comparisons have been presented. Validation on both a laboratory scale, as well as full scale, is particularly important if the model is to fulfill its two primary goals, namely instituting a credible toxic hazard protocol and being able to use laboratory scale experiments to check designs of full scale buildings and ships.

Jones. W. and Quintiere, J., "Prediction of Corridor Smoke Filling by Zone Models", Combustion Science Technology 35, 239 (1984).

Jones, W., "A Model for the Transport of Fire, Smoke and Toxic Gases", to be published in various forms in the Fire Safety Journal, as an ASTM Special Publication, an NBSIR (Model Documentation and User's Guide) and NTIS.

Bodant, X. and Jones, W., "A Note on the Calculation of Gas Flows in Buildings", to be published.

\section{Computer Graphics}

The purpose of this sub task is to support firstly the FAST model (previous sub task) and secondly, other theory and experimental work. The thrust is to provide input which can be utilized by the transport models and output which is easily understood and assimulated. We are working with state-of-the-art high resolution graphics display equipment and input devices. The goal is to be able to show smoke spread in buildings in real time in a three dimensional perspective animation.

Jones, W. and Fadell, A., "A Device Independent Graphics Kernel", to be published as an NBSIR.

\section{Associated Grants and Contracts}

1. Craig Beyler - Harvard University, "Prediction of Upper Layer Composition in Transient Compartment Fires." 
2. Edward Zukosk1 - Cal Tech, "Experimental Study of Environment and Heat Transfer in a Room Fire."

3. Simon Goren - Univeristy of California, "Dynamics of Smoke and Inert Tracers Produced in Porous Fuels."

4. Edward Wall - Federal Emergency Management Agency (FEMA), "Major Fire Investigations." 
CENTER FOR FIRE RESEARCH

NATIONAL BUREAU OF STANDARDS

FY 84

Institution: American Institute of Architects

Grant No.: NB82NADA3043

Grant Title: A Computerized Model for the Simulation of General Fire Emergency Evacuations

Principle Investigator: Mr. Daniel M. Alvord

American Institute of Architects Foundation

American Institute of Architects

Washington, D.C. 20006

NBS Scientific Officer: Mr. A. Jeffrey Shibe

Technical Abstract:

Objectives - The current objective of this project is to create a model that will investigate fire related emergency evacuation of commonly encountered types of buildings. This tool can be used as an aid in designing new buildings to decrease egress times in fire emergencies. It may also be employed to find "optimum" egress paths for existing buildings under various situations.

Approach and Future Plans - Discrete event deterministic simulation programs, either newly written programs or expanded versions of existing programs, will implement the model. Networks consisting of nodes and connections between nodes will represent the rooms, doors, halls, and stairs of a building together with the permissible travel paths between them. Congestion will be addressed by a separate mechanism. A fire simulation will eventually be linked to the model. Model output will appear in graphic format as well as the current numeric format. Finally, optimization capabilities will be investigated to enhance the model's versatility.

Progress to Date - Two simulation programs have already been written but lack many of the features discussed in the above section.

The first one, the Escape and Rescue Model, is a discrete-event simulation program written in SIMSCRIPT II.5, a simulation language. It was developed to model the emergency movement involved in escape and/or rescue of people from a board and care home housing a group of persons with varying degrees of physical or mental disabilities, along with a small live-in staff. It may also be used to model more general types of small structures, and need not utilize staff members. To simulate a facility, one must enter staff information, resident information, 
and building information. The building data is inputted as a network derived from a floorplan of the facility, and consists of discrete nodes and permissible connections between them. In the simulation, building occupants travel in straight lines from node to node along the connections. Those residents who require aid are provided appropriate assistance by the staff member. The model computes and prints the time to safety for each resident as well as his egress route, the total time to clear the building, and a record of significant events that occur in the course of evacuation. One advantage of the model is its flexibility. Residents of many different types may be simulated. Also, once building information has been inputted, factors such as initial location of building occupants, resident types, order-of-rescue, egress routes, etc., may be easily altered and the resultant variations in the evacuation times observed.

The second simulation program, the Fire Emergency Evacuation Simulation for Multifamily Buildings, is also written in SIMSCRIPT II.5. It models the movement and actions that occur in emergency evacuations of multifamily buildings, differing from the Escape and Rescue Model in several ways. It assumes that all building occupants are fully capable of unassisted egress once they are aware of the fire danger. Most occupants initiate egress almost immediately, but some residents only become aware of the fire threat when alerted by a staff member. The alerting process is performed by a staff member, assigned to a particular floor (or floors), who systematically knocks on each door of the floor to ascertain if anyone still remains. (The simulation may be run without any staff) The building data is inputted as a network derived from a floorplan of the structure. This process takes full advantage of the fact that living units are clustered about long, straight hallways. Given rather general information, the model can generate a node for each living unit on the floor. Residents are randomly assigned to each "generated" living unit based on criteria supplied by the user. Model output consists of a record of various events pertaining to each living unit and each stairway that occurred during the simulation.

At present, work is proceeding to convert the Escape and Rescue Model into a user-friendly FORTRAN program. Many features have been added. The model user will be able to run the model either in interactive or batch mode on any machine with a FORTRAN 77 compiler. This conversion process is almost finished. Next, the same conversion process will be performed on the Fire Emergency Evacuation Simulation for Multifamily Buildings.

\section{Reports:}

1. Alvord, D., The Escape and Rescue Model: A Simulation Model for the Emergency Evacuation of Board and Care Homes, NBSIR-GCR-83-453, National Bureau of Standards, Washington, D.C., December 1983. 
2. Alvord, D., The Fire Emergency Evacuation Simulation for Multifamily Buildings, National Bureau of Standards, Washington, D.C., forthcoming. 


\section{CENTER FOR FIRE RESEARCH \\ NATIONAL BUREAU OF STANDARDS \\ FY 84}

Institution: Brown University

Grant No.: NB83NADA4025

Grant Title: Soot Dynamics in Flames

Principal Investigator: Prof. Richard A. Dobbins

Division of Engineering

Brown University

Providence, Rhode Island 02912

Telephone: (401) 863-1422

Other Professional Personne1: C. Megarides (Ph.D. student)

NBS Scientific Officer: Dr. George Mulholland

Technical Abstract:

This project focuses attention on the dynamic character of the soot aerosol in a diffusion flame and seeks to provide details on the role of the mechanisms of particle formation, coagulation, surface growth, and particle oxidation as a function of height in a diffusion flame. The research program consists of a theoretical study of the aerosol general dynamic equation and an experimental study of the morphological character of soot determined by sampling soot particles using methods which afford moderate spatial resolution. During the first year the theoretical studies of the aerosol dynamic equation with source and surface growth terms have been performed.

Methods of Solution of the Aerosol Dynamic Equation. Soot particles in flames are subject to particle formation, coagulation, surface growth, and oxidation, and their size distribution can in principle be described by the aerosol dynamic equation. The particles are small compared with the mean free path of the gas molecules and are therefore in the free molecular regime. In this case there exists no exact solution to the aerosol dynamic equation and only approximate solutions are available. An approximate numerical method has been presented, for example, by Gelbard in the MAEROS code. Alternatively integral solutions have been applied which are also approximate in that they force the size distribution function to be of a prescribed form. Earlier experimental studies indicate a log-normal distribution function to be approximately applicable and this form is well adapted to the algebra of the integral solutions. The methods used to reduce the data from optical experiments usually assume the distribution to be static--a monodispersion or a self-preserving distribution. However, neither of these two possibilities is justified if gas-to- 
particle conversion is present either in the form of new particle formation or surface growth.

We have examined the relative merits of these two methods of solution. The numerical method is in principle a highly accurate technique but is in fact subject to an approximation resulting from the sectioning of the size distribution function which limits the accuracy of the method. The refinement of the section width requires a major modification of the code, which is not easily accomplished. The computer code and computer running time is extensive by comparison with the integral solution. The particle number concentrations yielded by the two methods compare favorably when they are used to examine the initial value problem. However even in this case the asymtotic long time limit--the self-preserving particle size distribution function--is not accurately predicted by the numerical method. The integral solution comes somewhat closer to this limit if the figure of merit is the dimensionless second moment given by

$$
f_{N}=\frac{M_{2} N}{f_{v}^{2}}
$$

Here $M_{2}$ is the second moment of the size distribution function, $N$ is the particle number concentration, and $f_{v}$ is the particle volume fraction. The value $f_{N}=1$ corresponds to a monodispersion and $f_{N}=2.087$ is the value given more recently by Graham and Robinson as applicable in the self-preserving limit. The numerical method predicts a value of $f_{N}$ equal to about 2.60 while the integral solution gives 2.33 . Thus, it is apparent that the accuracy of the numerical method is quite limited. (The quantity $f_{N}$ is important in the interpretation of optical experiments. It is the multiplicative correction factor which must be applied to the particle number concentration that is yielded by Rayleigh theory for a monodisperse aerosol.)

An interesting development is revealed by the numerical (MAEROS) solution when the source term is active. In this case the particles being nucleated are assumed to be of a prescribed constant narrow size distribution. The aggregate size distribution function of the total aerosol population then is found to be bimodal in character. The smaller mode (nucleation mode) corresponds to the distribution function of the newly formed particles. The larger mode (growth mode) corresponds to the population formed by newly formed particles interacting with one another to produce a population of ever increasing size.

The integral solution as presently implemented is monomodal in character and does not allow for the development of a bimodal form. Comparison of the numerical and integral solutions in these cases shows serious discrepancies between the solutions. Thus, at the moment of peak nucleation rates the second moment calculated by the integral method is larger by $55 \%$ than the value predicted by the 
integral solution. The number concentration is at later times influenced by this discrepancy and proves to be about $50 \% 10 \mathrm{w}$. Likewise the value of $f_{N}$ is found by the integral method to be low compared to the numerical method.

To correct this discrepancy we have formulated a bimodal integral solution. This solution is of somewhat greater algebraic complexity and its detailed implementation is temporarily being deferred pending further information on the importance of this method of solution.

Comparison of Experimental Data with Predictions of Aerosol Dynamic Equation. A more careful comparison of the predictions of the aerosol dynamic equation with the data from the optical experiment is being performed. In this case we use the integral solution with a surface growth term which is initiated at the moment when the nucleation term has a maximum. The form of the surface growth term is assumed to be a half sine wave as a description of the rate of formation of the particulate phase by this mechanism. The final ratio of surface growth to new particle formation is a controllable parameter $\left(A_{g}\right)$. For $A_{g}=0$ no surface growth occurs and for $A_{g}=1.0$ the final mass of particles formed by the two mechanisms of gas-to-particle conversion are equal. For $A_{g} \gg 1.0$ the maximum particle concentration is small and little coagulative growth occurs.

When moderate to large initial particle sizes (10 to $50 \mathrm{~nm}$ ) are assumed, we find poor agreement between the theory and the experiments regardless of the value assumed for $A_{g}$. This indicates that the initial size should be assumed to be very small. In this case both the integral and numerical methods encounter a difficulty and cannot run successfully. In the case of the integral solution the equation for the time derivative of the particle number concentration has two large terms on the right hand side when the source term is active. The accuracy of the calculation of the derivative is low and numerical instability ensues. This difficulty is currently being addressed by redefining the independent variable to eliminate the two competing terms of similar magnitude.

The physical implications of these mathematical results are important. In the region low in the flame where the intense particle formation rate is present, there exists a quasi-equilibrium between the source term and the coagulation term which directly controls particle number concentration. In this case the high particle concentration which is the driving force for coagulation results in the rapid broadening of the particle size distribution and a rapid increase in the quantity $f_{N}$. Thus the distortion of the particle concentration profile is especially marked in this region of the high particle formation rate. Further, the smaller the initial particle size, the more intense will be this distortion of the particle concentration profile.

Optical experiments conducted on diffusion flames reveal a coincidence of the maximum particle size with the minimum particle concen- 
tration in the region of intense particle formation rate. These results are obtained when the size distribution function is assumed to be of prescribed width throughout the space in which they are

generated. The results we describe constitute evidence that the spatial variation of the particle size distribution function may be responsible for this seemingly paradoxical observation. The improvement of the computational techniques will permit the more detailed modeling of the soot aerosol dynamics in the region of high particle production rate. The results also are suggestive of particle morphological features that should be investigated during the experimental work which will ensue in the second year of this research. 


\section{CENTER FOR FIRE RESEARCH \\ NATIONAL BUREAU OF STANDARDS \\ FY 84}

Institution: Brown University

Grant No.: $\quad$ NBS Grant NB83NADA 4017

Grant Title: Study of Effects of Material Properties on

Flaming Combustion of Charring Fuels

Principal Investigator: Professor M. Sibulkin

Division of Engineering

Brown University

Providence, RI 02912

Telephone: (401) 863-2867

Other Professional Personnel: S. S. Tewari, Graduate Research Assistant

K. Siskind, Undergraduate Research

Assistant

NBS Scientific Officer: Dr. V. Babrauskas

Technical Abstract:

The objectives of the present research program are to determine the effects of changes in material properties on the burning rates and extinction limits of solid fuels, and to determine how fire retardants affect these properties so as to cause extinction. Our emphas is has shifted from "vaporizing" fuels (PMMA) to "charring" fuels (cellulose). This year our efforts have been directed to the completion of a study of burning cellulose samples, and to preparing for a study of the heat of gasification of pure and fire retarded cellulose.

The flaming combustion of charring materials was studied using samples prepared from pure cellulose and from cellulose which had been fire retarded by the addition of sodium hydroxide and sodium carbonate. Vertically oriented, hemispherical nosed cylinders were burned at atmospheric pressure in mixtures of oxygen and nitrogen. In general, the burning rates showed slight to moderate decreases with time while the surface temperatures increased with time. Both trends are related to the increase in char layer thickness with time. Extinction was observed to begin at the stagnation point and then move downstream until the flame was completely extinguished. Examples of the burning rates for pure cellulose are shown in Fig. 1. Addition of a fire retardant to the cellulose fuel gave unexpected results (see Fig. 2). While a trace amount of retardant, 0.1 percent, causes a 10 percent reduction in burning rate, addition of more retardant has a negligible effect on burning rate. However, the amount of retardant needed to cause extinction varies with the oxygen concentration. Our extinction results are summarized in Fig. 3. For pure cellulose both stagnation point and complete extinction occur for $\mathrm{Y}_{0, \infty} \simeq 0.18$. As the oxygen concentration 
is increased above this value, the amount of retardant needed to cause extinction increases rapidly while the difference in $\mathrm{Y}_{\mathrm{R}}$ between stagnation point and complete extinction also increases. At sufficlently high oxygen concentrations no extinction is found for the retardant concentrations used in this study. A practical consequence of these findings is the need to exercise proper caution in using "fire retarded" cellulose products in oxygen enriched atmospheres. A paper presenting the results of this investigation is now in press.

The next major phase of this project is the measurement of the ef.. fective heat of gasification of the materials used in the flaming combustion study. This property is central to diffusion flame theory. An analysis was made to determine the relationship of the heat of gasification $h_{g}$, defined as $h_{g} \equiv \dot{q}^{\prime \prime}$ (in)/ $\dot{m}^{\prime \prime}$ (out), to the heat of pyrolysis, defined as $h_{p} \equiv h\left(T_{w}\right)$ [gas + char] $-h\left(T_{\infty}\right)$ [cellulose]. It is shown that $h_{g}=h_{p}$ only in the case of a pyrolysis wave moving through the material at a constant velocity. This is not the case for charring materials. Numerical calculations will be made to model the pyrolysis of cellulose and determine the effects of changes in material properties on the rate of volatile production and the heat of gasification.

A major effort is underway to complete the installation and calibration of the apparatus for the measurement of $h_{\mathrm{g}}$. A plan view of the installation is shown in Fig. 4, and a side view of a portion of the apparatus is shown in Fig. 5. The heart of the apparatus is an electronic balance with a speclally designed sample holder mounted within an extensively modified glass draft-shield chamber. A 2-stage gas supply system has been developed to first scavenge air from the chamber and replace it by an inert gas, and then to supply a reduced flow of inert gas to remove the products of pyrolysis. The exhaust gas from the chamber can be passed through a gas chromatograph to either detect traces of oxygen before pyrolysis or to analyse the volatiles during pyrolysis. The sample is heated by a radiant lamp assembly which has been designed to give a uniform surface heat flux with an intensity which simulates the energy flux to the sample surface during burning. The surface temperature during pyrolysis is measured using an infrared pyrometer with a $2.1 \mathrm{\mu m}$ detector which can "see" through the chamber window. The pyrometer is installed with a rotating mount to facilitate its calibration against a black-body furnace. The incident heat flux at the sample 1ocation is measured with a Gardon type radiation gage which has been calibrated at NBS. A number of water-cooled heat shields have been included in the design to minimize the heating of the electronic balance.

\section{Reports and Papers:}

"Investigation of Completeness of Combustion in a Wa11 Fire," M. Sibulkin and S. F. Malary, Comb. Science and Technology, in press.

"Comparison of Theoretical and Experimental Burning Rates for Wall Fires," S. F. Malary and M. Sibulkin, J. Fire Sciences, under review. 
"Effects of External Radiation on Solid-Fuel Diffusion Flames," M. Sibulkin and T. Gale, J. Fire Sciences, in press.

"Measurements of Flaming Combustion of Pure and Fire Retarded Cellulose," M. Sibulkin and S. S. Tewari, Combustion and Flame, in press.

"An Experimental Study of the Burning of Pure and Fire Retarded Cellulose, S. S. Tewari, Ph.D. Thesis, Brown University (1984).

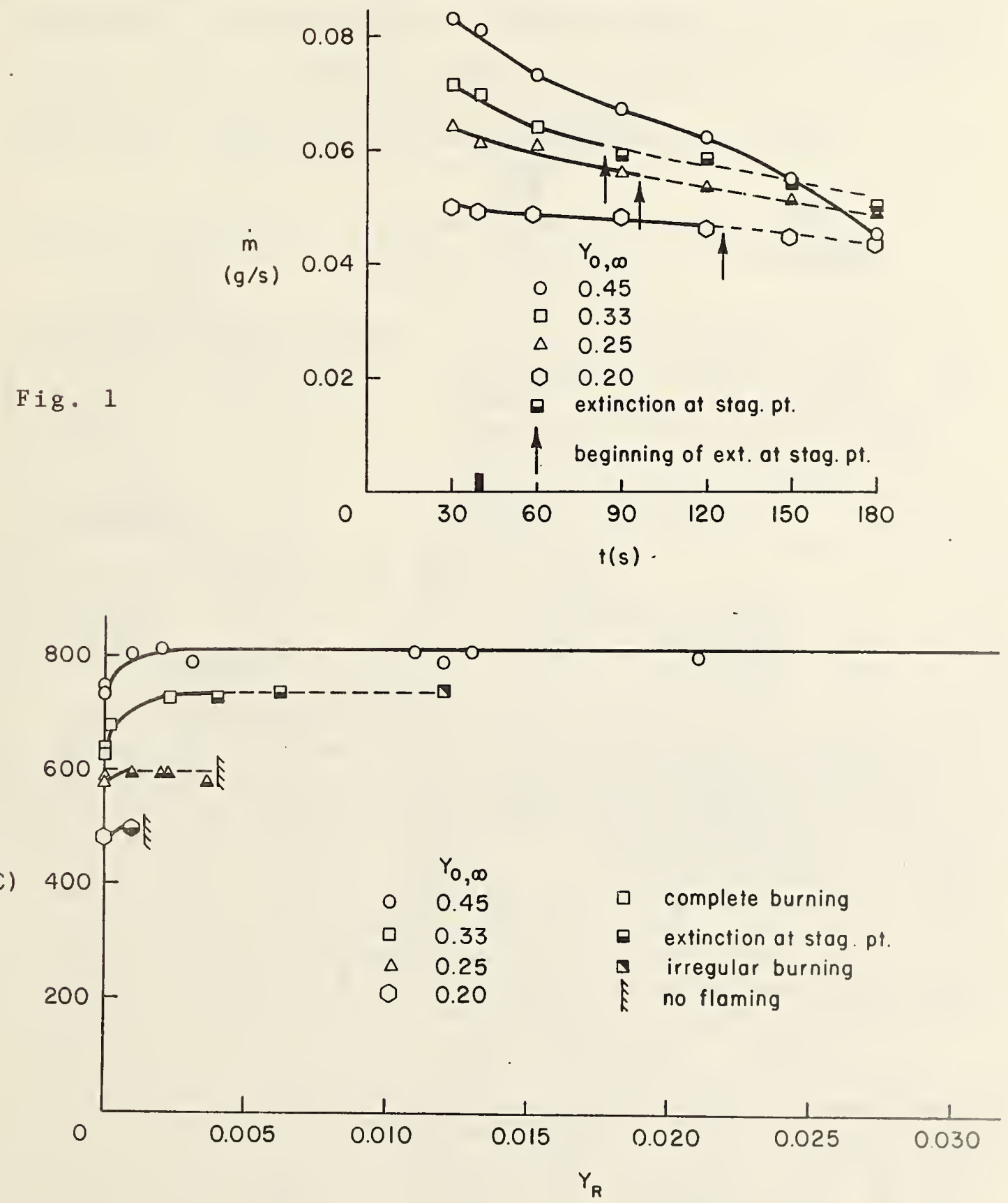

Fig. 2 

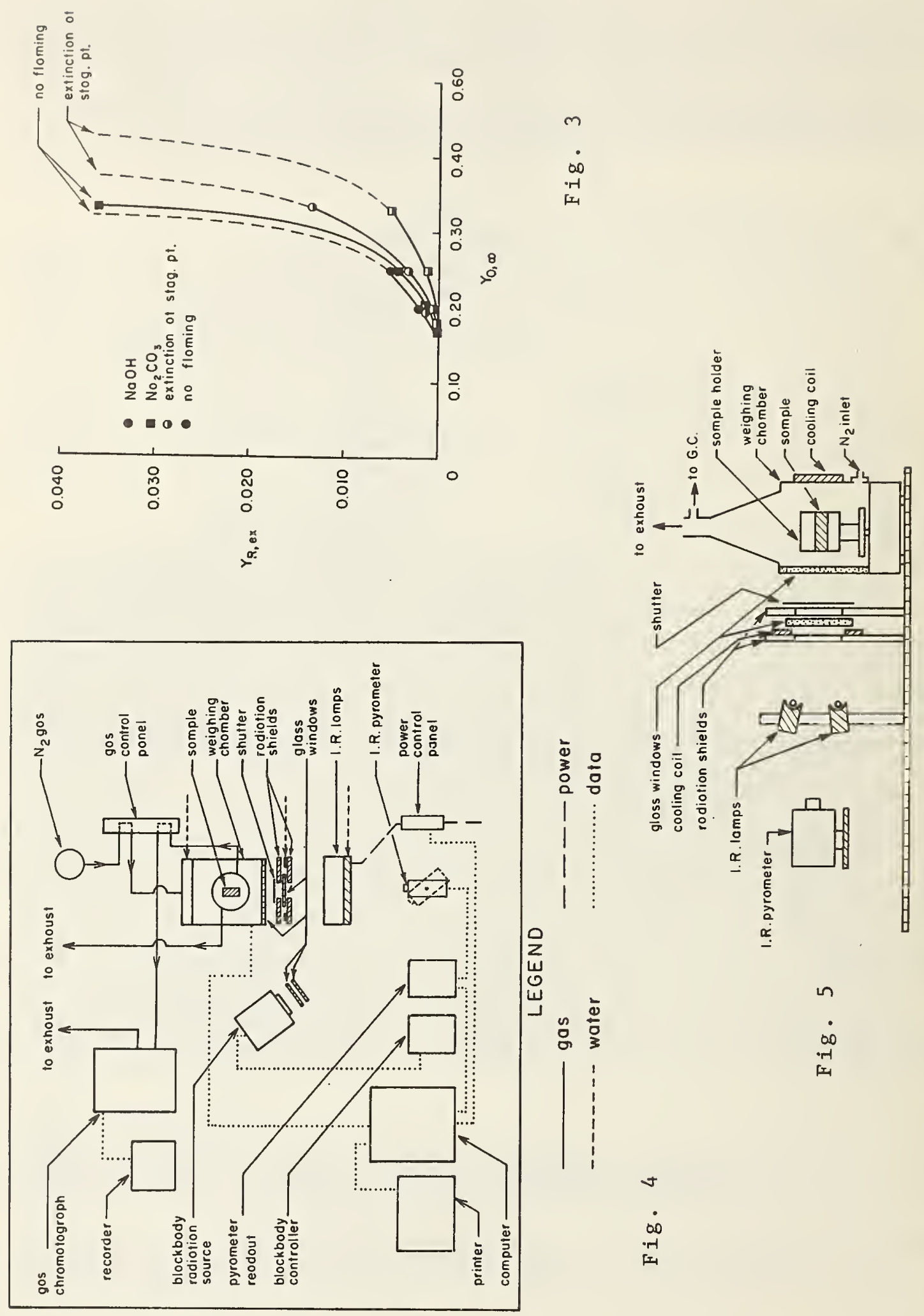


\title{
ANNUAL CONEEREHCE ON FIRE RESEARCH \\ CENTER FOR FIRE RESEARCH \\ NATIONAL BUREAU OF STANDARDS \\ GAITHERSBURG, MARYLAND
}

$$
\text { October } 17-19,1984
$$

\section{Institution: California Institute of Technology}

\section{Grant No.: NBS Grant NB82NADA3033}

Grant Title: Experimental Study of Environment and Heat Transfer in a Room Fire

\author{
Principal Investigator: Professor Edward E. Zukoski 301-46 \\ Califoraia Institute of Technology \\ Pasadena, CA 91125
}

\section{Other Professional Personnel: Professor Toshi Rubota}

Christopher Lim, Engr. Degree

Michael Chobotov, Ph.D. Candidate

Jean-Pierre Huot, Ph.D. Candidate

Steve Toner, $\mathrm{Ph} . \mathrm{D}$. Candidate

California Institute of Technology

Pasadena, CA 91125

NBS Scientific Officer: Dr. Walter Jones

Dr.J. G. Quintiere

\section{Technical Abstract:}

Smoke which is produced by a fire spreading through a building can act to aid in the spread of the flame by the transport of hot and perbaps combustible gas, and can be harmful to occupants because of it $s$ temperature and toxicity or because its opacity hinders the rapid movement of the occupants through the building. We are interested in developing models for the production and movement of smoke in complex structures and have been studying several processes which will be described below. These processes can not be described analytically because the flows are turbulent and are strongly influenced by turbulent mixing between streams in which buoyancy forces are predominant. Under certain circumstances, the combustion of the fuel produced in the fire can occur under conditions in which the concentration of oxygen in the ambient gas is far below normal and a fuel rich mixture can be produced in the smoke which can burn later in an adjacent space. The aim of the research work described here is to develope sufficient understanding of the fluid dynamic and chemical processes that rational models can be developed for the use in two layer fire codes. 
Mixing in a Doorway. During the past year we have completed work concerned with mixing, between the two layers within a room, which is caused by currents flowing into and out of a doorway. The currents in our experiments modeled those that would be produced by a fire burning with a steady heat release rate located with in the room.

The mixing process was complex and involved in some detail the flow within the roon which was produced by the inflowing fresh air and also the outflowing jet of hot gas. The inflowing stream produces a jet which interacts both with the upper or hot gas layer and with the gas within the cool or floor layer which may be at a higher temperature than the ambient fluid due to entrainment from the upper layer.

Entrainment of hot products of combustion from the upper layer into the lower layer occurred primarily at the interface between the inflowing jet and the ceiling layer gas but some mixing occurs all across the interface between the two layers.

A correlation was developed which predicts the entrainment for the geometric configurations we examined experimentally as a function of a Richardson number parameter. This correlation and the supporting data are discussed in a thesis by $\mathrm{Lim}$, Ref 1 . The results certainly depend on the geometry of the room used in the experiments but we believe that the correlation will give a useful estimate for this mixing process as long as the geometry of the room and the doorway are not drastically different from that investigated experimentally.

Combustion in the Ceiling Layer. We are continuing an investigation of the heat release in the ceiling layer when a flame extends far into that layer. The problem here is to predict the composition and heat release from the fire when a substantial part of the flame and combustion processes occur above the interface between the cool unvitiated gas in the lower layer and the hotter, vitiated gas in the ceiling layer. Combustion can continue even when the oxygen concentration in the upper layer is zero because oxygen is entrained into the flame from the the lower layer.

The results obtained during the past year are presented in the thesis by $\mathrm{Lim}$, Ref 1. For conditions in which the fuel-air ratio of the gases entering the ceiling layer were less than stoichiometric, the experiments are satisfactory and show that the combustion with in the flame is almost complete. However, when the fuel-air mixture in the fire plume is very fuel rich, our measurements are not as accurate as we want because our jnstrumentation technique did not permit concentration measurements for hydrogen bearing species. New experiments are being carried out in the current year to correct this situation.

Gravity Currents. We are interested in modeling the initial motion of smoke and hot gas in a long hallway or large room when hot gas is introduced into the space for the first time either through an opening 
or from a fire located within the space.

To have a concrete example in mind, consider the development of the ceiling layers produced by a fire in the two-dimensional structure shown in the sketches of Figure 1. Smoke spreading from a fire in a small room spills out under a door soffit into an adjoining hallway. The outflowing gas forms a buoyant plume, see Figure la, which impinges on the ceiling of the hall and produces a thin, high speed wall jet or gravity current. The flow in this wall-jet is supercritical, and the interaction of the head of this current with the ambient fluid produces a hydraulic jump in the supercritical layer, which entrains a substantial flow of ambient fluid. The gravity current formed downstream of this jump propagates across the ceiling with a constant depth and velocity, and little mixing.

A short time later, see Figure $1 \mathrm{~b}$, the front of this current impinges on the far wall of the hall and reflects as a group of waves on the interface which propagate back toward the jump. Mixing occurs during the impingement process but the waves do not break and do not cause any further entrainment or mixing. When the waves reach the hydraulic jump, the jump is submerged and no further entrainment of ambient fluid occurs there.

Heat transfer from the hot gas to the wall occurs throughout this process and it will affect the motion of the current, since the buoyancy of the current will be reduced.

Entrainment in the hydraulic jump is clearly an important feature of the flow described above. The total mass entrained into the layer depends on the entrainment rate and on the period during which it will act. This period is fixed by the geometry of the room, and the velocity of the front of the current and of the reflected waves which eventually submerge the jump. These features must be included in any accurate model of the flow. Also, there are situations in which the motion of the current can be important. For example, if the gravity current is deep enough to submerge a sprinkler system, the motion of the front will determine when the sprinkler can be set off.

The aim of the present experimental program is to obtain a good physical understanding of the important features of these flows and to develop analytic models for application in multi-room fire codes. This work will include a study of the processes which occur in the hydraulic jump at the entrance to the hallway and other entrance conditions not discussed here.

Two facilities have been constructed. The first is a square duct 0.6 m on a side and about $8 \mathrm{~m}$ long which will be used to study the motion of gravity currents of hot gas. The quantities being measured includf velocity and temperature fields, and heat transfer to the walls. The emphasis will be placed on the investigation of the effects of heat transfer on the gravity current. 
Many problems in describing horizontal flows of smoke in buildings arise because of geometric complexities of the space involved and these can be most conveniently studied with a water modeling technique in the second facility. The experimental technique used here involvings saltwater/water modeling: the geometry is inverted, salt water is used to model the hot gas, and water is used to model the cooler ambient fluid. The second facility is a model hallway $15 \mathrm{~cm}$ on a side and $250 \mathrm{~cm} 10 \mathrm{lg}$. To facilitate the study of flows at high Reynolds numbers, we also have access to a duct $1 \mathrm{~m}$ on a side and $20 \mathrm{~m}$ long. The effects of viscosity and density difference on flow will be investigated in these facilities in flow visualization will be a primary tool. addition, many problems in describing horizontal flows of smoke in buildings arise because of geometric complexities of the space involved and these can be most conveniently studied with this water modeling technique.

(a)

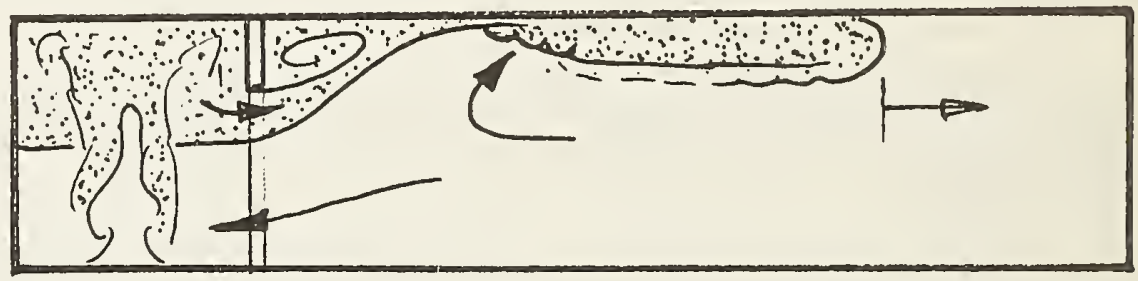

(b)

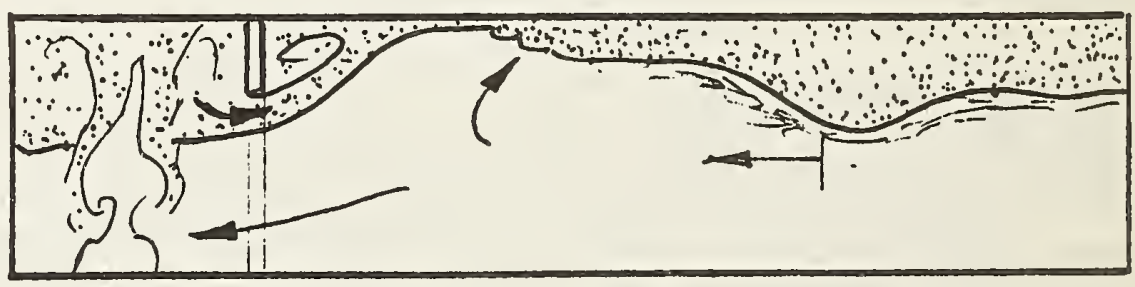

Figure 1. Gravity Current Flow in a Hallway

\section{Reports and Papers:}

1. C.S. Lim, "I. Mixing in Doorway Flows; II. Entrainment in Fire Plumes," Aeronautical Engineer Thesis, California Institute of Technology, Pasadena, California (1984).

2. B.M. Cetegen, E.E. Zukoski and T. Kubota, "Entrainment in the Near and Far Field of Fire Plumes," Combustion Science and Technology, (To Be Published).

3. E.E. Zukoski, B.M. Cetegen and T. Kubota, "Visible Structure of Buoyant Diffusion Flames," 20th Symposium (International) on Combustion, The Combustion Institute, Pittsburgh, Pennsylvania (1984). 


\section{CENTER FOR FIRE RESEARCB \\ NATIONAL BUREAU OF STANDARDS \\ FY 84}

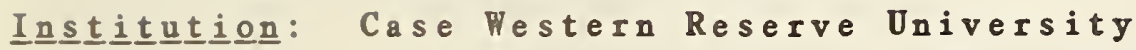

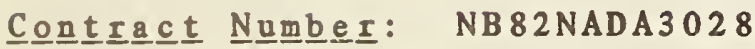

Contriact Títeㅗ: Experimental and Analytical Study of Fire Sprinkler Scaling Laws

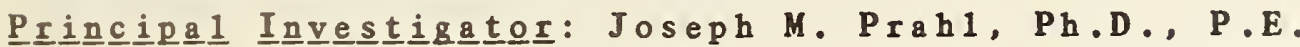

Assoc. Professor of Engineering

Department of Mechanical and

Aerospace Engineering

Case Hestern Reserve University

Cleveland, Ohio 44106

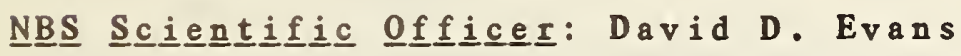

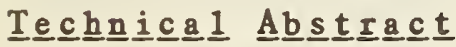

The objective of this project is to develop an experimental base that will de 1 ineate the relevant scaling parameters that govern the ultimate performance of a wide clas of firesprinklers. The sheat trajectory, sheet breakup, and subsequent droplet size distribution and droplet trajectories will be related dimensionlessly to the mechanical and thermal properties of the 1 iquid and gaseous fluids, the geometry and the initial dynamics of the liquid and gaseous streams.

Experimenta 1 data for water has been obtained on an apparatus developed to study the arisymmetric jet impingement on a flat disk which can be vibratedaxial y at a given frequency and chosen amplitude. The sheet of water leaving the disk is a 11 owed to breakup withot interference over the full $360^{\circ}$, whereas the discharge subsequent to sheet breakup is masked off to a $22.5^{\circ}$ sector for the purpose of determining the droplet radial discharge distribution. The sheet breakup radius is determined by direct observation and the radial discharge from the sector is collected in a series of raingutters spaning the floor of the sector norma 1 to the midangle radial direction. Variation of disk size and disk surface characteristics show no measurable effect on either sheet breakup radial location or on the measured discharge distribution.

Comparisons of the measured breakup radii with those of Huang [1] show qualitative agreement. Huang's experiment studies the sheet resulting from the impingement of two op- 
posing jets, whereas the present work considers the sheet produced by one jet impinging normal to a disk. To obtain quantitative agreement, the present work requires a disturbance amplitude ratio of exp(18) compared with Huangs exp(33), and Weber's original value of exp(12). The breakup radius normalized by the nozzle diameter and the Weber number to the minus one third power, plotted versus the frequency of disk oscillation normalized with respect to the frequency of maximum growth rate, the jet velocity divided by the nozzle diameter a 11 times the Weber number to the plus one third power, see Figure 1 , shows the minimum breakup radius occurs at a frequency of about 1 to 2 maximum growth rate frequencies.

The sprinkler flow distribution is presented in a nondimensional form which emphasizes the sprinkler's ability to uniformly spread the volume flow rate of water over the maximum possible floor area. The maximum radial extent of the sprinkler system is represented as $U \sqrt{2 y / g}$, where $U$ is the jet velocity, $y$, the distance of the disk above the floor and g, gravity. The non-dimensional application rate is the measured 'rain rate' from the gutter collectionsystem, normalized with respect to the 'ideal rain rate , the tota 1 flow rate from the nozzle divided by the marimum possible floor area. Figure 2 shows a typical distribution compared with the uniform distribution that would result over the maximum floor area.

An ana 1 ytica 1 relation for droplet trajectories is being developed for comparison with the measured discharge distribution so that droplet size distribution can be inferred. Work is progressing on isolating the effect of oscillation amplitude on the sheet breakup radius. The discharge distribution from some commercially available sprinkler heads wi 11 be determined and compared using the non-dimensional scheme presented above to establish the va1 idity and usefulness of this approach to sprinkler system performance comparisons.

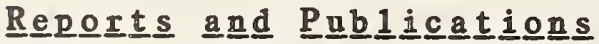

1. B. Wendt and J.M. Prah1, 'Flow Rate Distribution Performance for an Arisymmetric Vibrating Impact Fire Sprinkler Head', Department of Mechanical and Aerospace Engineering, Case Western Reserve University, Cleveland, Ohio 44106, Dec. 1983 .

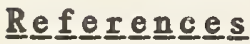

1. Huang, J.. 'The Breakup of Arisymmetric Liquid Sheets', JFM, Vo1 43, part 2, pp. 305-319, 1970 . 


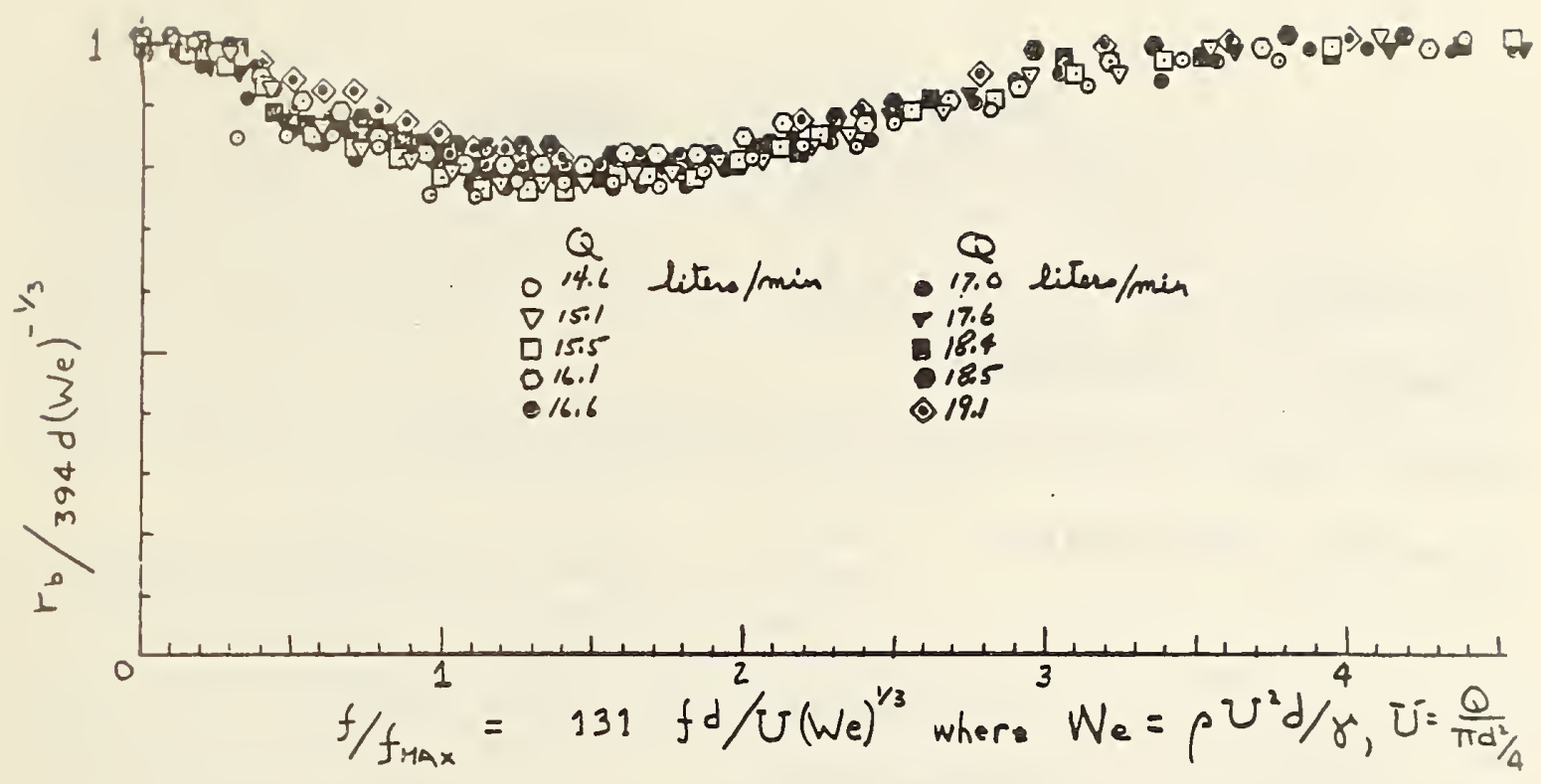

Figure 1. Nondimensional breakup radius versus nondimensional frequency for flow rates from 14.6 to 19.1 liters/minute

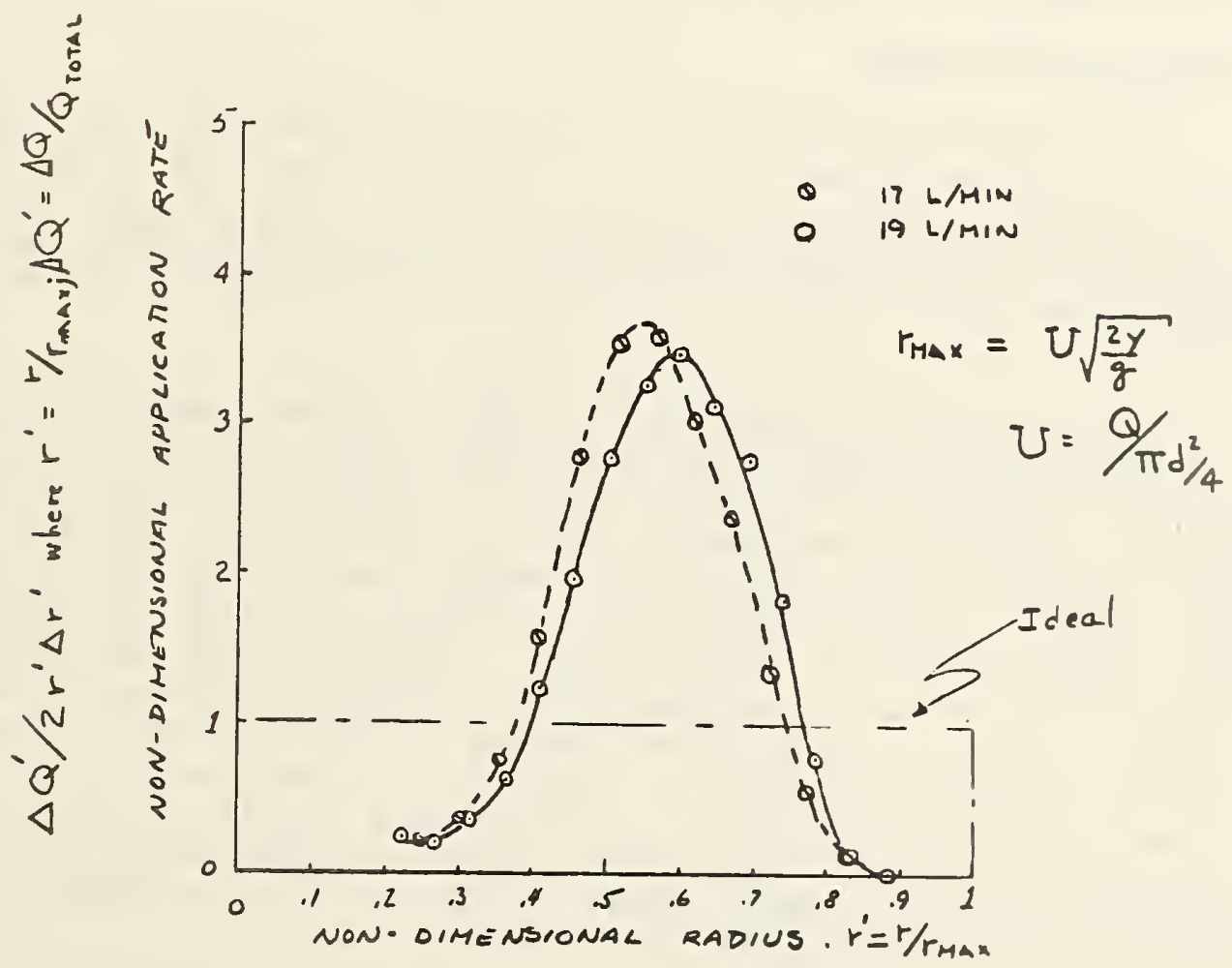

Figure 2. Nondimensional application rate versus nondimensional radius at zero frequency for flow rates of 17 and 19 liters/minute 


\section{CENTER FOR FIRE RESEARCH \\ NATIONAL BUREAU OF STANDARDS}

FY 84

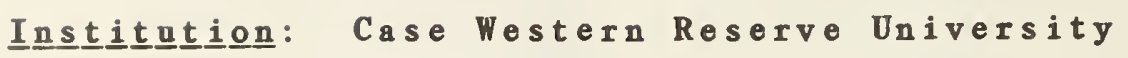

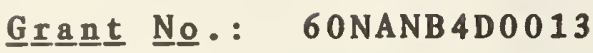

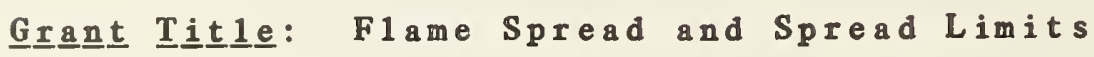

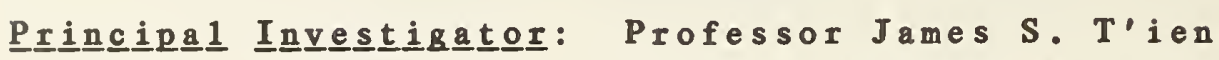

Dept. of Mechanica 1 and Aerospace Eng ineering

Case Western Reserve University

Cleveland, Ohio 44106

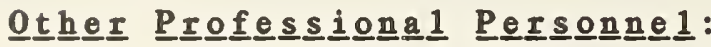

Charlie Chen (Graduate Student)

Ait Messaoudene (Grad. Student)

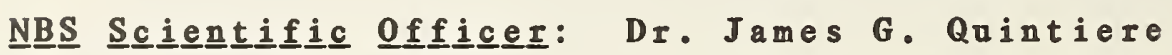

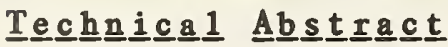

The overa 11 objective of this research program is to deve 1 op asic understanding of f 1 ame spread with specia 1 empasis on flame spread 1 imits. The work involves experimental and theoretica 1 modeling efforts for both downward (opposed f1ow) and upward (concurrent f1ow) flame spreads.

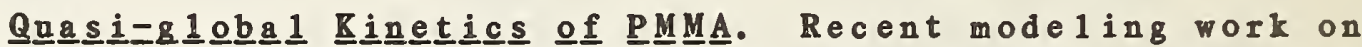
so 1 id fue 1 burning has utilized quasi-global chemical kinetic schemes. In the first step fue 1 and oxygen are to form $\mathrm{CO}$ and $\mathrm{H}_{2} \mathrm{O}$, subsequent steps convert $\mathrm{CO}$ to $\mathrm{CO}_{2}$ and $\mathrm{CO}_{2}$ back to co. In trying to compare model prediction with experiment, it was found that nokinetic data exists for the most common solid fuels for their first quasi-g1obal oridation step. A method for deducing those data is to compare the stagnation point flow calculation with extinction experiments. Since the extinction boundary a 1 ready exists for PMMA, a numerical model with the abovementioned kinetics is being set up. We expect that the oxidation data for PMMA applicable to quasi-global kinetics should appear shortiy.

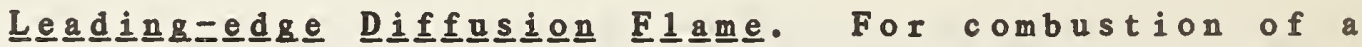
solid fue 1 p 1 ate in a convective flow, a majortion of the combustion zone can be treated by the boundary 1 ayer 
approximation. However, this is not applicable to the leading edge of the flame (upstream) because streamise heat conduction is essential there for flame stabilization. For a number of applications, a detailed analysis in this region becomes necessary. A more sophisticated model has been formulated and is being solved numerically to address the question of flame extinction and b 1 ow off. This a 1 sowil 1 provide the upstream condition for boundary layer analys when finite-rate kinetics are important.

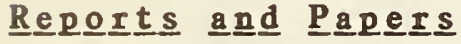

Chen, C.H. and T'ien, J.S., 'Fire Plume along Vertical Surfaces: Effect of Finite-Rate Chemical Reactions', Fire Dynamics and Beat Transfer, HTD - Vo1.25, p.17-28, Edited by J. G. Quintiere et a 1.. ASME (1983). Also to appear in Journa 1 of Heat Transfer. 


\section{CENTER FOR FIRE RESEARCH \\ NATIONAL BUREAU OF STANDARDS \\ FY 84}

Institution: Clemson University

Grant No.: $\quad$ NBS Grant NB80NADA1042

Grant Title: Ternary Reactions Among Polymer Substrate-OrganohalogenAntimony 0xides in the Condensed Phase Under Pyrolytic, Oxidative and Flaming Conditions

Principal Investigator: Dr. M. J. Drews

School of Textiles

Clemson University

Clemson, South Carolina 29631

Other Professional Personnel: Dr. C. W. Jarvis, Co-principal Investigator

Dr. J. Reece, Post-doctoral Research Associate

Mr. T. Gilstrap, Graduate Assistant

NBS Scientific officer: Dr. G. Mallard

Technical Abstract:

The objective of this study is to determine the contributions of the solid phase interactions, occuring in antimony oxide/organohalogen/ thermoplastic polymer substrate compositions, to the overall system chemistry during combustion. Of particular interest is the role of the polymer substrate in the generation of volatile antimony and halogen containing species. Small scale degradation data are to be integrated with the results from laboratory scale flaming combustion experiments conducted at the Center for Fire Research of the National Bureau of Standards. The flaming combustion and degradation data are to be, used in an attempt to develop a comprehensive model for the chemistry which occurs in the condensed phase, under both flaming and non-flaming degradation conditions. This model is to be used in the identification of the controlling parameters for optimizing the efficiency of organohalogen/antimony oxide flame retardant combinations in specific polymer substrates.

Three polymers and three organobromine compounds of significantly different thermal stability and primary decomposition pathways were chosen in an attempt to generalize the results of this study to other systems containing oxides of antimony. The polymer substrates are polyethylene terephthalate (PET), polypropylene (PP), and polymethylmethacrylate (PMMA). Decabromodiphenyl oxide (DBDPO), tetrabromobisphenol-A (TBBPA) and hexabromocyclododecane (HBCD) are the organohalogen compounds being used as the model halogen sources. 
The research plan is divided into two concurrent pathways: a set of small scale degradation studies and a series of laboratory scale flaming combustion experiments utilizing the cone calorimeter at the Center for Fire Research at the National Bureau of Standards.

The small scale work employs isothermal and dynamic thermal analysis, and isothermal tube furnace experiments with antimony and bromide ion monitoring of the volatile products as a probe into the solid phase reactions. From these data a temperature profile of antimony and bromide ion (or $\mathrm{HBr}$ ) volatilization is also developed. The basic experimental sequence consists of a study of the individual components followed by the binary mixtures (polymer/organohalogen, polymer/antimony oxide and organohalogen/antimony oxide) followed by the ternary mixture.

In the combustion experiments, only the three polymer substrates and the ternary mixtures at different ratios of polymer to organohalogen/ antimony oxide additive are studied. In these experiments $\mathrm{O}_{2}$ depletion, $\mathrm{CO}$ and $\mathrm{CO}_{2}$ formation, mass loss and sample temperature as a function of time as well as relative gravimetric smoke yield are measured.

The small scale degradation studies on the individual components and the binary mixtures have been completed. The most important conclusion is that no reactions have been observed in these mixtures which could account for the antimony volatilization which occurred in the flaming combustion experiments of those samples containing either $\mathrm{DBDPO} / \mathrm{Sb}_{2} \mathrm{O}_{3}$ or $\mathrm{TBBPA} / \mathrm{Sb}_{2} \mathrm{O}_{3}$. For these two organohalogen compounds, which do not readily dehydrohalogenate, a polymer substrate must be present for significant antimony volatilization to occur.

The complete interpretation of the small scale degradation work has been hindered by difficulties encountered in obtaining mass balances for antimony and bromine. To overcome these problems, sequential thermal analysis and tube furnace pyrolysis experiments have been employed to study the system $\mathrm{PP} / \mathrm{DBDPO} / \mathrm{Sb}_{2} \mathrm{O}_{3}$. The results from these new experiments have clearly demonstrated the critical nature of the solid state chemistry in controlling the generation of volatile antimony species from this system. These data suggest that the formation of volatile antimony from this ternary mixture may involve pathways which have not been previously reported. New experiments using electron spectroscopy for chemical analysis (ESCA) and new analytical procedures are currently in progress.

While the combustion data analyzed to date represent a limited sample, they clearly indicate that the solid state chemistry can not be completely isolated from the gas phase reactions. In particular these data reflect the effects of the relative additive stabilities on the overall ability of a halogen/antimony system to disturb the combustion envelope as represented by oxygen depletion and carbon monoxide/dioxide formation. That these effects occur, even in the downward buring candlelike geometry using thermally thick samples is surprising but in accord with the basic hypothesis of this work. 
This initial data set consisted of 28 experiments conducted over a period of two years which generated approximately 100,000 observations. Analysis of these data points has identified several internal inconsistencies, which apparently resulted from modifications to various procedural aspects of the burns. Consequently, a totally new set of data acquisition software has been written to eliminate these problems in future experiments.

The results of this systematic investigation are intended to make available new basic information in several important areas: formation of volatile antimony species from reactions of antimony oxides with organo halogens that cannot by themselves eliminate hydrogen halide; the effect of the polymer substrate on the reactions which produce volatile antimony halides and oxy halides; and the first systematic study on the controlled combustion of thermoplastic materials containing organohalogen/antimony oxide flame retardants. The systems description which this research program seeks to develop should make it possible to model more accurately combustion performance of these materials in fire situations and lead to a greater understanding of the thermal characteristics necessary for the more efficient flame retardation of thermoplastic materials.

\section{Reports and Papers:}

Drews, M. J., Jarvis, C. W., Leibner, E. A., "Organobromine/Ant imony Oxide/Polymer Substrate Interactions in the Solid Phase. Part 1. Binary Interactions, "Organic Coatings and Plastics Preprints, 43, 181 (1980).

Gilstrap, T. L., "A Study of Polymer/Antimony Oxide Interactions During Pyrolysis," Masters Thesis, Clemson University, May 1984.

Hansel, J. D., "Sol id Phase Interactions Among Antimony Oxides, Decabromodiphenyl Oxide and Polypropylene Under Pyrolytic Conditions," Masters Thesis in preparation. 
CENTER FOR FIRE RESEARCH

NATIONAL BUREAU OF STANDARDS

FY 84

Institution: Colorado School of Mines

Grant No.: NBS1 NADA2020

Grant Title: Characterization of Aerosols from Fires

Principal Investigator: Professor Kent J. Voorhees

Department of Chemistry and Geochemistry

Colorado School of Mines

Golden, Co 80401

Other Professional Personnel: Dr. R. Tsao, Post-Doctoral Associate

Mr. S.A. Durfee, Ph.D. Candidate

NBS Scientific Officer: Ms. Maya Paaba

Technical Abstract

The objective of this research program is to determine, using pyrolysis/mass spectrometry (Py-MS)/pattern recognition procedures, the composition of the polymeric materials in combustion aerosols and relate this information to the fuels involved in the combustion process. Single polymer and wood samples have been individually decomposed in both flaming and nonflaming modes and the aerosols collected. The pyrolysis/mass spectra have been recorded as reference spectra for these materials. Polymer and wood mixtures have also been decomposed and the aerosols investigated by Py-MS. Various pattern recognition procedures with and without reference spectra have been used to deternine the number of components as well as identification of the components of the mixture. A similar procedure has also been applied to single polymer and wood samples and combination mixtures where gasoline was present.

During the first two years of the program, the methodology was developed and applied primarily to nonflaming aerosol analysis. The summary of this work is reported in the first paper listed under Papers and Reports. In addition, work was done using a modified approach of the methodology for analysis of gasoline in aerosols from possible arson investigation. The work is summarized in the second paper listed. 
The major effort for the past year has been the analysis of aerosols from large scale flaming combustion. The cone furnace at NBS was selected based on past work which indicated that the aerosols formed from this furnace were more similar to full scale aerosols than the aerosol generated in the potts furnace in the flaming mode. Two pound samples were used in all decompositions. Twenty-one materials were used in the study to form mixtures containing up to four components. All mixtures were formulated by NBS staff and were used in the study in a blind mode.

Table 1 summarizes the results of the visual characteristic peak analysis of the aerosol pyrolysis data. About 58 percent of the compounds were identified in the study. More importantly the table presents trends where it is clear that the identifications are based on the class of the polymer. For example, the polyurethanes are identified 100 percent correctly while materials such as polyethylene were not identified in any of the analyses. Examination of the mass spectra associated with the various polymers indicates that for those materials which are identified with a high degree of confidence, strong characteristic peaks are present. For materials like polyethylene, a large number of equal intensity peaks are present.

Factor analysis has been conducted on some individual mixtures containing both materials which we re easily identified as well as never identified. The results of the analysis on a limited number of samples are nearly 100 percent identification. Unfortunately, factor analysis has not been completed on the entire data set.

These results show that fuels involved in flaming combustion can be identified with varying degrees of confidence. Future work will be focused on evaluating identification conficence levels for an expanded group of materials.

Papers and Reports

Rushung Tsao and Kent J. Voorhees, "Analysis of Smoke Aerosols from Nonflaming Combustion by Pyrolysis/Mass Spectrometry with Pattern Recognition," Analytical Chemistry, 1984, 56, 368-373.

Rushung Tsao and Kent J. Voorhees, "Fingerprinting of Gasoline in Combustion Aerosols by Pyrolysis/Mass Spectrometry with Factor Analysis," Analytical Chemistry, 1984, 56, 1297-1301. 
Table 1. The result of flaming combustion in NBS cone combustion chamber

Standard Materials

$\begin{array}{lllllllllllllllllll}\text { Mixture } & \mathrm{A}^{*} & \mathrm{~B} & \mathrm{C} & \mathrm{D} & \mathrm{E} & \mathrm{F} & \mathrm{G} & \mathrm{H} & \mathrm{I} & \mathrm{J} & \mathrm{K} & \mathrm{L} & \mathrm{M} & \mathrm{N} & \mathrm{O} & \mathrm{P} & \mathrm{Q}\end{array}$

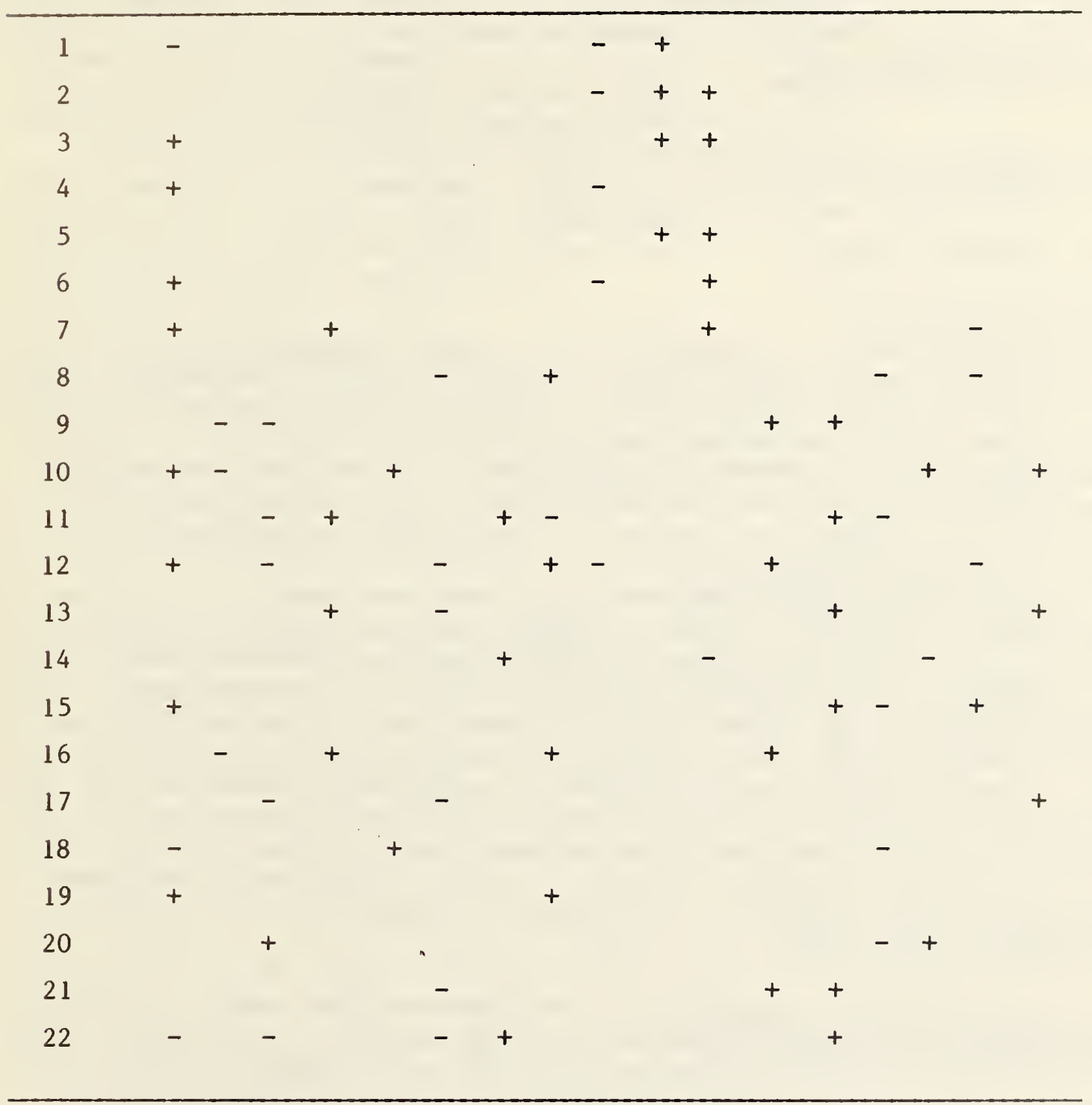

Success

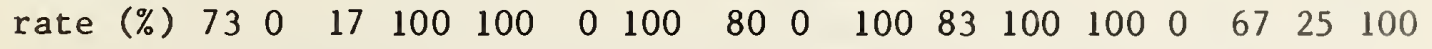

*Materials: A. Douglas fir, B. cardboard, C. cotton,

D. polystyrene, E. polyurethane GM-29, F. polyethylene sheet G. PVC pipe, H. nylon carpet, I. polyester

carpet, J. polyurethane GM-21, K. ABS pipe, L. Coke bottle, M. polyurethane GM-24, N. acrylic blanket, 0. wool blanket, P. PVC sheet, Q. plexiglas 
CENTER FOR FIRE RESEARCH

NATIONAL BUREAU OF STANDARDS

FY 84

Institution:

Grant No:

Title:

Principal Investigators:

Other Professional Personnel:

NBS Scientific officer:

Factory Mutual Research Corp., Norwood, MA 02062 NB83-NADA-4014

Calculated Interaction of Water Droplet Sprays

with Fire Plumes in Compartments

Dr. Ronald L. Alpert

Basic Research Department

(617) 762-4300, ext. 2776

Dr. Mary Delichatsios

Ms. Mary K. Mathews

Dr. John de Ris

Dr. Bernard McCaffrey

Technical Abstract:

The objective of this program is to predict mathematically the interaction of water droplet sprays with fire plumes in compartments. Our goal is to obtain general interaction correlations relating spray penetration and cooling of the fire environment to controlling spray and fire plume parameters. Another primary objective of the program is to provide a rugged computer code that can be transferred to CFR/NBS for routine, cost-efficient calculation of spray cooling and penetration.

In our research approach, two major tasks are being undertaken. In the first task, a simplified, axisymmetric problem is being studied by a numerical modeling technique (TEACH-T) now in use at FMRC. Calculations are performed giving spray penetration, spray cooling and gas flows for a fire simulated by a zone of uniform volumetric heat release. Because these calculations use excessive computer time, we have undertaken a major effort (Task 2) to improve the accuracy, numerical stability and computational efficiency of the existing code. The improved computer code will then be tested against existing analytical solutions, and used to perform applied calculations for a broad range of sprinkler, fire and compartment configurations.

Current Calculation Technique: The axisymmetric flow induced by the impingement of a buoyant plume on a ceiling has been studied previously in some detail at Factory Mutual, NBS and elsewhere because such a flow is associated with hazardous fires in buildings. Plume impingement results in the development of a ceiling-jet of hot gas flowing radially outward from the plume axis. An array of automatic, fire suppression sprinklers actuated by the ceiling-jet initiate droplet sprays which must cool the hot gas flow while providing a flux of liquid to the burning fuel.

Although the complete, three dimensional problem of predicting actuation patterns for a sprinkler array is far too complex at present, a simpler, axisymmetric problem is being considered to investigate the plume-spray interaction. In this axisymmetric problem, a 
downward facing spray is assumed to be located on the axis of a rising buoyant plume from a fire. To simulate the spray from a fire suppression sprinkler, droplet trajectories originate from a point source at the celling with uniformly distributed initial trajectory angles up to a maximum of $90^{\circ}$ from the vertical. The liquid mass flow rate injected along each trajectory is adjusted to give a uniform mass flow per steradian in the spray envelope. The fire plume source is simulated by specifying uniformly distributed sources of volumetric energy addition within a cylindrical (flame) region at a rate of $1200 \mathrm{~kW} / \mathrm{m}^{3}$ (based on measurements in propane pool fires by Orloff and by Santo and Delichatsios at Factory Mutual).

The numerical computation code used for this problem is a modified version of the widely used TEACH-T elliptic code for recirculating gas flows. Results of the numerical calculations consist of a description of the properties of the induced air flow field along with detailed droplet trajectories.

Plume-Spray Calculation Results: Calculations are performed first with a plume source alone, without a spray, in order to verify the accuracy of the numerical technique for a buoyancy dominated flow. Patterns of air streamlines and plume gas temperatures and velocities have been compared with experimental measurements. The results obtained with a crude $16 \times 16$ point mesh agree within \pm ( 15 to $30 \%$ ) with existing plume correlations.

With the simulated sprinkler at the ceiling boundary and the plume source at the floor boundary, a numerical solution is next obtained for the resultant flow fleld. Figure 1 shows the calculated air flow streamlines when a droplet spray of $4.6 \mathrm{~kg} / \mathrm{s}$ total water flow operates in the presence of the distributed heat source plume. The main effect of this spray is to deflect the incoming air flow (to be entrained by the plume) downward and to sharply decrease the peak excess gas temperature at the ceiling. A much greater effect on the plume flow field is achieved if a narrower outer spray angle $\left(57.3^{\circ}\right.$ from the vertical instead of $90^{\circ}$ ) is used, even with a reduced water flow rate.

Another feature of interest in these calculations is the behavior of droplets in the different trajectories of the spray. Asterisk symbols in the figure indicate the innermost and outermost trajectories. Under certain conditions (reduced water flow rate and/or small droplets) the downward motion of the inner droplets may be completely stopped and reversed by the upward thrust of the plume, and this may have important implications for fire suppression.

of particular interest is the efficiency of spray cooling and penetration of droplets through the plume. Correlations are being developed from the calculated flow properties to show how the total energy absorption by the spray and the near-ceiling flow conditions depend on the relative strengths of the spray and plume. The spray water flow reaching the plume source at floor level compared to that in the absence of a plume is also being correlated as a function of plume and spray properties. This penetration ratio ultimately determines whether direct extinguishment of a fire is possible. 
Improvements to the Calculation Algorithm: The numerical technique used for the preceding spray interaction problem allows a descrip-

tion of spray-induced flow fields to be obtained, but at a considerable cost in computer time (roughly 10 minutes on the IBM 370/158

even for relatively course $16 \times 16$ mesh spacings). Much more efficient gas phase algorithms are clearly needed to make accurate numerical solutions of buoyant turbulent flows in large-scale domains practical.

During our first year program, we have examined potential improvements in the accuracy of the code. Strict second order spatial accuracy and, possibly, second order temporal accuracy are necessary for our practical applications. We have analyzed a quadratic upwind $A D I$ (alternating direction implicit) algorithm that appears to satisfy most of the requirements for accuracy and stability.

Considerable emphasis has also been placed on improving the iterative solution of the coupled pressure-velocity equations which presently consumes most of the computation time in the numerical code. The new methods analyzed make use of highly efficient algorithms for solving the pressure equation directly and thus reduce the number of required iterations.

Recent Developments: New boundary conditions have been incorporated into the TEACH-T code to better simulate compartment fires. Calculations are in progress for the case of a ceiling (or floor) boundary obstructed by an axisymmetric partial side-wall (or curtain wal1). This boundary condition results in the formation of a hot gas layer within which the usual ceiling-jet and the spray origin are submerged. Converged solutions are being obtained with this partial side-wall boundary condition for the case of a plume without a spray. Calculations are also being performed to determine the spatial variation of response times of typical thermally actuated detectors. In order to properly visualize the buoyancy-induced streamlines and the detector response time variations near the sidewall boundary, more accurate contour fitting routines are being developed.

Another code enhancement already completed allows for the simulation of a hot-jet plume source in an annular region at the floor boundary. Calculations to be performed with this boundary condition can be compared directly with measurements of spray penetration and cooling in an annular hot-jet planned for later this year by NBS/CFR.

Conclusions and Future Plans: Sample problems involving interactions of droplet sprays with buoyant flows have been solved numerically. Calculated properties of the interaction flow field in many cases appear to depend on a ratio of droplet spray momentum to that induced by the buoyancy source. It is expected that improved correlations of this type, developed from more extensive calculations, should prove to be useful for the optimization of water spray protection. 
Because these calculations use excessive computer time, we have undertaken a major effort to improve the accuracy and computational efficlency of the present code. During the second year program we will refine the improvements to the computer code and will perform applied calculation for a broad range of sprinkler, fire and compartment configurations.

\section{Reports and Papers}

1. Alpert, R.L., "Calculated Interaction of Sprays with Large-Scale Buoyant Flows," Journal of Heat Transfer, Vol. 106, May 1984, pp. 310-317.

2. Alpert, R.L., "Numerical Modeling of the Interaction Between Automatic Sprinkler Sprays and Fire Plumes," paper presented at a Symposium on Computer Applications in Fire Protection, Society of Fire Protection Engineers, Leesburg, Virginia, March 19-20, 1984.

3. Beier, R.A., de Ris, J., Baum, H.R., "Accuracy of Finite Difference Methods in Recirculating Flows," Numerical Heat Transfer, Vol. 6, No. 3, pp. 283-302, July-Sept. 1983.

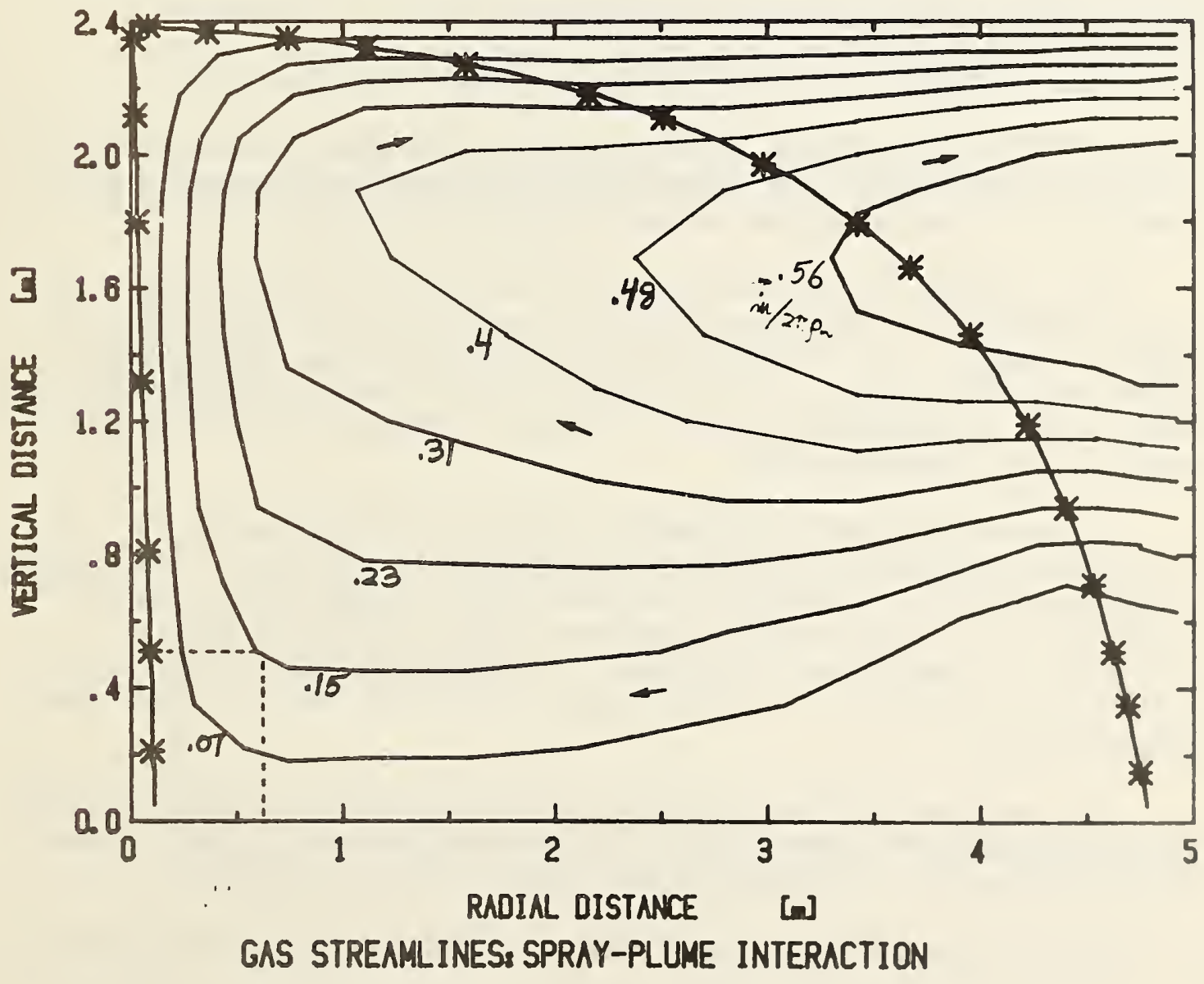




\author{
CENTER FOR FIRE RESEARCH \\ NATIONAL BUREAU OF STANDARDS \\ FY 84
}

Institution: Factory Mutual Research Corporation

Norwood, Massachusetts 02062

Grant No.: $\quad$ NB83NADA4021

Grant Title: Determination of Fuel Parameters for Fire Modeling

Principal Investigator: Archibald Tewarson, Ph. D. Senior Research Specialist

Manager, Flammability Section

Factory Mutual Research Corporation

1151 Boston-Providence Turnpike

Norwood, Massachusetts 02062

Other Professional Personnel: J. A. Steciak

S. D. Ogden

NBS Scientific Officer: Dr. V. Babrauskas

Technical Abstract:

The objective of this grant study is to examine the scale effects on the fire properties of materials (combustion and generation efficiencies of chemical compounds and "smoke" properties).

The experiments were performed in the Factory Mutual (FM) SmallScale Apparatus ( $0.1 \mathrm{~m}$ sample), FM Intermediate-Scale Apparatus ( $0.3 \mathrm{~m}$ sample), and FM Fire Products Collector (materials arranged within the dimensions of $\sim 3 \times 3 \times 3 \mathrm{~m}$ ). In addition, experimental results reported in the literature for wood crib enclosure fires were used for the scaling study.

The materials and arrangements used in the study were:

1) three-dimensional arrangement of materials: cellulosic (corrugated paper cartons, shredded paper and wood cribs); cellulosic-aromatic (corrugated paper and polystyrene) and three semi-rigid foams;

2) horizontal pool-1ike arrangement: polymethylmethacrylate, polystyrene, and polyvinyl chloride; and 3) sheets of five aircraft paneling materials.

For scaling, the heat release rate and generation rates of chemical compounds were normalized by the generation rate of fuel vapors. Overventilated fire conditions were used in the experiments.

From the experimental data obtained in this study as well as in 
our previous grant study for pool fires, it was found that combustion chemistry is conserved for overventilated turbulent fires. This finding is based on the fact that combustion and generation efficiencies of $\mathrm{CO}, \mathrm{CO}_{2}, \mathrm{H}_{2} \mathrm{O}$, and hydrocarbons show little dependency on fire size, configuration and arrangement of materials. This finding is consistent with the Schvab-Zeldovich scalar correlations of de Ris and Orloff.

From the experimental results for wood cribs measured in our apparatus and data reported in the literature for wood crib enclosure fires, it was found that mass air-to-fuel stoichiometric fraction was a useful parameter for the correlation of the data.

The data from this grant study are used as inputs to fire models for designing a known degree of fire protection into an occupancy and for improving materials for passive fire protection.

\section{Reports and Papers:}

1. Tewarson, A. and Steciak, A., "Fire Ventilation," Combustion and Flame, 53, 123, 1983.

2. Tewarson, A., "Fully Developed Enclosure Fires of Wood Cribs," Paper accepted for 20th Symposium (International) on Combustion, The Combustion Institute, Pittsburgh, Pennsylvania, 1984.

3. Tewarson, A., "Scale Effects on Fire Properties of Materials," Technical Report, National Bureau of Standards grant study (to be issued August 1984). 


\section{CENTER FOR FIRE RESEARCH \\ NATIONAL BUREAU OF STANDARDS \\ FY 84}

Institution: Factory Mutual Research Corporation

Grant No.: $\quad$ INB83NADA4054

Grant Title: Effects of Water Discharge Rate and Drop Size on Spray Cooling in Residential Fires

Principal Investigator: Hsiang-Cheng Kung

Manager, Applied Mechanics Section

Factory Mutual Research Corporation

1151 Boston-Providence Turnpike

Norwood, Massachusetts 02062

Other Professional Personnel: Dr. Hong-Zeng You

William R. Brown

NBS Scientific Officer: Edward K. Budnick

Technical Abstract:

A research program is being conducted to investigate spray cooling in room fires. The objective of this program is to investigate: 1) the spray cooling ability in a room as affected by water discharge rate, drop size distribution, and fire size; and 2) thermal response of remote sprinkler links before and after sprinkler operation.

The program is of experimental nature. Most of the fire tests will be conducted in a $3.66 \mathrm{~m} \times 7.32 \mathrm{~m} \mathrm{x} 2.44 \mathrm{~m}$ high test room. To explore the effect of room size, a limited number of fire tests will be conducted in a larger room ( $4.27 \mathrm{~m} \mathrm{x} 8.54 \mathrm{~m} \times 2.44 \mathrm{~m} \mathrm{high})$. The fire source used in the program is an easily reproducible heptane spray fire. Three constant heptane consumption rates have been selected to approximate heat release rates of upholstered furniture at sprinkler actuation.

Sprinkler sprays generated from three geometrically similar sprinkler nozzles are being investigated. The linear-scale ratios of the nozzles, referenced to the largest nozzle, are $1,3 / 4$ and $5 / 8$. For each nozzle, three water discharge pressures will be tested.

Only one sprinkler nozzle is installed at the ceiling inside the test room. The water flow to the nozzle is controlled by a solenoid valve immediately upstream of the nozzle, A simulated residential sprinkler link (RTI value: 28 ( $\sec \times \mathrm{m})^{1 / 2}$ ) is used to actuate the solenoid valve through a temperature controller when the link 
temperature reaches a predetermined value.

Construction of a calorimeter (fire products collector) has been completed. The calorimeter consists of a $2.44 \mathrm{~m}$ diameter hood, a $0.61 \mathrm{~m}$ diameter stack and other duct work. An electric blower has been installed at the duct outlet. The calorimeter will be used to collect the combustion gases exiting from the opening of the test room and to measure heat release rates of the effluent gases. A $0.36 \mathrm{~m}$ diameter orifice plate has been installed at the stack inlet to achieve uniform flow inside the stack at about $3 \mathrm{~m}$ (five stack diameters) downstream of the orifice plate. An instrumentation station is located at $3.05 \mathrm{~m}$ downstream of the orifice plate to measure temperature, velocity and gas concentrations $\left(\mathrm{CO}, \mathrm{CO}_{2}, \mathrm{O}_{2}\right.$ and total hydrocarbon) of the stack gases.

In the room fire tests conducted, the total heat release rate of the heptane spray fire located inside the test room was derived from the measurements of the calorimeter, using the carbon balance method. The convective heat leaving the room opening was determined from the stack gas temperature and velocity. In order to determine the heat loss rate through the walls and the ceiling, surface heat flux gages and surface thermocouples have been installed on the ceiling and walls. In the sprinklered fire tests with constant heptane consumption rates, a steady-state condition occurred after a period of sprinkler operation. During steady state, the heat absorption rate of the sprinkler spray was obtained by the difference between the heat release rate of the fire and the sum of 1 ) the heat loss rates due to heat transmission through the ceiling and walls, and 2 ) the convective and radiative heat losses through the room opening. It is expected that a correlation will be established between spray cooling ability (heat absorption rate of the spray) and the variables: fire size, water discharge rate, and median drop size of the spray.

To investigate the thermal responses of sprinkler links, four sets of simulated links have been installed underneath the ceiling, one set adjacent to the sprinkler nozzle, the other three at $2.44,3.05$ and $3.66 \mathrm{~m}$ from the nozzle. Each link set consists of three brass disks of different thermal sensitivities. A total of 46 gas-temperaturemeasuring thermocouples have been installed for detailed mapping of ceiling gas temperatures and vertical room temperature profiles. In addition, five bidirectional flow probes have been mounted to measure ceiling flow velocities.

Based on detailed mapping of ceiling gas temperatures and velocities, an attempt will be made to develop a ceiling gas flow model for the flow prior to sprinkler operation. Employing this model, the thermal responses of simulated sprinkler links before sprinkler actuation will be predicted.

The effects of fire size, water discharge rate, and median drop 
size on the thermal responses of remote links after sprinkler operation will be investigated. Correlations between steady-state link temperature and the variables: heat release rate of the fire, water discharge rate and median drop size will be developed.

It is expected that the results of the research program will improve the scientific understanding of spray cooling in room fires and provide useful inputs to fire protection engineering.

$\underline{\text { Reports and Papers }}$

iNo reports and/or papers have resulted from this work as yet. 
CENTER FOR FIRE RESEARCH

NATIONAL BUREAU OF STANDARDS

FY 84

Institution: Factory Mutual Research Corporation

Grant No.: $\quad$ NB83NADA4046

Grant Title: Experimental Fire and Smoke Verification Data for Multiroom and Corridor Conditions

Principal Investigator: Dr. Gunnar Heskestad

Factory Mutual Research Corporation

1151 Boston-Providence Turnpike

Norwood, MA 02062

Telephone: (617) 762-4300

Other Professional Personnel: Mr. John P. Bill

NBS Scientific Officer: Mr. Edward R. Budnick

Technical Abstract:

The objective is to establish data on multiroom fire situations with particular emphasis on health care facilities. The data wil be used for testing fire modeling and engineering calculations specifically carried out at the Center for Fire Research. However, the data will, of course, also become avallable to the fire research community at large. A number of fire and related life-safety issues are to be addressed in the total program: burning rates and heat-release rates of patient-room furnishings; celling jet in burn room; descent of smoke layer in burn room and bulldup of pressure gradients; escape of smoke through open or closed door to corridor; propagation of smoke front down corridor celling and buildup of smoke layer; penetration of smoke and toxic gases into patient rooms communicating with corridor through closed or open doors; passage of smoke through suspended ceilings or ventilation ducting; and response of sprinklers and fire detectors. Both pre-flashover and post-flashover situations are to be included.

The test facility is now nearly ready for routine testing. It has been built within FMRC's large fire test building located at West Glocester, Rhode Island. Figure 1 shows a layout of the fac1lity with indications of instrumentation. There is a "burn room" and two so-called "target rooms", each measuring 3.66 m square, attached to $2.44 \mathrm{~m}$ wide $\mathrm{x} 18.90$ m long corridor. Three access doors to the enclosure are provided, but not shown; these w111 be sealed tight during tests. The facility is actually built 3.05 w high, with a subcelling $2.44 \mathrm{~m}$ high, forming a $0.6 \mathrm{~m}$ high concealed space above the subceiling. At some advanced stage of the program, the 
inftially solid subcelling w1ll be replaced with a permeable, suspended ceiling in order to study associated effects on smoke travel from room to room. Each of the three rooms is provided with a vent to the outside near floor level. The vent mass flow will be measured, whether it is natural or forced with fans.

Gypsum board on wood studs is used throughout. 'In addition, the walls and ceiling of the burn room have been overlain with Marinite (Johns Manville) to harden against repeated fire exposure

Most of the instrumentation indicated in Figure 1 is fairly standard, except perhaps the "brass disks" and "turbidimeters." The brass disks are thin, $25 \mathrm{~mm}$ dia. brass discs provided with thermocouples to measure thermal response, simulating heat detectors and also to provide some measure of the gas velocity when coupled with the response of an adjacent thermocouple. The turbidimeters, of in-house design ${ }^{*}$, measure the turbidity of the smoke at three wavelengths from which can be deduced, with the aid of Mie scattering theory, a characteristic particle size and particle volume fraction. Eight wall pressure taps are provided for measuring six pressure differentials, including that between the burn room and the exterior of the facility.

Three types of fires will be investigated: 1) steady propylene fires at approximately 50 and $500 \mathrm{~kW}$, using "sandbox" burners; 2) propylene fires programmed to grow parabolically with time to reach flashover size in four to eight minutes (sandbox burner under computer control); and 3) naturally growing fires in mattress-size slabs of foamed polyurethane with potentials for spread to other fuel elements. Various combinations will be investigated of open and closed doors, open or closed window to the burn room, natural or forced ventilation in all rooms, and solid celling or permeable suspended ceiling. Closed doors and suspended ceilings will be carefully characterized for leakage in special tests.

Experiments are expected to continue through Apri1 1985.

* J. S. Newman, "Development and Design of a Smoke Turbidimeter," FMRC OFOR3.RC, July 1982. 


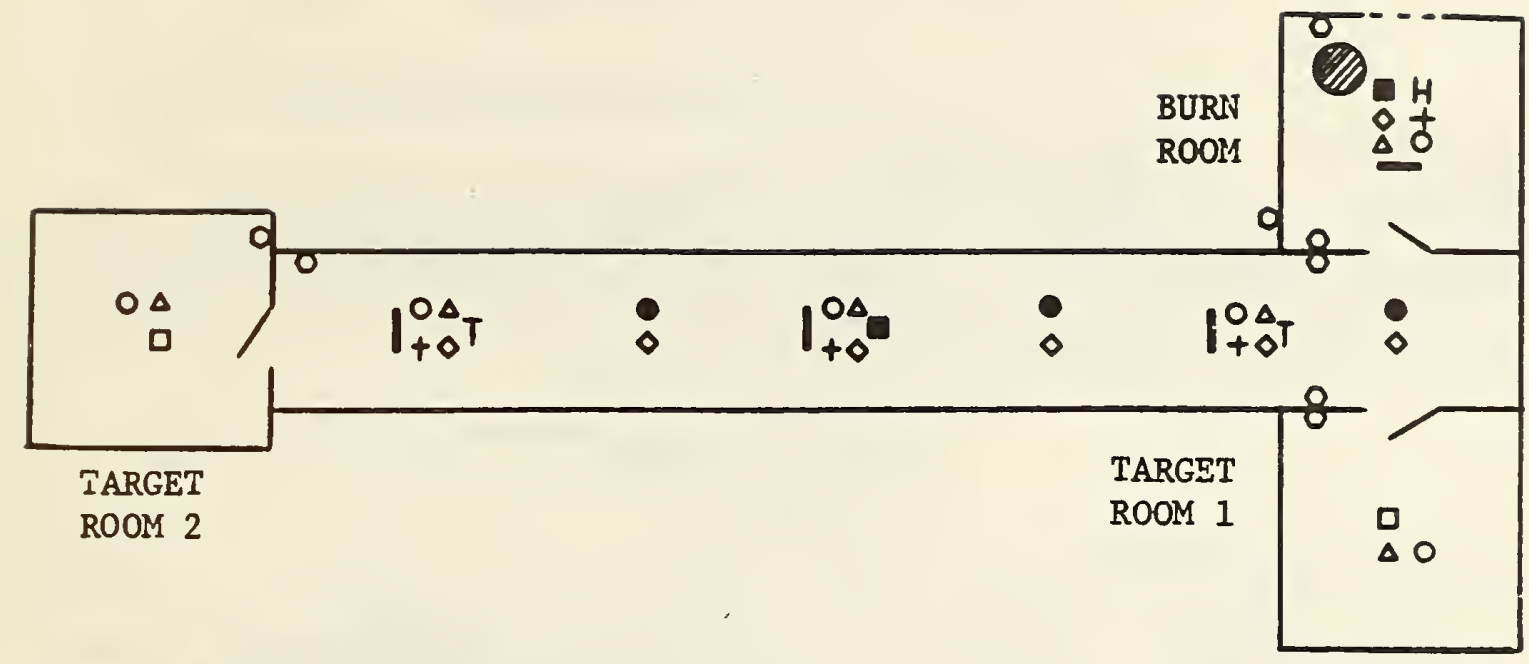

Fire Source

- Vertical Thermocouple Array (8 Levels)

$\Delta$ Vertical Photometer Array (4 Levels)

+ Ceiling Thermocouple (Imbedded in Ceil. Surf. Layer)

$\checkmark$ Brass Disk Under Ceiling (Simulates Heat Detector)

$H$ Bidirectional Flow Probe Under Ceiling

- Eye-Level Sampling of $\mathrm{O}_{2}, \mathrm{CO}_{2}, \mathrm{CO}$

- Ionization-Photoel. Pair of Smoke Detectors

- Ceiling Gas Thermocouple

- Eye-Level Sampling of $\mathrm{CO}_{2}, \mathrm{CO}$

$T$ Turbidimeter Under Celling

O Wall Pressure Taps (0.39 m From Ceiling)

Figure 1. Facility with instrumentation. Corridor measures $2.44 \mathrm{~m}$ x $18.9 \mathrm{~m}$, and each room measures $3.66 \mathrm{~m} \mathrm{x} 3.66 \mathrm{~m}$. Celling height is $2.44 \mathrm{~m}$. 


\section{CENTER FOR FIRE RESEARCH NATIONAL BUREAU OF STANDARDS \\ FY 84}

Institution: Factory Mutual Research Corp., Norwood, MA 02062

Grant No: NB82 NADA 3030

Title:

Prediction of Fire Dynamics

Principal Investigators:

Raymond Friedman (617)762-4300, ext. 2870 Howard W. Emmons (617) 495-2847

Other Professional Personnel: R. L. Alpert

M. A. Delichatsios

J. de Ris

G. H. Markstein

L. Orloff

NBS Scientific Officer:

J. Quintiere

Technical Abstract:

The objectives are to improve the scientific understanding of fire and provide useful inputs to fire safety engineering. The five current tasks are: develop a computer code for predicting development of a fire in a building; measure entrainment rates into fire plumes; characterize flame radiation; correlate distribution of chemical species in pool fires; and develop a technique for studying transient pyrolysis and flame radiation of charring fuels.

1. Prediction of Fire in Buildings

The objective of this task is to examine the ultimate requirements of a computer program for the spread and decay of a fire in a building large or small - and to take appropriate steps to move the present Computer Fire, Code program in that direction.

1) The general computer fire code requirements will be discussed in a series of reports on the various components which must be correctly predicted by a successful program. These reports will effectively be chapters in a book on "The Prediction of Fires in Buildings". A tentative outline is given as Appendix 1. The first few chapters will be completed in this first contract year.

2. The use of CFCV has shown how the physical phenomena of fires can produce such rapid changes that the numerical algorithm gets into difficulties. The ignition of target objects can cause very large and rapid fluctuations of flow through the vents. These fluctuations are real. They are frequently reported in real fires as wooshes. All computer codes must be used to seek out the presence of such phenomena and then efforts must be made to so write the physical equations that the numerical method will not bomb out but will give a sufficiently accurate description of the real phenomena.

3. An important phenomenon not yet included in any zone model computer fire code is the nonsteady ceiling jet. Models which instantaneously produce a hot layer of uniform properties over the entire ceiling of a room work well for small rooms but badly for large ones. The nonsteady ceiling jet is responsible for the delay in the spread of fire down a corridor. The velocity of the advancing front of a ceiling jet is given by 


$$
u_{f}=\sqrt{g H}(1-\delta / H)\left(1-\rho / \rho_{a}\right)^{1 / 2}
$$

relative to the cold gas in front of it.

If the ceiling jet in a corridor is fed at a rate $\dot{m}_{u}$ at a density $\rho$ from a fire in a room into which cold air at density $\rho_{\text {flows }} u_{\text {fl }}$ a rate $\dot{\mathrm{m}}_{\mathrm{D}}$, the front velocity and the hot layer depth are given by quadratic equations while the cold flow out the opposite end of the corridor is given by

$$
M_{a}=\frac{M}{R}-M_{D} \text { (conservation of volume) }
$$

where $M_{a}=\frac{\dot{\mathrm{m}}_{\mathrm{a}}}{\rho_{\mathrm{a}} \mathrm{Hw} \sqrt{\mathrm{gH}}}, \mathrm{M}_{\mathrm{u}}=\frac{\dot{\mathrm{m}}_{\mathrm{u}}}{\rho_{\mathrm{a}} \mathrm{Hw} \sqrt{\mathrm{gh}}}, \mathrm{M}_{\mathrm{D}}=\frac{\dot{\mathrm{m}}_{\mathrm{D}}}{\rho_{\mathrm{a}} \mathrm{Hw} \sqrt{\mathrm{gH}}}, \mathrm{R}=\rho_{\mathrm{a}}$

The solutions to the quadratic equations for the velocity, $C=\frac{c_{f}}{\sqrt{g H}}$,

and depth, $\Delta=\delta / H$, are shown in Fig. 1. Since some of the curves

for $\dot{\mathrm{m}}_{\mathrm{p}}>0$ (flow into the fire room) have a vertical tangent, we learn that buoyancy has a limited capacity to move fire gases out of the fire room.

$\underline{\text { Appendix }}$

I. Introduction and General Components and Phenomena

(Fire, Plumes, Layers, Vents, Heat Transfers, Flows, Brands, etc.)

II. Components

1. Fires

a. Growing (slab, line)

b. Pool

c. Burner

d. Crib

e. Wa11

f. Corner

g. Ceiling

h. Furniture

i. Ventilation limited

j. Burn-Out

2. Extinguishment and Detection
a. Sprinklers
b. Hose Streams

c. Other agents

d. Detectors

1. Ionization

ii. Photo

1i1. Thermal

3. Plumes
a. Point source
b. Line source
c. Area source

d. On wall

e. In corner

f. By vent 
4. Layers

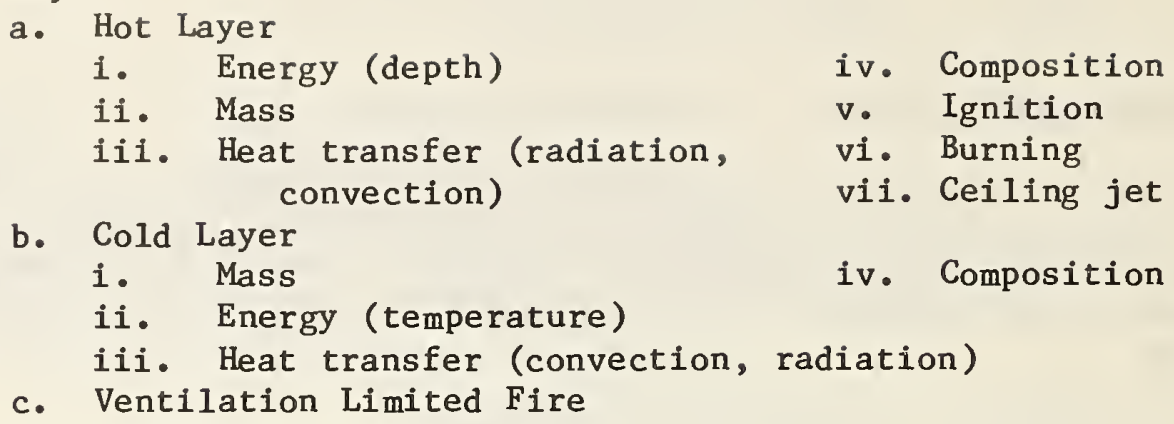

5. Vents
a. Door or window
b. Sky light or roof holes
d. Flow entrainment
c. Forced
e. Flow apportionment

6. Walls
a. Solid
b. Layered
c. Hollow

7. Building Flows
a. Mean flows
b. Buoyant flows
i. Ceiling jets
ii. Stairwells
c. Ventilation system
d. Shafts
(elevator, wall)
e. Dynamic effects
(sounds and explosions )

8. Wind and Weather
a. Building pressure distributions
b. Moisture

III. Phenomena

1. Heating
a. Conduction
b. Melting
c. Structural failure

2. Pyrolysis
a. Heat of Pyrolysis
b. Pyrolysis products
c. Arrhenius or pyrolysis temperature

3. Ignition
a. Arrhenius or ignition temperature
c. Spontaneous
b. Pilot
d. Hot layer ignition

4. Burning
a. Heat of combustion
e. Layer combustion
b. Efficiency and rate of heat release f. Vitiation
c. Combustion products
g. Ventilation limited
d. Flame temperature and radiation 


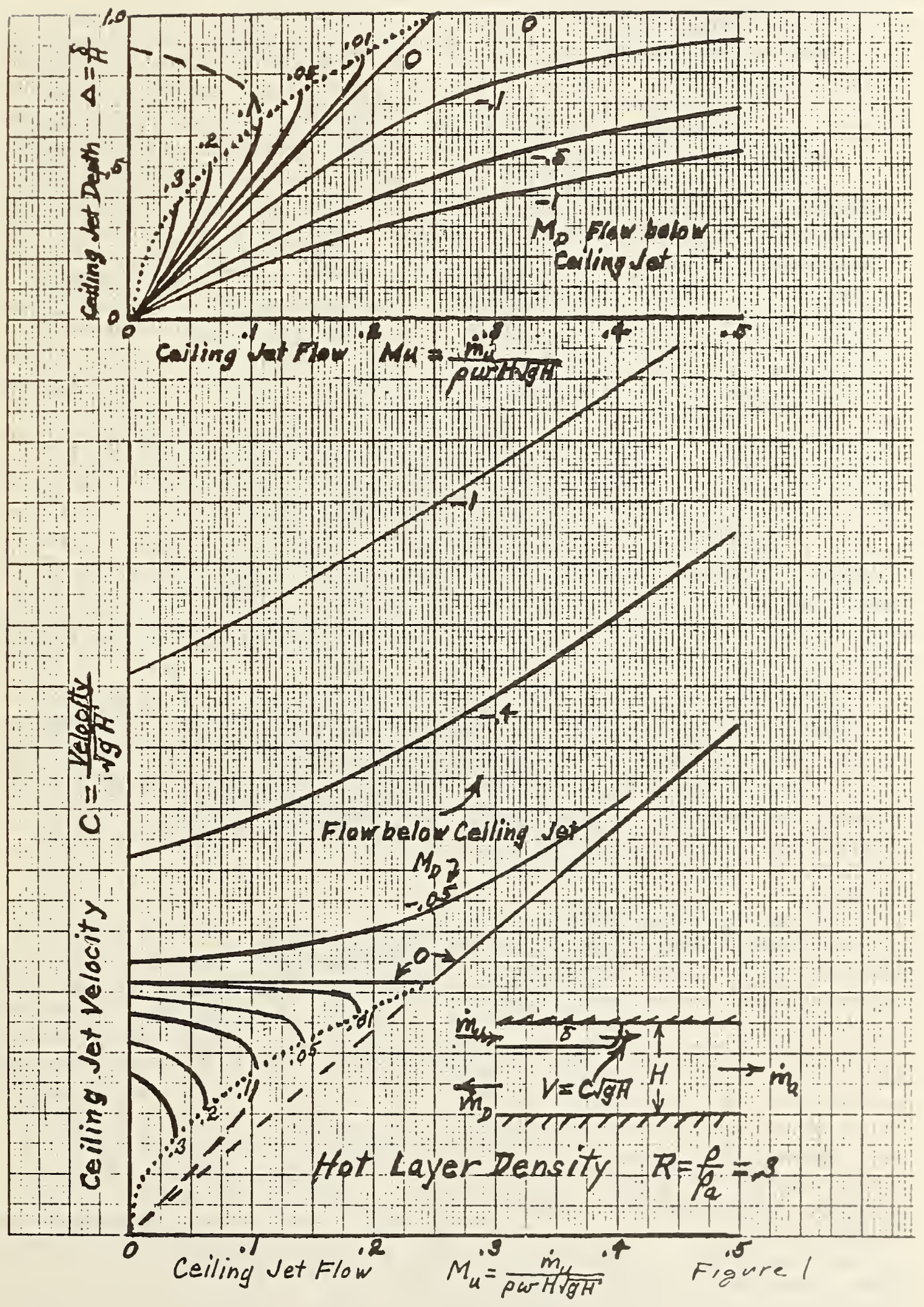


2. Entrainment in Pool Fires

We have completed the measurements of entrainment rates into turbulent buoyant jet flames, in a $1.2 \mathrm{~m}$ diameter enclosure. The main results are:

1) For turbulent jet fires controlled only by buoyancy, air entrainment rates into the flames are independent of the fuel supply rate and increase with the $5 / 2$ power of the distance from the nozzle exit. This behavior is similar to an expression recommended previously by Zukoski; however, our measurements provided an entrainment rate by a factor of two smaller than the previous measurements by Zukoski. This discrepancy was ascribed to two factors: 1) the difference in the fire source sizes ( $200 \mathrm{~mm}$ in Zukoski compared to 12, 23, and $30 \mathrm{~mm}$ dia in the present study); and b) the absence in our experiments of large-scale toroidal structures in contrast to Zukoski's pool fires.

2) If one decreases the nozzle size (from $23 \mathrm{~mm}$ to $12 \mathrm{~mm}$ dia for 20-50 kW flames) the increased nozzle momentum delays (stabilizes) the buoyancy driven transition to turbulence causing the entrainment to depend slightly on the total heat release, while its variation with height is similar to the larger $(23 \mathrm{~mm})$ nozzle but with a virtual origin above the nozzle exit. The entrainment rates for a 30 and a $23 \mathrm{~mm}$ diameter buoyant jet fire coincide with each other.

3) Based on the present experimental results, we have shown that existing integral models for turbulent burning require significant modifications in order to include the apparent nonequilibrium nature of turbulence in fire plumes. A possible modification has been suggested which takes into account the variation of turbulent velocity intensities along the fire.

Entrainment rates have also been measured for a $190 \mathrm{~mm}$ diameter propane pool fire in the $1.2 \mathrm{~m}$ diameter enclosure. The entrainment rates agree with Beyler's, which were obtained using a different technique. Both Beyler's and FMRC's results for both pool and jet fires were correlated by a single curve of entrainment relative to stoichiometry versus height plus fire source diameter all divided by heat release to the two-fifths power.

\section{Radiation from Flames}

In many fires, energy transfer from the flame to the fuel and to the surroundings occurs predominantly by thermal radiation. The main objective of the present task is the development of techniques for measuring the pertinent radiative properties of fires, and to provide a quantitative basis for predicting the resulting radiative energy transfer. The rate of fire growth and the spread of fire to new fuel elements depends critically on this energy transfer, and its quantitative assessment is thus essential for estimating fire losses and threat to life safety.

Recent work under this task has concentrated on measurements of total radiant emission from turbulent and laminar buoyant diffusion flames, with particular emphasis on the relationship between radiant emission and sooting tendency of the fuel. For buoyant turbulent flame jets, the radiative fraction of total rate of heat release is a convenient measure of radiant emission, since it is independent of fuel flow rate over a wide range of flow rates and thus primarily a function of fuel chemistry. The sooting tendency in diffusion flames is customarily 
measured by the flame height of a laminar diffusion flame (or, equivalently, the fuel mass flow rate) at which soot just begins to issue from the flame tip (smoke point). In the present work, a linear correlation between radiative fraction of buoyant turbulent flame jets and smokepoint flame height was established for a variety of hydrocarbon fuels of widely varying sooting tendency. It may thus be possible to predict radiant emission of fairly large turbulent diffusion flames from measurements of the smoke point, performed with small laminar flames. The results further indicated that for fuels of high sooting tendency, the radiative fraction saturates at a value of about 42 percent.

In order to gain a deeper insight into the relationship between radiation and sooting tendency, it seemed indispensable to perform measurements on laminar diffusion flames over a wide range of experimental conditions. Work thus far has been performed with pure hydrocarbon fuels, binary fuel mixtures and nitrogen-diluted fuels burning in air, as well as pure or nitrogen-diluted fuels burning in atmospheres with reduced or increased oxygen fraction.

With laminar flames, radiative fraction is not constant but increases with increasing fuel flow rate. However, one obtains simple results for mixtures of olefins and with butadiene, whether pure, in binary mixtures, or diluted with moderate amounts of nitrogen. For all these fuels burning in air, at the smoke point the total loss fraction, consisting primarily of radiant fraction augmented by a small constant heat loss (about 3 watt) to the burner, had a value of about 30 percent, independent of fuel composition. Analogous results were also obtained with increased or reduced oxygen concentration in the atmosphere, but under these conditions the total loss fraction at the smoke point increased with increasing ambient oxygen concentration. Furthermore, for the olefins and butadiene a linear mixing rule for the smoke point, previously found by other investigators, was confirmed.

However, with binary mixtures of olefins and paraffins distinct deviations from these results are encountered. In view of the important influence of flame temperature on sooting tendency, it was suspected that the deviations were at least in part caused by flame temperature variations. Therefore, future work will be performed under conditions where the adiabatic flame temperature is held constant for a variety of fuel mixtures. To maintain constant flame temperature, varying amounts of nitrogen diluent will be added to the fuel mixtures and/or the atmosphere. In addition we will control the adiabatic flame temperature by preheating the fuel.

It is also planned to perform further measurements on turbulent flame jets, and to extend the study to turbulent vertical-wall flames.

\section{Chemical Modeling of Large Pool Fires}

In a continuation of earlier work, local chemical species concentrations have been measured in propane pool fires of $38 \mathrm{~cm}$ and $76 \mathrm{~cm}$ diameter, at combustion rates from 50 to $283 \mathrm{~kW}$. Burner lip size has also been varied. The axial composition data are linearly correlated when the normalized mixture fraction, u, (averaged over the atomic. $p^{\prime} \xi^{-}$ cies $C, H, O$, and $N$ ) is plotted on log paper against $(Z+D+5 L) / \dot{Q}^{2 / 5}$, where $\mathrm{Z}$ is the height above the burner surface, $\mathrm{D}$ and $\mathrm{L}$ are the diameter 
and lip height of the burner, and $Q$ is the heat release rate. The normalized mixture fraction, $\xi$, is the average of $\left(M_{i}-M_{i \infty}\right) /\left(M_{i f}-M_{1 \infty}\right)$ where $M_{1}, M_{i f}$, and $M_{1 \infty}$ are the mass fractions of element $\mathrm{C}, \mathrm{H}, \mathrm{O}$ or $\mathrm{N}$ at the sampling point, in the injected fuel, and in the ambient. For these large pool fires burning in the open, the slope of the correlation is $-7 / 2$. However, similar correlations for buoyant turbulent jets and small pool fires burning in our $1.2 \mathrm{~m}$ diameter enclosure having a very quiescent atmosphere indicate a $-5 / 2$ power decay. Two possible explanations for this significant difference in decay rate are ( 1 ) the "open" fires are more turbulent due to vorticity in the ambient, and thus entrain air at a greater rate; and (2) the mixture fraction is "smeared" laterally to a greater extent in the meandering "open" fires.

The success of the $(Z+D+5 L) / \dot{Q}^{2 / 5}$ parameter is consistent with Froude modeling coupled with a virtual source relationship closely related to that obtained by Heskestad.

\section{Flame Radiation from Charring Fuels}

A pyrolysis chamber has been designed for producing fuel vapors from charring combustible solids in a horizontal configuration up to $30 \mathrm{~cm}$ square. An electrically heated radiant panel and inert purge gas will be used. The effluent will be burned as a turbulent, buoyant jet diffusion flame. The time-dependent total and radiative heat release rates of this flame will be measured. A range of charring fuels will be studied.

\section{Future Plans}

The computer fire code will continue to be extended. The nonsteady ceiling jet model will be incorporated into the computer fire code. Numerical instability problems in the model will be traced down to their sources and corrected rather than relying on ad hoc fixes. The next items to be added to the fire code are the burning of the hot layer, flames out the door into the next room, temperature and composition of the cold layer, and buoyant flow throughout a building.

A program to measure the effect of ambient vitiation and fuel diluents, on radiative properties of buoyant turbulent jet diffusion flames will be undertaken. Also, mean species concentrations will be correlated. Radiative fraction of heat release rate, Schmidt temperatures, and absorption cross-sections will be simultaneously and nonintrusively measured. Jet centerline mean species concentrations will be obtained with a constant mass flow sampling probe. The ambient can be reduced to $15 \% \quad \mathrm{O}_{2}$ using steam addition plus combustion products. The fuel itself can be diluted with $\mathrm{N}_{2}, \mathrm{CO}_{2}$ or steam.

A program will be initiated to measure the radiant fraction of heat release rate for gaseous-fuel vertical wall fires. Concurrently, similar measurements will be made on pool and jet fires with inerts added at dilution ratios predicted by theory so as to simulate the cooling effect of the wall in a wall fire. Radiative characteristics of narrow horizontal slices will be measured as well as the overall radiation from wall fires, and results compared with theory.

The pyrolysis chamber described above will be used to measure transient pyrolysis properties of charring fuels and the radiant heat 
release fraction $x_{R}$ of their burning pyrolysis products. In addition to $X_{R}$, measurements will be made of: sample surface temperature, pyrolysis vapor temperature, mass loss, and chemically determined heat release rate, all time-dependent, for various imposed heat fluxes. Results will be interpreted in terms of "equivalent" transient pyrolysis properties and the "normal soot point" of the pyrolysis gases. Results should be useful in predicting flame spread and burning rates in various use situations from flammability properties.

\section{Technical Reports and Publications}

1. Markstein, G.H., "Soot Formation, Radiant Emission and Absorption in Laminar Ethylene and Propylene Diffusion Flames," Technical Report No. RC83-BT-6, June 1983.

2. de Ris, J., "Flammability Testing: State-of-the Art," Paper presented at the Seventeenth Asilomar Conference on Fire and Blast Effects of Nuclear Weapons, Monterey, CA, Technical Report No. RC83-BT-7, June 1983.

3. Delichatsios, M.A., "A Scientific Analysis of Stored Plastic Fire Tests," Fire Science and Technology, Vol. 3, No. 2., pp. 73-103, 1983.

4. Delichatsios, M.A., "Flame Heights in Turbulent Wall Fires With Significant Flame Radiation," Paper presented at the NBS Center for Fire Research Annual Conf., Washngton, D.C., August 23-25, 1983 , Combustion Science and Technology, in press, 1984.

5. Markstein, G.H. "Measurements on Gaseous-Fuel Pool Fires With A Fibre-Optic Absorption Probe," Paper presented at the NBS Center for Fire Research Annual Conf., CST, Washington, D.C. August 23-25, 1983 Combustion Science and Technology, in press, 1984.

6. Alpert, R.L., "Pressure Modeling of Fire Growth on Char-Forming and Laminated Materials," Technical Report RC83-BT-11, December 1983.

7. Delichatsios, M.A., "Entrainment Measurements in Turbulent Buoyant Jet Flames and Implications for Modeling," 20th International Symposium on Combustion, Univ. of Michigan, Ann Arbor, MI, Aug. 12-17, 1984.

8. Markstein, G.H., de Ris, J., "Radiant Emission and Absorption By Laminar Ethylene and Propylene Diffusion Flames," 20th International Symposium on Combustion, Univ • of Michigan, Ann Arbor, MI, August 12-17, 1984.

9. Markstein, G.H. "Relationship Between Soot Point and Radiant Emission From Buoyant Turbulent and Laminar Diffusion Flames," 20th International Symposium on Combustion, Univ. of Michigan, Ann Arbor, MI, August 12-17, 1984. 
10. Most, J.M., Sztal, B., Delichatsios, M.A., "Turbulent Wall Fires LDV and Temperature Measurements and Implications," Second International Symposium on Applications of Laser Anemometry to Fluid Mechanics, Lisbon, Portugal, July 2-4, 1984.

11. Delichatsios, M.A., "Modeling of Aircraft Cabin Fires," Report No. OHOJ2.BU, June 1984.

12. de Ris J., Markstein, G.H., "Estimated Particulate Emissions from Large Urban and Forest Fires," Technical Memorandum, June 1983. 


\section{CENTER FOR FIRE RESEARCH \\ NATIONAL BUREAU OF STANDARDS \\ FY 84}

Institution: Harvard University

Grant Number: 60NANB4D0010

Grant Title: Prediction of Upper Layer Composition in Transient Compartment Fires

Principal Investigator: Professor Howard Emmons

Division of Applied Science

Harvard University

Cambridge, MA 02138

Other Professional Personnel: Dr. Craig Beyler (Postdoctoral Fellow)

NBS Scientific Officer: Mr. Richard Bukowski

\section{$\underline{\text { Technical Abstract: }}$}

The objective of this project is to establish methods and data required to predict the composition of a hot gas layer formed by the collection of products of combustion from a burning object. The major focus of current work is the determination of the mass of major chemical species produced per unit mass of fuel volatilized for a range of fuels and ventilation conditions.

It has been demonstrated in previous work (1) that the production rate of major species in buoyant diffusion flames is principally a function of the fuel and the amount of air which is entrained into the flame below the hot gas layer. In the previous work simple gaseous and liquid fuels were burned in steady state. In transient fire conditions where the quasi-steady state assumption is not appropriate, the production rates will also be a function of the layer oxygen concentration. Several extensions to the previous work will be required to provide a general predictive method for hot gas layer composition in transient fires. In this project the methods used for gaseous and liquid fuels are being adapted to the burning of solid fuels found in compartment fires in order both to build a data base with fuels relevant to compartment fires and to test the generality of the results of the previous work.

The production rates of $\mathrm{CO}_{2}, \mathrm{CO}, \mathrm{H}_{2} \mathrm{O}, \mathrm{H}$, and total hydrocarbons (THC); the consumption rate of oxygen; and the smoke obscuration potential are measured and correlated as a function of the ratio of the fuel volatilization rate to the oxygen entrained below the hot gas 
layer. Figure 1 shows the results of experiments performed with PMMA as a fuel. The figure clearly illustrates that at low fuel-to-oxygen ratios, the production rates are as one would expect for burning in the open. At higher fuel-to-oxygen ratios, insufficient oxygen is entrained to burn the PMMA completely. At these fuel-to-oxygen ratios, increased production rates of products of incomplete combustion ( $\mathrm{CO}, \mathrm{H}_{2}$, and $\mathrm{THC}$ ) are observed. The plateau in $\mathrm{CO}$ and $\mathrm{H}_{2}$ production at large fuel-tooxygen ratios is typical of the behavior observed for gaseous andliquid fuels. Production rate correlations have also been developed for polyethylene and wood.

The use of chemical species production rate correlations (like Figure 1) in compartment fire models will provide improved predictions of the toxic hazards of the smoke and toxic gases produced in compartment fires.

\section{References:}

1. Beyler, C.L., Development and Burning of a Layer of Incomplete Combustion Products Generated by a Buoyant Diffusion Flame, Ph.D. Thesis, Harvard University, 1983. 

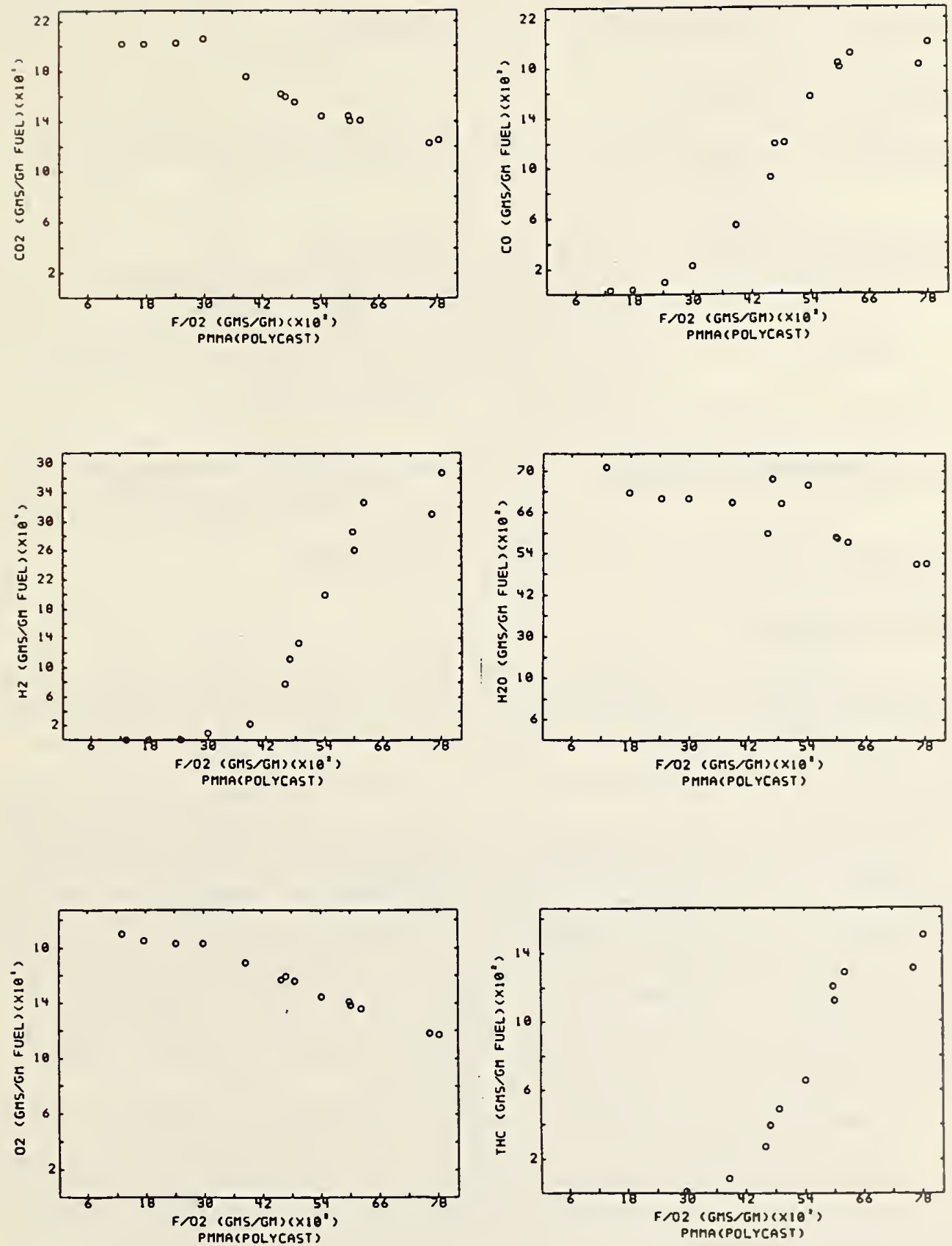

FIGURE 1 
CENTER FOR FIRE RESEARCH

NATIONAL BUREAU OF STANDARDS

FY 84

Institution: The Pennsylvania State University

Grant No.: NB81NADA2044

Grant Title: An Investigation of Turbulent Fires on Vertical and Inclined Walls

Principal Investigator: Professor G. M. Faeth

Department of Mechanical Engineering

The Pennsylvania State University

315 Mechanical Engineering Building

University Park, PA 16802

Telephone: (814)865-3743

Other Professional Personnel: S. M. Jeng, Research Assistant

M. -C. Lai, Graduate Assistant

NBS Scientific Officer: Dr. James G. Quintiere

Technical Abstract:

Introduction. The objective of this investigation is to study the structure and radiation properties of turbulent fires along walls. The findings can be applied to modeling fires in structures, the development of material test codes and the development of fire detectors.

Measurements in both noncombusting and combusting flows along plain surfaces are used to evaluate models of mean and turbulent structure as well as flame radiation properties. Noncombusting flows are considered to provide systematic evaluation of analysis. Various wall inclinations provide information on stratification which is an important aspect of fires within structures. Both nonluminous and luminous flames are treated, the former to provide baseline information on radiation from turbulent flames, the latter due to the importance of radiation from soot in fires.

During this report period, work concentrated on aspects of the study which are preparatory for measurements and analysis of wall fires. This included: predictions of spectral radiation intensities and radiative heat fluxes for conditions of earlier measurements in nonluminous axisymmetric fires, measurements of the structure of laminar flames to be used in state relationships needed for conserved-scalar analysis of turbulent flames; and measurements of mean and turbulent properties in noncombusting wall plumes along vertical and inclined walls.

Nonluminous Flame Radiation. During earlier work, measurements were completed of the structure and radiation properties of round 
turbulent buoyant diffusion flames fueled with natural gas (largely methane). Predictions of the structure of these flames were also carried out, using the conserved-scalar formalism in conjunction with a $k-\varepsilon-g$ turbulence model. This approach is based on scalar properties being only a function of mixture fraction (the fraction of mass which is fuel) to yield state relationships. The laminar flamelet method was used to find state relationships, based on measurements in laminar flames which have been found to yield universal state relationships for a wide range of flame strain rates and length scales. This tactic also provided good predictions of measured spectral radiation intensities for the flames, using predicted mean properties. A stochastic analysis, which approximately treats effects of turbulent fluctuations, suggested 20-30\% increases in spectral intensities due to turbulence, but this difference was difficult to detect since combined experimental and theoretical uncertainties were of similar magnitude, c.f. references $1-4,6$ and 7 for details.

During this report period, calculations were extended to predict total radiative hat fluxes at various locations around the fires. This involved summing contributions over all wavelengths and incremental paths through the flames to the radiative heat flux transducers. A portion of the results are illustrated in Fig. 1. Agreement between predictions and measurements is reasonably good, which represents one of the first instances where both structure and radiation properties have been successfully predicted for buoyant flames. This work provides the necessary background for similar analysis of radiation from wall fires, c.f. reference 5 for more details.

Laminar Flame Structure. The theoretical approach being developed requires state relationships which are found by measuring temperatures and species concentrations in laminar flames and then correlating the results as a function of mixture fraction. A laminar flame apparatus was assembled and these measurements were carried out for fuels planned for the wall fire tests, e.g., local natural gas (largely methane for nonluminous flame tests) and ethene (for sooting luminous flame tests). The ethene tests included measurements of soot volume fraction, using methods developed at NBS.

The results indicated that nearly universal plots of temperature and species mass fractions were obtained irrespective of position in the flame. Past results suggested similar behavior for methane, propane and $n$-heptane; therefore, evidence of the approximate universality of these plots is growing--strengthening the case for the laminar flamelet method. An interesting additional finding was that soot volume fractions also roughly correlate with mixture fraction, suggesting the potential for eventual treatment of luminous flames in the same manner as nonluminous flames. This idea will be explored during subsequent work with wall fires.

Buoyant Wall Plumes. Moving directly from axisymmetric flames to wall fires represents a large step; therefore, preliminary tests and 
analysis of noncombusting wall plumes have been undertaken. The tests involve an $800 \times 1000 \mathrm{~mm}$ wall which can be inclined 0-600 to introduce effects of stratification. Initial work has been at the Boussinesq limit, involving carbon dioxide/air mixtures, having a maximum density variation of $4 \%$, and injected from a slot at the asymptotic Froude number to speed flow development. Mean and turbulent velocities and the Reynolds stress are measured using laser Doppler anemometry (LDA). Mean concentrations are measured using isokinetic sampling and analysis with a continuous NDIR detector. However, more useful measurements of mean and fluctuating concentrations (with potential for measuring cross-correlations with velocity) are being undertaken using off-resonance laser-induced fluorescence (ORLIF) based on fluorescence from iodine vapor tracer in the slot flow.

A portion of the results are illustrated in Fig. 2 for a vertical wall. Streamwise mean and fluctuating velocities and mean concentrations (by sampling) are plotted as a function of distance from the wall, $y$, divided by distance above the slot, $x$, which is the similarity variable for the outer portion of the flow. Various distances above the slot, normalized by the slot height $b$, are considered. The results are qualitatively similar to earlier hot-wire measurements by Grella and Faeth (1975) in thermal wall plumes, but are more useful for development of theory due to the increased reliability of LDA measurements. An unusual feature of these flows (and wall fires as well) is their thickness, which far exceeds buoyant natural convection boundary layers. There are also significant effects of laminarization near the wall due to low rates of turbulence production near the velocity maximum. These features make the wall plume an excellent flow for definitive evaluation of buoyant turbulence analysis--particularly when inclined surfaces are considered to introduce effects of stratification.

Conclusions: The conserved-scalar turbulence analysis, combined with the laminar flamelet approximation, continues to look encouraging as a means of predicting the structure and radiation properties of buoyant flames. The potential for treating soot and luminous flame radiation in the same manner looks promising as well, from initial results, but must be studied more thoroughly. The wall plume experiments are yielding results useful for testing predictions of turbulence properties for buoyant wall flows.

Subsequent work will involve measurements in strongly--buoyant noncombusting wall plumes and wall fires, as well as computations to evaluate methods of analysis.

\section{Reports and Papers:}

1. S.-M. Jeng and G. M. Faeth, "Species Concentrations and Turbulence Properties in Buoyant Methane Diffusion Flames," J. Heat Transfer, in press.

2. S.-M. Jeng and G. M. Faeth, "Predictions of Mean Scalar Properties in Turbulent Propane Diffusion Flames," J. Heat Transfer, in press. 
3. S.-M. Jeng, M.-C. Lai and G. M. Faeth, "Nonluminous Radiation in Turbulent Buoyant Axisymmetric Flames," Comb. Sci. and Tech., in press.

4. S.-M. Jeng, M. - C. Lai and G. M. Faeth, "Infrared Radiation from Gases in Buoyant, Turbulent Methane Diffusion Flames," Proceedings of the Sixteenth Fall Technical Meeting, Eastern Section of the Combustion Institute, Pittsburgh, 1983.

5. S.-M. Jeng and G. M. Faeth, "Radiative Heat Fluxes Near Turbulent Buoyant Methane Diffusion Flames," J. Heat Transfer, in press.

6. S.-M. Jeng, M.-C. La1 and G. M. Faeth, "An Investigation of Axisymmetric Buoyant Turbulent Diffusion Flames: Flow Structure and Radiation Properties," Report No. NBS-GCR-84-458, January 1984.

7. S.-M. Jeng, "An Investigation of the Structure and Radiation Properties of Turbulent Buoyant Diffusion Flames," Ph.D. Thesis, The Pennsylvania State University, May 1984.

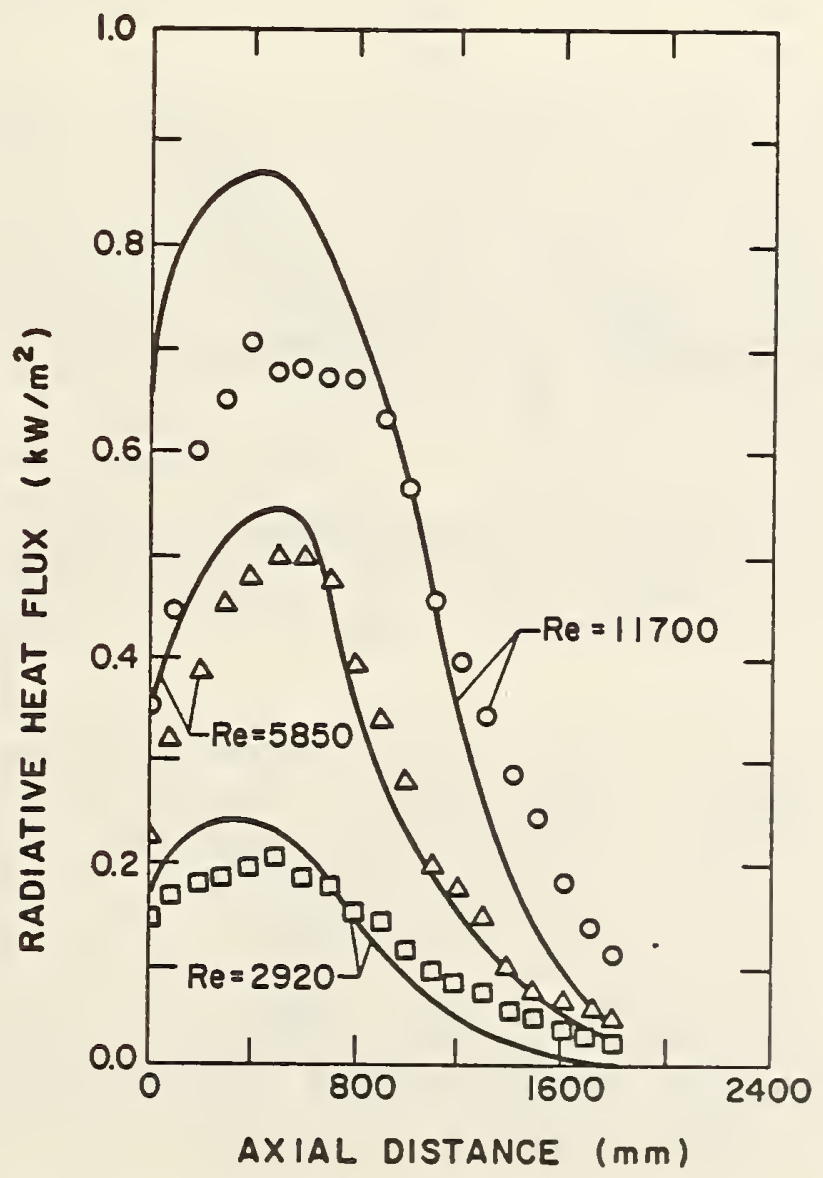

Figure 1. Total radiative heat flux distribution parallel to the axis of methane flames. 

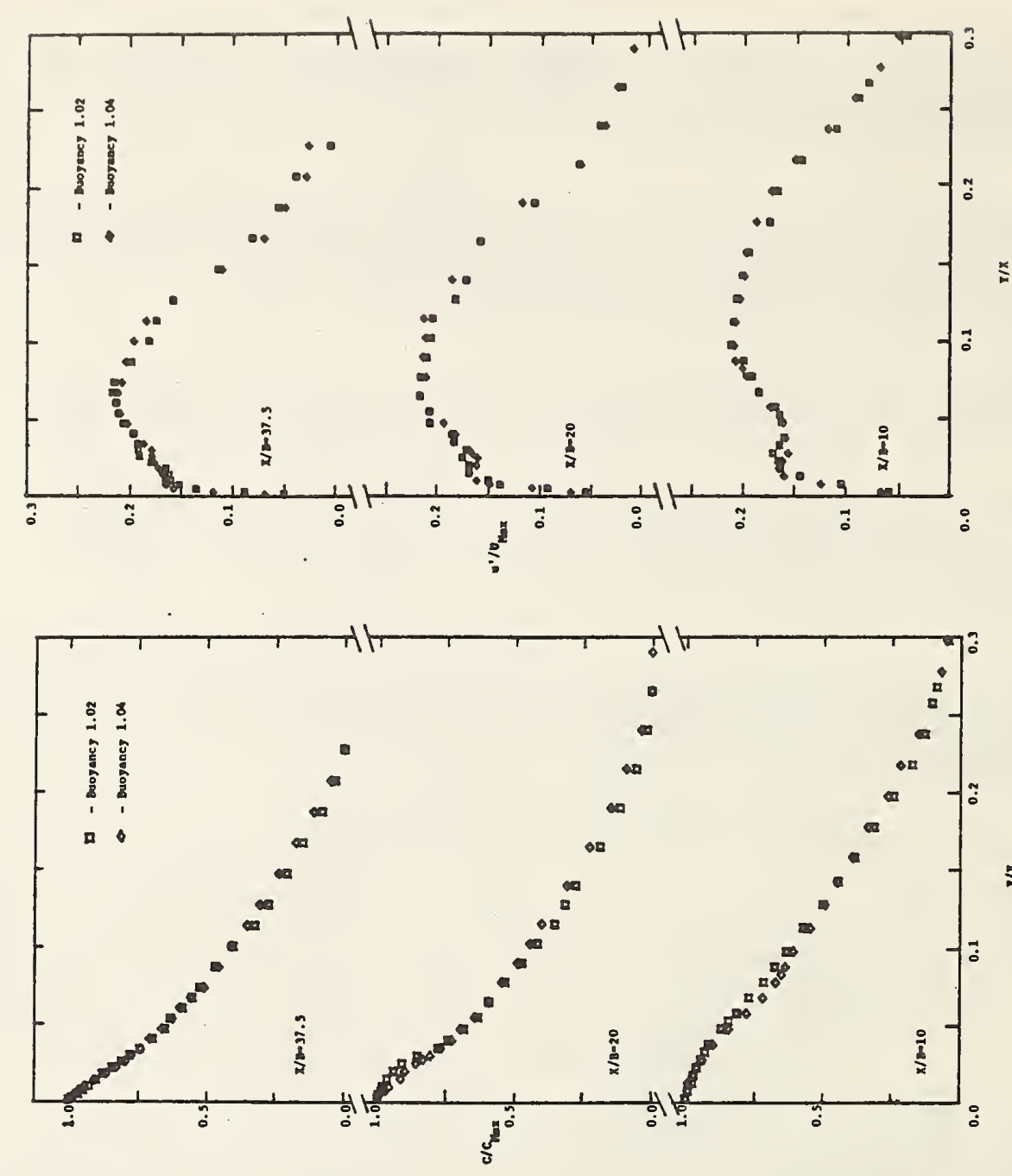

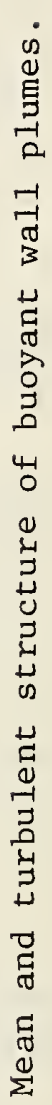

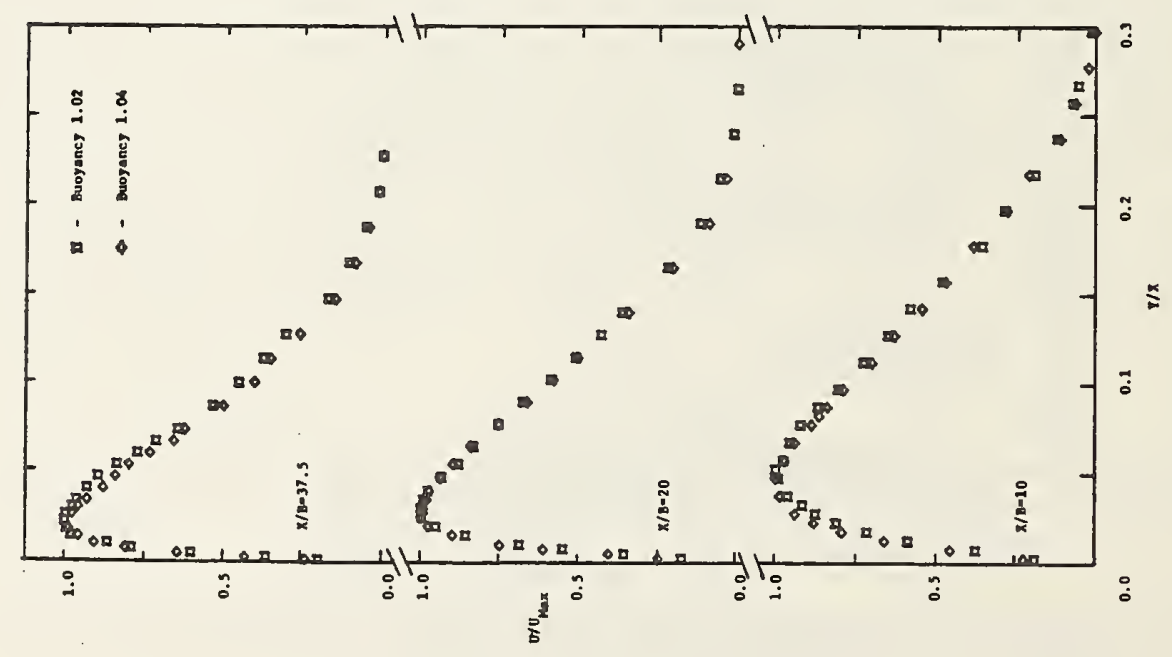

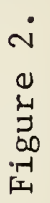


CENTER FOR FIRE RESEARCH

NATIONAL BUREAU OF STANDARDS

FY 84

\section{Institution: Princeton University}

Contract Number: NB83NADA4007

Contract Title: Flow Field Effects on the Sooting Structure of Diffusion Flames

Principal Investigator: Irvin Glassman

Professor

Department of Mechanical and Aerospace

Engineering

Princeton University

Princeton, New Jersey 08544

NBS Scientific Officer: Kermit Smyth

Technical Abstract

In major, as well as minor, fire conflagrations, smoke inhalation is a primary contributor to the casualty rate. The particulate matter in smoke is soot formed during the burning of the fuel mass in a diffusion controlled combustion system. Earlier Princeton work on soot formation in both pre-mixed and diffusion controlled combustion systems has established the fuel pyrolysis rate as a dominant factor in a system's propensity to soot. It follows then that temperature is an important parameter with regard to a combustible material's tendency to soot. However, it is the time that a fluld element is exposed to pyrolysis temperatures in a flame that determines the amount of particulate matter formed. This time, and other factors in flame configurations, are controlled by the overall flow situation in the combustion system. In order to evaluate how control of the fluid mechanical situation could affect the extent (and character) of the soot process, the present program was undertaken.

As inferred, the production of soot in diffusion flames can be influenced significantly by the flow field in and around a flame. The convection of particles by the flow can also determine their residence time in regions of growth and oxidation and, in addition, in many experimental configurations the fuel stream entrains oxidizer at the base of the burner. These latter effects serve to complicate the interpretation of soot measurements in arrangements such as Wolfhard-Parker and tubular burners. Consequently, it is necessary to have a well-controlled and well-defined flow field in which the interaction of fluid flow and chemistry on soot production in a diffusion flame can be clearly elucidated. Thus we have chosen the following "opposed jet" diffusion flame configuration. 
Fuel is ejected uniformly from a porous cylindrical, ceramic burner which is housed in a low turbulence wind tunnel supplied with oxygen and nitrogen. A laminar diffusion flame is stabilized in the forward stagnation region of the burner. Measurements of the flow and temperature fields are obtained along the stagnation streamline with an LDV system and a radiation-corrected thermocouple. A laser light scattering - extinction measurement yields data on soot particle number density, particle size and soot volume fraction. Measurements of the soot characteristics are made along the stagnation streamline from their region of formation on the fuel side of the flame up to the stagnation point. Along the stagnation streamline the flow is one-dimensional and the velocity data permit the interpretation of the light scattering measurements in terms of time rather than distance. Consequently, rates of formation, surface growth and coagulation in the diffusion flame can be inferred from the data. More complex, two-dimensional flow fields do not readily permit the interpretation of soot behavior in these terms.

Last year results were reported on the effect of varying the oxygen index. This contract year the primary concern was to determine the effect of oxidizer velocity. As before temperature, velocities, number density, volume density and mean particle sizes were measured. The results obtained showed that the soot loading, represented by the soot volume fraction, was found to decrease with increasing oxidizer velocity; e.g., $\emptyset=1.1 \times 10^{-6}, 7.4 \times 10^{-7}, 5.8 \times$ $10^{-7}$ and $3.3 \times 10^{-7}$ for oxidizer velocities of $21,38,58$ and $67 \mathrm{~cm} / \mathrm{sec} \mathrm{respec}-$ tively. The variation in peak measured temperature was very small (1907-1927K). The number of soot particles did not vary significantly within this velocity range. Maximum particle size decreased with increasing oxidizer velocity as a result of the reduced residence time for coagulation and for surface growth reactions with fuel pyrolysis product. The specific surface growth rates $(\emptyset / S)$, when examined in terms of particle age, show the typical decrease with time (age). For velocities of 21,38 , and $58 \mathrm{~cm} / \mathrm{sec}$, the rates are very similar. In the highest approach velocity case, $67 \mathrm{~cm} / \mathrm{sec}$, the growth rates are lower than those of the other cases except very close to the stagnation zone.

Reports and Papers

Kennedy, I.M., Vandsburger, U., Dryer, F.L. and Glassman, I., "Soot Formation in the Forward Stagnation Region of a Porous Cylinder", Western States Section/ Combustion Institute Paper 82-39, 1982.

Vandsburger, U., Kennedy, I.M., Dryer, F.L. and Glassman, I., "The Effect of Oxygen Index on the Sooting Structure of a Diffusion Flame", Eastern States Section/Combustion Institute Meeting, Paper No. 8, 1982.

Vandsburger, U., Kennedy, I.M. and Glassman, I., "Sooting Counterflow Diffusion Flames with Varying 0xygen Index", Combustion Science and Technology 39, 263 (1984)

Vandsburger, U., Kennedy, I.M. and Glassman, I., "Sooting Counterflow Diffusion Flames with Varying Velocity Gradients," accepted for publication in 20th Symposium (International) on Combustion (1984). 
CENTER FOR FIRE RESEARCH

NATIONAL BUREAU OF STANDAROS

FY84

Institution: Rutgers, The State University of New Jersey, New Brunswick, New Jersey

Grant No.: $\quad$ NB83NADA4047

Grant Title: Negatively Buoyant Flows Generated in Enclosure Fires

Principal Investigator: Professor Yogesh Jaluria

Department of Mechanical and Aerospace

Engineering

Rutgers, The State University of New Jersey

New Brunswick, New Jersey 08903

Telephone: (201) 932-3652

\section{Other Professional Personnel: D. Goldman (M.S. Student)}

NBS Scientific Officer: Or. Leonard Cooper

\section{Technical Abstract}

The objective of this project is to carry out a detailed experimental study of negatively-buoyant flows generated in enclosure fires. In particular, the study considers the free boundary circumstance of two-dimensional jets of heated fluid discharged downward, thus giving rise to a negatively-buoyant situation. The study also considers the flow adjacent to an adiabatic, or isothermal, vertical boundary, which represents the walls of a room with a fire. These circumstances arise at various stages in the growth of an enclosure fire. Of particular interest are the downward penetration of the flow, the entrainment of adjacent fluid into the flow and the nature of the flow that arises in the region where the flow is negatively-buoyant, see Fig. 1. Quantitative information on the penetration depth and on the flow rate is needed in the modeling of the enclosure fire growth processes, particularly by means of zone models. The results are to be presented in terms of generalized variables, employing non-dimensional governing parameters, so as to permit the use of the obtained data for different enclosure dimensions and energy input values. The results obtained are also expected to be important in the analytical work that may be carried out in the future to consolidate these measurements and, thus, form the basis for an analytical model to simulate these flows.

The experimental arrangement has been completed. Air is sent through a copper tube, which is heated by means of strip heaters wrapped around it. A blower with an adjustable flow rate is used for generating the flow. The copper tube is held vertically above a glass tank which is $1.5 \mathrm{~m} \mathrm{high} \mathrm{and} \mathrm{is} 0.4 \mathrm{~m} \times 0.3 \mathrm{~m}$ in cross-section. The 
blower is located at the top of the tube and a diffuser is positioned at the entrance of the tank. The diffuser spreads out the heated air flowing through the tube and discharges the air downward into the tank as a two-dimensional jet, see Fig. 2. Measurements of velocity and temperature, by means of a hot-wire anemometer and thermocouples respectively, have indicated a fairly uniform flow in the jet at the discharge location.

A considerable amount of effort has been spent on obtaining a satisfactory visualization technique. Because of the relatively small density change across the tank, the shadowgraph and Schlieren techniques were found to yield a fairly weak flow pattern. We are now using smoke for visualization. The smoke is generated by the evaporation of mineral oil as it flows through an electrically-heated steel tube. A dense white smoke is obtained. This smoke may be injected at various locations in the tank and has been found to be adequate for the visualization of the flow. Using this technique, the downward flow penetration is presently being studied. We are interested in determining the dependence of the penetration on the input momentum and buoyancy, as characterized by the inlet Reynolds and Grashof numbers based on the width of the discharge slot and the inflow velocity and temperature.

An array of thermocouples for measuring the temperature field has also been placed in the tank. Some measurements have been taken on the time-dependent behavior of the temperature and velocity distributions. We are presentiy investigating the approach to steady state at large time. The jet is presently located at the middle point of the top cover of the tank and will soon be moved adjacent to the walls in order to study the penetrative effects in that case. A hot-wire anemometer has also been located in the flow, in order to determine the velocity distribution. It is found that the flow initially demonstrates a strong dependence on time, eventually settiling into a quasi-steady situation, as the walls heat up. Because of the opening at the bottom, a steady flow arises finally. The measurements are presently directed at studying the transient behavior and the approach to steady state. Once adequate information is obtained on these characteristics, a detalled investigation of the velocity and temperature fields will be undertaken. These measurements would, therefore, indicate the downward penetration of the flow, the resulting entrainment and the effect of the wall on the flow. Some of the results obtained will be discussed at the Center for Fire Research Conference in October, 1984. 

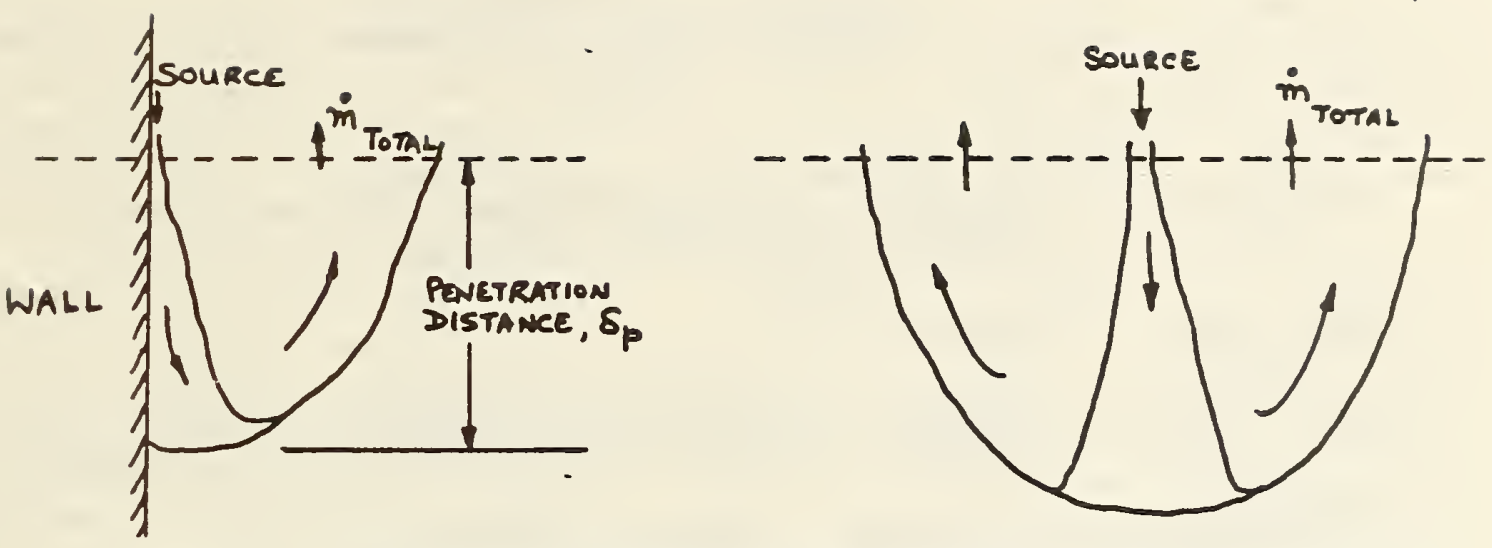

Fig. 1. Negatively buoyant flows arising in enclosure fires.

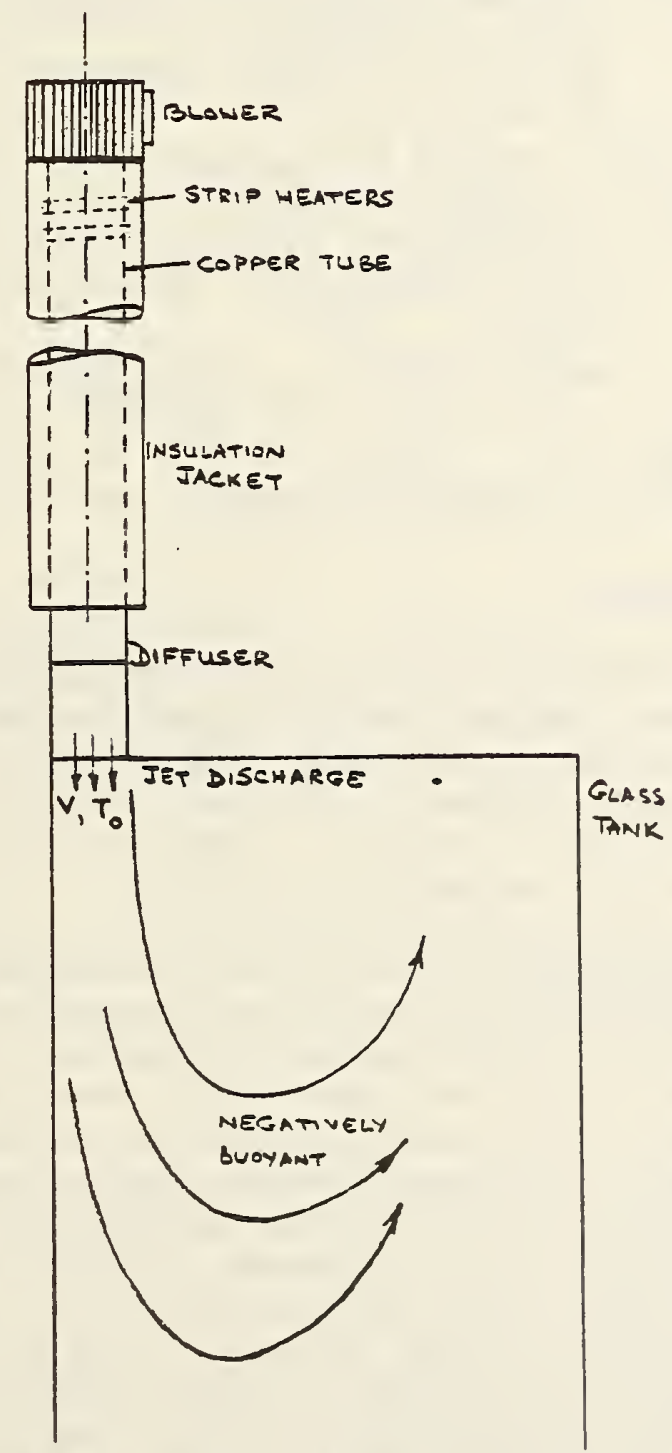

Fig.2. Sketch of the experimental system for the study of negatively-buoyant flows generated in enclosure fires. 


\section{CENTER FOR FIRE RESEARCH \\ NATIONAL BUREAU OF STANDARDS \\ FY 84}

Institution: Department of Fire Technology, Southwest Research Institute, San Antonio, Texas

Grant No.: $\quad$ NB83NADA4015

Grant Title: "Analysis of Hazards to Life Safety in Fires: A Comprehensive Multi-Dimensional Research Program"

Principle

Investigator: Dr. Gordon E. Hartzell, Director

Department of Fire Technology

Southwest Research Institute

6220 Culebra Road

San Antonio, Texas 78238

Other

Dr. Harold L. Kaplan

Professional Dr. Arthur F. Grand

Personnel: Dr. Steven C. Packham

Walter G. Switzer

Howard W. Stacy

Deggary N. Priest

NBS Scientific

Officer: Dr. Barbara C. Levin

Technical Abstract:

The overall objective of this research program is to develop methodology to assess toxicological hazards to human life from the time course of analytical data as provided by a fire model. The first year objectives of the program were to assess and select appropriate animal models and to develop concentration-lethality relationships for $\mathrm{HCl}$ alone and in combination with $\mathrm{CO}$.

The Animal Model. The investigators for this program completed a thorough review of available data for $\mathrm{CO}$, HCN and HCl administered both to rodents and to nonhuman primates. Of particular additional importance were data developed under other funding at SwRI for primate studies involving $\mathrm{HCl}$ and $\mathrm{CO}$. Analysis of the data provided considerable evidence that the rat can be used as a reasonable model for primates with respect to behavioral and lethal sensitivity.

The review of data revealed that $C t$ product (ppm-minutes) doses of both $\mathrm{CO}$ and $\mathrm{HCN}$ causing incapacitation in rats (as measured by leg flexion, activity wheel, pole climb, rotarod and shuttle-box paradigms), monkeys and baboons were reasonably comparable. While the $c t$ product dose causing a response does vary as a function of exposure concentration, especially over extended regions of the ct-response curve, comparable Ct product doses were found to be behaviorally ef- 
fective for $\mathrm{CO}$ and for $\mathrm{HCN}$ in both rats and primates throughout the central regions of the Ct-response curves. On the strength of this broad data base and the similarity known to exist in COHb saturation dynamics for a wide range of mammals, it was concluded that the rat could serve as an adequate model for human intoxication from the common narcotic fire gases when comparable responses are involved.

of critical concern was the relevance of the rat as a model for primates upon exposure to HCl. "Conventional wisdom" has long dictated a greater sensitivity to acid gases by mouth breathing primates than obligatory nose-breathing rodents. References citing HCl levels being dangerous to humans from even short exposures seemed to support the theory of greater human sensitivity. However, none of the sources offered primate data in support of the stated dangerous concentrations for man. From research performed at Southwest Research Institute (SwRI) under Federal Aviation Administration sponsorship, considerable similarity was observed in the post-exposure lethal toxicity of HCl in baboons and in rats. Even massive doses of $\mathrm{HCl}$ did not cause incapacitation due to sensory irritation in either species. Doses sufficient to cause post-exposure respiratory tract damage leading to death were lower than those required to cause physiological incapacitation. In consideration of these findings, the rat appeared to be a reasonable model for estimating lethal doses (ppm-minute) of BC1 for primates.

Toxicity of HCl Atmospheres. A msjor objective of the first year's work plan was to develop the quantitative relationships involved with the toxicity of BCl atmospheres such that models can be developed for the prediction of the toxicological effects of BCl when present in fire gases.

The toxicological effects of $\mathrm{BCl}$ can be divided into two major categories, those resulting from its action as a sensory irritant during exposure and those resulting in post-exposure respiratory effects. In view of the findings from the SwRI non-human primate studies, a significant part of this study concentrated on postexposure lethality of rats attributed to varying times of exposure to $\mathrm{HCl}$ in air.

$\mathrm{LC}_{50}{ }^{\prime} \mathrm{s}$ for HCl were determined for exposure times of $5,10,15$, $22.5,30$ and 60 minutes. A plot of post-exposure $L_{50}$ 's against exposure time is shown in Figure 1 . It should be noted that each point on the curve represents at least five experiments, each using six rats. Thus, the overall curve was derived from a population of at least 150 subjects.

The $L_{50}$ as a function of exposure time curve shown in Figure 1 was developed by exposing rats to a "squarewave" constant concentration of HCl. Gas concentrations, of course, do not remain constant in a real fire or in smoke from laboratory combustion devices. Thus, the applicability of Figure \& for the prediction of toxicological effects from exposure to changing gas concentrations is limited.

A useful concept way be that of expressing exposure dose as the Ct product (concentration $x$ time) producing 50-percent lethality, i.e., the $\mathrm{L}(\mathrm{Ct})_{50}$. However, the $\mathrm{L}(\mathrm{Ct})_{50}$ was found not to be constant over the range of concentrations of $\mathrm{HCl}$ studied. The L(Ct) 50 values varied from about $80,000 \mathrm{ppm}-m i n$ for a 5-minute exposure to $16,000 \mathrm{ppm}$ 
to about $170,000 \mathrm{ppm}-\mathrm{min}$ for a 60-minute exposure to 2,800 $\mathrm{ppm}$. This shows that higher doses ( $C t$ products) can be tolerated if the $\mathrm{HCl}$ concentration is relatively low.

It is of significance that the Ct product for 50-percent lethality (post exposure) of rats lies in the general range of $80,000-$ $170,000 \mathrm{ppm}-\mathrm{min}$ for $\mathrm{HCl}$. Three non-human primates (juvenile baboons) were subjected at SwRI to exposure doses of $\mathrm{HCl}$ in approximately the same range $(150,000 \mathrm{ppm}-\mathrm{min}$, based on 5-, 15- and 30-minute exposure intervals) without either incapacitation or post-exposure deaths occurring. However, these exposures were quite severe and, in the opinion of the investigators, only slightly higher doses would likely have resulted in post-exposure deaths. Even the doses employed might have led to post-exposure lethality had medication (antibiotics and steriods) not have been administered to the animals. From comparable data between the rat exposures in this project and our non-human primate work at SwRI, it would appear that the rat is, indeed, a reasonable model for primates in so far as pulmonary irritant effects are concerned.

Even relatively low concentrations of $\mathrm{HCl}$ act as a sensory irritant which, through a decrease in respiratory minute volume, would be expected to alter the rate of loading of other toxicants such as $c 0$. This effect should manifest itself in slower rates of carboxyhemoglobin loading and resulting longer times to incapacitation and death due to $C O$ within an exposure. Expressed another way, $C O$ should have higher "apparent" $\mathrm{LC}_{50}$ 's and $\mathrm{EC}_{50}$ 's in the presence of $\mathrm{HCl}$, under conditions of equivalent exposure time.

Experimental studies confirmed expectations in part. The presence of $1000 \mathrm{ppm} \mathrm{HCl}$ did, indeed, slow the loading of $\mathrm{CO}$ and extend mean times to effect, with the phenomenon being increasingly more pronounced at CO concentrations below about $4000 \mathrm{ppm}$. For 30-minute exposures, this is in the sublethal, incapacitating range of $\mathrm{CO}$. The effect of the combination of $\mathrm{CO}$ and $\mathrm{HCl}$ is barely detectable at the 30-minute $\mathrm{LC}_{50}$ of $\mathrm{CO}$.

To further elucidate these effects of a sensory irritant on the loading of $\mathrm{CO}$, a body plethysmographic technique was developed for determination of the respiratory minute volume (RMV) of rats during exposure. The apparatus, compatible with standard head-only exposures in the NBS 200-L smoke exposure chamber, provides continuous recording of respiratory patterns from which respiratory rate and tidal volume can be derived for calculation of RMV.

Data collected in our laboratory using this technique has been used in combination with a linear regression formula for COHb saturation rates in rats with very promising results. Verifiable modeling of effects from respiratory irritants and stimulants during inhalation intoxication can now be undertaken.

Development of Methodology for the Modeling of Toxicological Effects. The modeling of intoxication by $\mathrm{CO}$ is facilitated by the use of blood $\mathrm{COHb}$ as a measure of body burden. Unfortunately, no such measure of body burden for $\mathrm{HCl}$ and $\mathrm{HCN}$ exist. Modeling of toxicological effects of these toxicants, as well as for $\mathrm{CO}$, is being developed which involves continuous calculation of incremental exposure doses 
(Ct products) and relating each to that required to produce a given effect at the particular concentration. The effect, either incapacitation or lethality, would have the greatest probability of occurring at the time at which the summation of the fractional doses becomes unity for a given toxicant.

Toxicological modeling based on the concept of summation of fractional doses is not new. The SwRI model differs significantly in the following ways:

a) Ct products are experimentally determined using animal models which provide reasonable extrapolation to humans, rather than being estimated from TLV occupational exposure data.

b) Ct products are not assumed to be constant but, rather, are expressed as a functon of concentration.

c) Simple additivity of fractional effect doses for combinations of toxicants is not assumed in the SwRI model. Interactions between toxicants are to be determined experimentally; otherwise toxicants are treated independently.

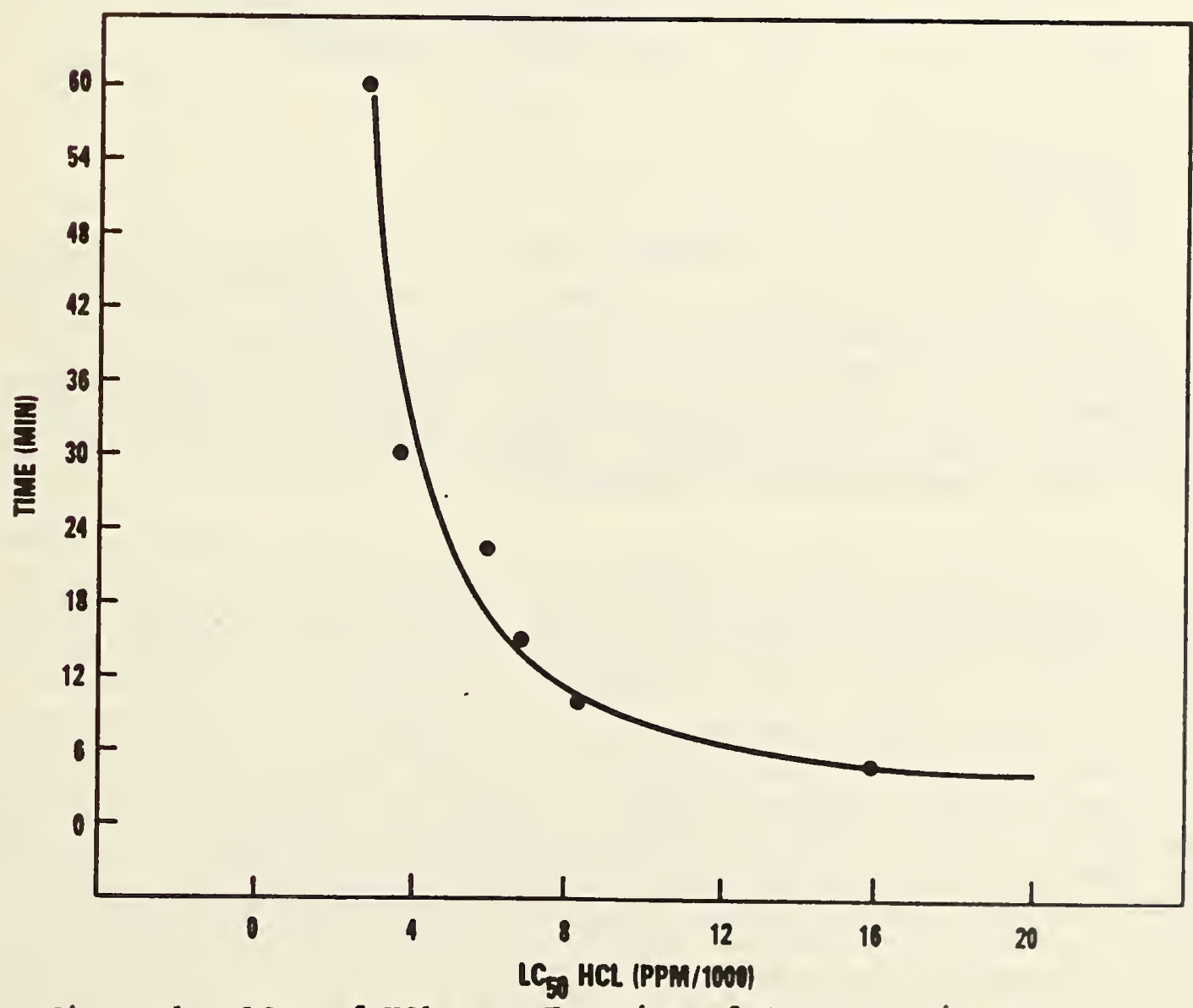

Figure 1. $\mathrm{LC}_{50}$ of $\mathrm{HCl}$ as a Function of Exposure Time. 
CENTER FOR FIRE RESEARCH

NATIONAL BUREAU OF STANDARDS

FLY 84

Institution: Stanford University

Grant No.: $\quad$ NBS Grant NB 83NAD 4019

Grant Title: The Behavior of Furniture Frames During Fire

Principle Investigator: Professor George S. Springer

Department of Aeronautics and Astronautics

Stanford University

Stanford, California 94305

Telephone: (415) 497-4135

Other Professional Personnel: F.K. Chang (Post Doctoral Fellow)

W.I. Lee (Post Doctoral Fellow)

E. Callius (Ph.D. candidate)

J. Burwasser (M.S. student)

P. Homer (M.S. student)

NBS Scientific Office: William J. Parker

Technical Abstract:

The objective of this investigation is to evaluate the behavior of furniture frames during fire. In order to achieve this objective tests are being performed measuring the strengths and deflections of wooden and plastic furniture frame joints exposed to elevated temperatures. The time of failure of the joints is also recorded. In conjunction with the tests a model is also being developed for describing the response of joints to high temperature environments.

A preliminary series of tests were performed with southern pine. In these tests the thermal response of southern pine was evaluated by measuring the mass losses of $3 \mathrm{in.} \mathrm{by} 2 \mathrm{in.} \mathrm{by} 3 / 4 \mathrm{in}$. specimens exposed to 75,160 , and $245^{\circ} \mathrm{C}$. The mass (weight) losses were recorded as functions of exposure time. The data were compared to the results of an analytical model discussed below. Good agreement was found between the data and the results of the model, supporting the validity of the model. Following the mass loss measurements, tests were performed with different types of joints made of southern pine. The geometries of the joints are shown in Table 1. Each joint was exposed to a constant temperature of either $100^{\circ} \mathrm{C}, 160^{\circ} \mathrm{C}$ or $245^{\circ} \mathrm{C}$ for a predetermined length of time. The joint was then loaded and the deflection of the joint was measured. These measurements provided the load versus deflection for each joint, the deflection at failure, and the load at failure. A total of 532 joints were used in these tests. Attempts are now being made to 
relate the degradation of the strengths of different types of joints to the degradation of the strengths of solid corners and bends (top figure, Table 1). As will be discussed below, the changes in strengths of solid corners and bends can be predicted by an analytical model. Thus, once relationships between the strengths of joints and corners and bends are established, the model also provides the changes in the strengths of joints exposed to elevated temperatures.

In addition to testing, analytical models are being developed to simulate the response of corners and bends to elevated temperatures. The specific goal in constructing the model is to describe the changes in the thermal and mechanical properties of corners and bends, and to predict the time of failure. The model is developed in four steps, a) calculation of the temperature distribution and mass loss inside corners and bends, (b) calculation of the changes in stress and strains with time, c) estimation of the changes in strength and moduli with time and, (d) prediction of the failure time.

In the first part of the model the temperature distribution inside the wood and the mass loss are calculated. This part of the model is formulated on the basis of the law of conservation of energy, with the chemical reactions represented by a single step Arrhenius bulk reaction. The calculations are performed for two dimensional geometries. As was noted above, the results of the model agree well with the mass loss data generated in this study.

The second part of the model is used to calculate the stresses and strains in corners and bends. The stresses and strains are calculated using a two-dimensional finite element method of solution of the governing equations.

The third part of the model provides a means of estimating the changes in strengths and moduli. This model is based on the hypothesis that degradation in mechanical properties are related to the mass loss caused by volatilization of the wood. The validity of this hypothesis was shown to be reasonable by the results of tests performed with rectangular slabs.

The fourth part of the model provides the failure time of corners and bends during fire exposure. The model relates the applied stresses to the allowable strength through an appropriate failure criterion.

On the basis of the models a "user friendly" computer code is now being developed. All four steps of the model are incorporated into this code. The code can be applied to loaded corners and bends exposed to elevated temperatures, and provides the stresses and strains in the wood as well as the following parameters, a) temperature distribution inside the wood, b) mass loss, c) strength loss, d) stiffness loss, and c) failure time.

Work is now in progress to complete the model and to compare the 
results of the model to data. It is planned to extend the investigation to higher temperatures and to the study the behavior of joints formed of plastics.

The data generated and the model developed in this investigation will provide means of evaluating the response of different types of furniture frames to fire and of estimating the failure time. This information will help in establishing appropriate endurance ratings for furniture, and will lead to more fire resistant furniture design and construction methods.

Reports and Papers:

1. G.S. Springer, F.K. Chang, and P. Homer, "The Behavior of Furniture Frames During Fire", Report to the Center for Fire Research, National Bureau of Standards, October 1984.

2. G.S. Springer, M.H. Do and D.A. Stanke, "Mass Loss of and Temperature Distribution in Southern Pine and Douglas Fir in the Range 100 to $800^{\circ} \mathrm{C}^{\prime \prime}$, 1 , No. 4, 271-284 (1983).

3. G.S. Springer, M.H. Do, "Model for Predicting Changes in the Strength and Moduli of Wood Exposed to Elevated Temperatures", Jo. of Fire Sciences, 1, No. 4, 285-296 (1983).

4. G.S. Springer, M.H. Do, "Failure Time of Loaded Wooden Beams During Fire", Jo. of Fire Sciences, 1, No. 4, 297-303 (1983). 


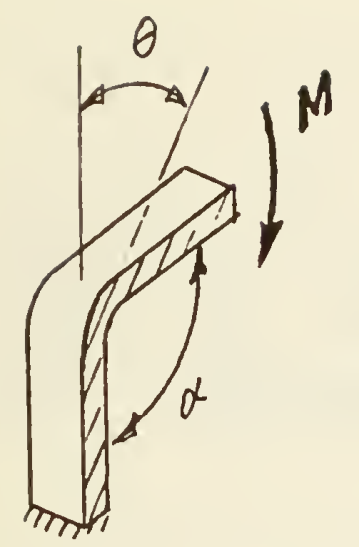

Angles: $\alpha=60^{\circ}, 90^{\circ}, 120^{\circ}$

Grain Orientations: $\theta=30^{\circ}, 45^{\circ}, 60^{\circ}$

Fasteners: 2 screws or nails with and without brackets

Fasteners: 2 screws or nails with and without brackets

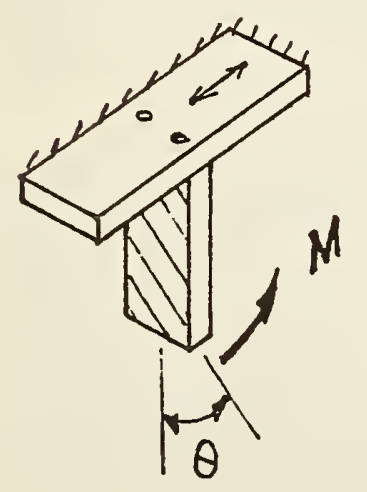

Fasteners: 2 screws or nails

Grain Orientation: $\theta=0^{\circ}$ or $90^{\circ}$ 


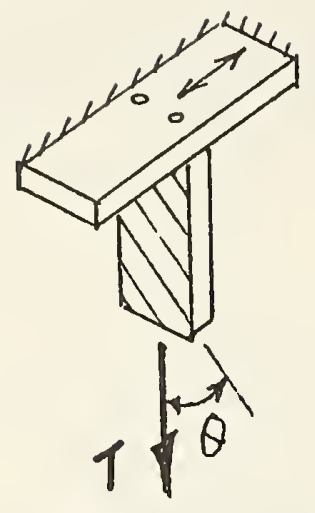

Fasteners: 2 screws or nails

Grain Orientations: $\theta=0^{\circ}$ and $90^{\circ}$

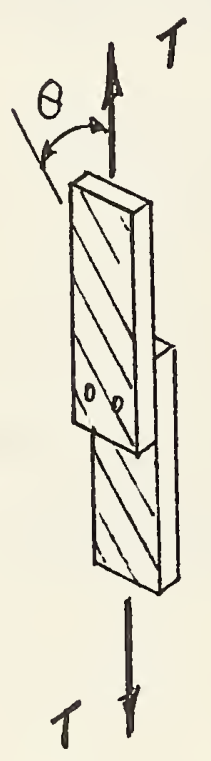

Fasteners: 2 screws, 2 nails, or a single bolt (centered)

Grain Orientation: $\theta=0^{\circ}$ or $90^{\circ}$

Thickness: 0.75 in (nominal)

Width: Solid Elbow (first figure) 1.5 in (nominal)

Width: Joints : 3 in (nominal) 


\section{CENTER FOR FIRE RESEARCH \\ NATIONAL BUREAU OF STANDARDS}

FY 84

Institution: TRW

Contract Number: MB82SBCA1662

Contract Title: Modeling of Wind-Aided Flame Spread

Principal Investigator: Francis Fendell

Engineering Sciences Laboratory

TRW Space and Technology Group

Redondo Beach, CA 90278

Telephone: (213) 536-2757

Other Professional Personnel: George Carrier, Harvard University

NBS Scientific Officer: Howard Baum

Technical Abstract:

1. Introduction. A major goal of fire dynamics is prediction of the rate of fire spread from knowledge of (1) the physicochemical properties of the combustible materials and (2) the thermohydrodynamic environment. Flame-propagation rates become particularly significant under wind-aided conditions; in general, far more rapid fire advance is associated with situations in which hot gaseous products of homogeneous combustion preheat (by conduction, convection, and/or radiation) still uninvolved downwind combustible materials. In contrast, in spread against the wind, fire advance usually is much slower because combustion products flow over already involved portions of the combustibles, and only gas-phase radiation and solid-phase conduction can effect preheating.

With the more rapid advance connected with wind-aiding, quasisteady approximation tends to be inadequate and explicit accounting for temporal derivatives is required; thus, even the simplest scenarios in wind-aiding spread entail dependence on two spatial coordinates and on time. Accordingly, progress to date in quantifying wind-aided flame spread is modest. Here, the goal is to provide enough quantitative accuracy to permit correct ordering of materials with respect to supporting of fire spread, even if the predicted rate of spread is not precise. It may be worth noting that consistent orderings of materials, but not precise quantitative values, are reproduced by purportedly standardized laboratory testing of materials in a severe fire environment.

At the rudimentary present state of quantitative analysis, there are three geometric arrangements that would appear to warrant attention. One may distinguish usefully (1) fire spread across a horizontal solid slab constituting the ceiling of a room or corridor, such that forced-convection arising from a boundary constraint is the source of the aiding wind; (2) fire spread up a vertical wall, such that free convection is a source of the aiding wind; and (3) fire spread across a horizontal solid slab constituting the floor of a room or corridor or forest, such that a boundary constraint is the source of the aiding wind but buoyancy plays a crucial 
role. While perhaps the first two cases are of primary interest within a structure and while perhaps the third case is of primary interest in wildlands and in spread between structures, nevertheless comparing the cases is mutually illuminating. Of course, the generalities presented here find many exceptions; for example, the torching out of a single tree in a so-called passive crown fire entails many features in common with case (2). Here, primary attention is to be placed on case (1), which (for all its difficulties) may be the most straightforward and tractable of the three cases. Space precludes comments concerning the other two cases (but see the references). However, before any of the cases are discussed, some general remarks on formulation are apropos.

2. Formulation. A formulation is sought in which all the significant phenomena are incorporated in the simplest reasonable form, such that convection, diffusion, radiative transfer, chemical exothermicity, buoyancy, pyrolysis, char formation, and char erosion are all treated to a comparable degree of accuracy. The framework for such a formulation is furnished by the so-called Shvab-Zeldovich approximation, in which the dynamics and energetics are decoupled as much as reasonably possible, and in which a generic fuel vapor is taken to react exothermically with oxygen in a direct one-step irreversible rapid homogeneous chemical reaction.

One advantage introduced by wind-aiding is that the flow speeds, and hence the Reynolds number, tend to be large enough to permit adoption of the boundary-layer approximation: diffusion transverse to streaming is retained, but diffusion in the streamwise direction may be omitted, in the lowest order of approximation. Furthermore, with the streaming well defined, it is possible to approximate convective transport of mass, momentum, and heat in the manner of Oseen; that is, it is possible to 1 inearize the streamwise convective transport. It should be noted, however, that in free-burning problems, in which the fuel vapor usually is either pyrolyzed from a solid or evaporated from a liquid pool, the convective transport transverse to the principal streaming warrants careful treatment. Indeed, where there is interphase mass transfer (at a rate that appears as an eigenfunction to be identified in the course of solution), the convective transport transverse to streaming entails nonlinearity.

The conventional Shvab-Zeldovich formulation concerns gas-phase phenomena. A consistent level of accuracy is required for the formulation of the solid phase. It is suggested here that the often-adopted twoparameter (gasification temperature, specific endothermic heat of gasification), sublimation-type (or evaporation-type) model of gasification may not be adequate to recover behavior of a char-forming body. Upon heating to a fairly well-defined temperature, the preponderance of synthetic and natural polymers undergo thermal degradation partially to a carbonaceous, porous matrix, and partially to (in part, combustible) vapor that traverses the (usually relatively thin) porous matrix to reach the gas phase. The heat-retention properties of the matrix are crucial under forced-convection-extinction conditions, and probably warrant retention under vigorous-burning conditions as well. Furthermore, at highenough temperature, the carbonaceous char erodes in a forced-convective flow; this may be owing to loss of mechanical strength such that spalling 
occurs, or it may be due to chemical attack (such as reduction by the char of carbon dioxide, and, to a lesser degree, of water vapor). In any case, the char layer tends not to increase indefinitely in thickness in the present context, but rather tends to remain thin relative to the depth of the gas-phase boundary layer and of the pristine-solid thermal layer (such that an approximate integral-type treatment of the char layer suffices). The point to be emphasized is that a formulation, consistent with the Shvab-Zeldovich spirit, is available that encompasses the usually endothermic onset of char formation and gasification, the onset of char erosion, and the heat-retention properties of the char, but that does not introduce spatially distributed, finite-rate processes of uncertain rate and mechanism and of limited generality.

Radiative transfer involves reradiative cooling of the gas-solid interface, radiative heating of the gas-solid interface from cooling of vitiated bulk-gas air, and radiative heating of the gas-solid interface from nonconductive transport from the gas-phase flame (probably in the presence of soot). It is the last of these three processes that probably presents the greatest challenge in seeking a compromise between fidelity to the physics and tractability of the formulation. In this regard, the recent work of Howard Baum of the Center for Fire Reasarch is noteworthy.

In summary, wind-aided flame challenges modeler to incorporate tractable formulation of charring and radiative transfer in an explicitly unsteady, spatially (at least) two-dimensional problem involving close coupling of the solid and gas domains.

3. The Ceiling Geometry. Wind-aided flame spread along a thick semiinfinite horizontal slab (such that burn-through, and thus exhaustion of outgassing capacity, is not achieved), entails a parabolic boundary/initial-value problem. In particular, one may envision the air stream over the leading edge becoming hot and vitiated at time zero. One seeks the rate at which the char-formation front at the solid-gas interface, and the rate at which the char-erosion front at the solid-gas interface progress downwind, as a function of the thermohydrodynamic environment and the physicochemical slab properties; these fronts characterize the extent of slab "involvement". While knowledge of the progression rates of these fronts does not constitute a complete solution throughout the threeindependent-variable space, such knowledge does provide the knowledge of particular engineering significance, and theoretically one can later ascertain meticulous details if one wishes.

Either by use of point-source solution for a second-order parabolic operator, or alternatively by Weiner-Hopf-like arguments in the inversion of Fourier transforms, Volterra integral equations have been derived that relate the dependent variables and their fluxes in the gas-solid interfacial plane; of course. such relations reduce the three-independentvariable problem to a two-independent-variable (time and streamwise distance) problem. These integral equations are supplemented by locally appropriate algebraic relations between the dependent variable and their fluxes in the interfacial plane; the phrase locally appropriate alludes to the fact that different algebraic relations pertain to the preheat, char formation, and char erosion zones. The integral equations are also 
supplemented by an ordinary differential equation, evolved from a transversely averaged (i.e., approximate integral-type) treatment of the conservation-of-energy equation for the (relatively thin) char layer. In fact, the problem as rephrased in the interfacial plane is of hyperbolic character, with fluid-particle paths and fixed downwind stations delineating a characteristics grid on which the car-formation front and charerosion front are shock-like loci, i.e., loci noncoincident in general with a characteristic curve. Cauchy (boundary) data, specified along the boundaries of the two-dimensional (streamwise-distance/time) solution space, is propagated across the characteristics mesh in customary, nodeto-node, stepwise procedure (with iteration).

The boundary data consists partly of the temporal (downwind) history of the first hot particle of vitiated-air flow across the leading edge at the starting instant; the requisite Abel integral equation is treated by known procedures. The boundary data consists partly of the selfsimilar solution to the steady flow past a semi-infinite, fully involved charring slab (in the absence of any radiative transfer); this steady solution holds instantaneously at the leading edge (since there is no upwind transfer of information in the formulation). Solution to this generalized Emmons problem has been thoroughly explored, not only because it furnishes requisite boundary data for initiating the complete solution for all sites and times in the interfacial plane, but also because it permits solution even upon relaxation of approximations required for tractability under nonselfsimilar conditions. For example, it is possible to investigate the consequences attendant on adoption of the Oseen approximation of convective transport, of Lewis-Semenov number unity, of approximate integral treatment (rather than exact treatment) of the char layer, of a sublimating pseudomechanism (rather than diffusively controlled chemical reduction) for char erosion, etc. The findings, documented in a publication listed below, are, succinctly, that none of the approximations compromise trends at all, but quantitative precision is sacrificed.

Attention is now being turned to incorporating concepts concerning the amount and location of soot on the fuel-rich side of the gas-phase diffusion flame, and its role in radiative transfer; clearly accounting for this phenomenon now necessitates identification of diffusion-flame position. It should be appreciated that exceptional solids that gasify without charring and burn without sooting admit far simpler, selfsimilar solution throughout the solution domain.

Reports and Papers:

Carrier, G., Fendel1, F., and Fink, S. (1983), "Towards Wind-Aided Flame Spread Along a Horizontal Charring Slab: The Steady-Flow Problem," Combustion Science and Technology 32, 161-210.

R. D. Fleeter, F. E. Fende11, L. M. Cohen, N. Gat, and A. Witte, (1984), "Laboratory Facility for Wind-Aided Firespread Along a Fuel Matrix," Combustion and Flame, to appear. 
CENTER FOR FIRE RESEARCH

NATIONAL BUREAU OF STANDARDS

FY 84

Institution: University of California, Berkeley

Grant No.: $\quad$ NB83NADA4020

Grant Title: Fire Propagation in Concurrent Flows

Principle Investigator: Professor A. C. Fernandez-Pello

Department of Mechanical Engineering

University of California

Berkeley, CA. 94720

$\begin{array}{ll}\text { Other Professional Personnel: } & \text { C. -P. Mao, Ph.D. Candidate } \\ \text { H.-T. Loh, Ph.D. Candidate }\end{array}$

NBS Scientific officer: H. R. Baum

Technical Abstract:

Experimental and theoretical studies of the process of flow assisted fire spread over the surface of combustible surfaces have been

carried out. Research efforts have concentrated on two aspects of this mode of fire spread: 1) Fire spread in a concurrent forced (or mixed) flow; and 2) Fire spread along the walls of an enclosure in natural convection. During this reporting period a series of experiments of the dependence on the velocity and oxygen concentration of the concurrent forced flow of the rate of flame spread over thick PMMA sheets have been completed. The results indicate that this form of fire spread is primarily controlled by heat transfer from the flame to the unburnt combustible. Experiments with thin paper sheets are currently underway. Efforts on the second task have concentrated on the numerical analysis of the structure of a diffusion flame, established over a burning fuel surface. The results indicate the existence of significant longitudinal diffusion of heat and species ahead of the flame front. An analysis on the spread of flames in an enclosure is currently in progress.

Experimental study of concurrent flame spread in a forced flow. Measurements on the rate of flame spread over a combustible flat surface in a forced gaseous flow of varied velocities and oxygen concentrations moving in the direction of flame propagation are being taken. The experiments are carried out in a small scale combustion tunnel with a test section $61 \mathrm{~cm}$ long by $12.7 \mathrm{~cm}$ wide by $7.6 \mathrm{~cm}$ high. The thick fuel specimens are mounted flush in one of the walls of the test section with the upstream leading edge placed $1.5 \mathrm{~cm}$ from the exit plane of the convergent nozzle of the tunnel so that a flat plate flow is generated over the fuel surface. The thin fuel specimens are mounted in a metallic frame which is positioned in the middle of the test section to generate a flat plate flow. PMMA sheets, $1.27 \mathrm{~cm}$ thick, and Whatman $3 \mathrm{M}$ filter paper sheets $0.03 \mathrm{~cm}$ thick have been used as fuels to represent ther- 
mally thick and thin fuels, respectively. The gaseous flow in the tunnel consists of a mixture of $\mathrm{O}_{2}$ and $\mathrm{N}_{2}$, the flow rates of which are previously metered with critical nozzles. The gas velocity is measured with a hot wire anemometer and a pitot tube. Surface temperature histories provided by thermocouples embedded at fixed distances along the fuel surface are used to determine the rate of flame spread. The spread rate is calculated from the distance between two consecutive thermocouples and the time lapse of pyrolysis arrival to the thermocouples.

The results of the measurements of the rate of spread of the pyrolysis front over PMMA sheets shows that the rate of flame spread is time independent, linearly dependent on the flow velocity and approximately square power dependent on the oxygen concentration of the gas. The spread rate data can be correlated very well with a parameter deduced from heat transfer models of the flame spread process, indicating that in the flow assisted mode of flame spread, heat transfer from the flame to the condensed fuel is the primary mechanism controlling the spread of the flame. The measurements taken under mixed convective conditions on the spread of flames over the surface of thin filter paper sheets show that the rate of spread of the pyrolysis front depends on time according to a power law. The exponent varies slightly from the free to the forced convective limit. For forced flow conditions the flame spread process is practically independent of the velocity of the flow. Only limited agreement is found between the experiment and the predictions from the available models of flow assisted flame spread over thermally thin fuels. It appears that this disagreement is due primarily to transient effects caused by the variation of the pyrolysis length, particularly during the initiation of the flame spread process. Currently we are performing experiments with longer paper sheets at higher oxygen concentrations to find if a steady state flame spread is reached and whether the transient effects are the result of pyrolysis length variations.

Numerical Analysis of a Diffusion Flame Near Its Leading Edge. An analysis of the fluid mechanical and thermal structure of the leading edge of a diffusion flame over a pyrolyzing flat combustible surface in a mixed convective flow has been performed. The analysis considers pressure variations in the flow, longtitudinal diffusional effects and finite rate kinetics. Two cases were analyzed, one with isothermal walls surrounding the burning surface and the other with adiabatic walls. In both cases the convection was varied from buoyancy controlled to forced flow controlled conditions. The results of the analysis show that upstream from the flame leading edge a region of elevated pressure is generated by the conjunction of the gas thermal expansion (due to upstream heat transfer from the flame) and the fuel addition in the pyrolysis zone. The pressure gradients perturb the flow causing its deflection and deceleration or acceleration. The convective flow in turn, by hampering the diffusive processes, limits the zone of influence of the flame to regions that are closer to the vaporizing fuel surface and thereby creates strong temperature and species gradients near the reaction zone. If the non-combustible upstream surface is 
isothermal, the low temperatures near the surface cause the reaction to freeze, and a quenching layer is formed near the surface. The fuel and oxidizer mix in this layer. However, for the adiabatic case, the reaction rate is fast, practically up to the surface, and very little leakage of fuel or oxidizer occurs through the reaction zone.

The descriptions obtained from this analysis of the processes taking place in the vicinity of the leading edge of the flame are very useful for the explanation of a number of experimental observations of the gas flow pattern and temperature distributions in stationary and slowly spreading diffusion flames. Of particular interest are the results in the. vicinity of the pyrolysis front where finite rate kinetics are important.: It is found that there is a considerable. longtitudinal diffusion of heat and mass in this region and that a quenching layer exists near the surface. The reaction rate is very small in the vicinity of the solid surface because the surface temperature is relatively low, and the rate of the chemical reaction is very. sensitive to temperature. The small reaction rate permits the leakage of oxygen through the reaction zone, which, in conjunction with the upstream diffusion of fuel vapor, forms a region upstream from the pyrolysis front where a mixture of fuel vapor and oxidizer is present. This result has a relevant impact on the description of the controlling mechanisms of flame spread in opposed flows, a subject that has been controversial for some time. It supports a mechanism of flame spread recently proposed by Ray and Glassman (Combustion Science and Technology, 32, 33 , 1983) in which a premixed flame generated by the upstream diffusion of fuel vapor leads to the diffusion flame generated by the burning surface.

Free Convection Flame Spread in Enclosures. A numerical analysis of the free, flow assisted, spread of flames over the surface of a. thick combustible material.in a vertical wall-ceíling geometrical configuration is being carried out. In order to reduce computing costs, the gas and solid phase analyses are uncoupled by means of an isothermal wall condition at the gas/solid interface. This approximation is based on experimental information and has shown positive results in previous analytical studies of related problems. The gas phase analysis is also treated as quasi-steady, because the transport processes in the gas are faster than the rate of spread of the pyrolysis front. Once the analyses for the two phases are uncoupled, the flame spread process is solved using a leapfrogging approach. The gas phase equations are solved for increasing lengths of the pyrolyzing region, and the flame length and heat flux at the interface are calculated for each pyrolysis length. This information is used as boundary conditions for the numerical solution of the solid phase, transient, energy equation. The rate of spread of the pyrolysis front is obtained from the calculated temperature profiles by imposing the condition that at the pyrolysis front the surface temperature is equal to the evaporation temperature of the solid. The current results seem to agree qualitatively with the experimental results. A major problem with this analysis is the high computer costs associated with the numerical calculations. At present we are searching for ways to reduce the time currently required to run the 
computer program.

Reports and Papers

Mao, C.-P, Fernandez-Pello, A. C. and Pagni, P. J., "Mixed Convective Burning of a Fuel Surface with Arbitrary Inclination," Journal of Heat Transfer, (in press).

Fernandez-Pello, A. C., "Flame Spread Modeling," Combustion Science and Technology, (In press).

Mao, C.-P, Kodama, H., and Fernandez-Pello, A. C., "Convective Structure of a Diffusion Flame over a Flat Combustible Surface," Combustion and Flame, (in press).

Loh, H. T. and Fernandez-Pello, A. C., "A Study of the Controlling Mechanisms of Flow Assisted Flame Spread," accepted for presentation at the 19th Symposium (Internationa1) on Combustion, to be held at Ann Arbor, Michigan, August 12-17, 1984. 
CENTER FOR FIRE RESEARCH

NATIONAL BUREAU OF STANDARDS

FY 84

Institution: University of California - Berkeley

Grant No.: $\quad$ 60NANB4D0018

Grant Title: Flame Radiation

Principal Investigator: Professor Chang-Lin Tien

Mechanical Engineering Department

University of California

Berkeley, California 94720

Telephone: (415) 642-0877

Other Professional Personnel: M. A. Brosmer (Ph.D student)

K. Y. Lee (Ph.D student)

Z. Y. Zhong (Post Doctoral)

NBS Scientific Officer: Dr. Takashi Kashiwagi

Technical Abstract:

The current objective of this project is to establish a simple physical framework for the calculation of radiation from complex fire phenomena. The research approach aims at developing approximate formulations by systematic experimentation and analysis of the fundamental aspects of the problem. The present research is focused on two primary topics: 1) Experimental and theoretical determination of radiative properties of gases evolved from burning condensed fuels, principally PMMA, and 2) Development of a simple calculation scheme for the determination of radiation absorption in a thin non-isothermal layer composed of these gases.

Radiation Properties of Gases Evolved from Condensed Fuels. A significant energy input is required to ignite and maintain continuous burning of a condensed fuel. It has been found that this energy is primarily transported to the fuel by means of thermal radiation from the flame zone. The radiant energy must pass through a thin gas layer which is composed of numerous species which evolve from the fuel surface, and attenuate the incoming energy. These gases, which are primarily hydrocarbons, therefore strongly influence the ignition and combustion process. A combined analytic and experimental research effort is directed toward the determination of the infrared radiation characteristics of the evolved gases. The experimental phase consists of the determination of the spectral absorption of several hydrocarbons commonly evolved from condensed fuels. These gases include methyl methacrylate $\left(\mathrm{C}_{5} \mathrm{H}_{8} \mathrm{O}_{2}\right)$, propane $\left(\mathrm{C}_{3} \mathrm{H}_{8}\right)$, propylene $\left(\mathrm{C}_{3} \mathrm{H}_{6}\right)$, ethane $\left(\mathrm{C}_{2} \mathrm{H}_{6}\right)$, ethylene $\left(\mathrm{C}_{2} \mathrm{H}_{4}\right)^{3}$, acetylene $\left(\mathrm{C}_{2} \mathrm{H}_{2}\right)$, and methane $\left(\mathrm{CH}_{4}\right)^{3}$. Infrared measurements are being made for 1 atm. pressure and a temperature range of 300 to $900 \mathrm{~K}$. The spectral absorption data is used to evaluate the spectral mean and total band 
properties. The total band properties are then used to specify the gas emissivity. Results have thus far been obtained for both methane and propylene. Typical absorptivity and emissivity curves are shown in Figs. 1 and 2 for propylene for an effective pressure of one. The analytic portion of this project is then to develop a simple modeling scheme to specify the overall absorption characteristics of the entire infrared region. A preliminary model has been developed which successfully groups the primary infrared bands of $\mathrm{H}_{2} \mathrm{O}, \mathrm{CO}_{2}, \mathrm{CO}$, and $\mathrm{SO}_{2}$ and accurately predicts the radiation behavior. It wil' be applied to the hydrocarbon data in an effort to describe the infrared radiation characteristics of the gases.

Radiative Energy Attenuation by a Non-Isothermal Smoke Layer. One of the most important elements for accurate determination of the energy feedback from the flame is the radiation blockage due to the pyrolyzed gaseous and particulate components in the smoke layer. Radiation blockage by a soot layer has been analyzed, and will be extended to include the effects of hydrocarbon gases. It is found that the blockage effect may be significant even in small scale fires for a sooty polymer fuel such as polystyrene(PS). The information on radiation blockage has been utilized to investigate the effect of radiative heat attenuation on the mechanisms of condensed fuel ignition. With the inclusion of blockage, predicted ignition delay time and fuel surface temperature history are in better agreement with experimental data as compared to previous analyses. The shift of ignition delay time due to blockage is presented in Fig. 3. It can be noted that the blockage effect is more pronounced as the heat flux and soot content of the system increase. The assumption of radiative equilibrium has been relaxed in the study of cold wall flame-quenching to include gas phase conduction. Using the singular perturbation technique, the quenching distance has been determined as a function of various physical properties. It has been found that the quenching distance tends to increase as the heat source intensity and optical thickness of the system decrease. Furthermore, the fuel surface emissivity is of minor importance in determining the quenching distance.

\section{Reports and Papers:}

1. M. A. Brosmer and C. L. Tien, "Infrared Radiation Properties of Methane at Elevated Temperatures," to be submitted for journal publication.

2. K. Y. Lee, Z. Y. Zhong and C. L. Tien, "Blockage of Thermal Radiation by the Soot Layer in Combustion of Condensed Fuels, " to be presented at the Twentieth Symp. (Int.) on Combust., August (1984).

3. K. Y. Lee and C. L. Tien, "Radiation-Induced Ignition of Condensed Fuels Including Effects of Radiation Blockage," submitted for journal publication.

4. K. Y. Lee and C. L. Tien, "Flame Wall-Quenching by Radiation and Conduction in Combustion of Condensed Fuels," to be submitted for journal publication. 


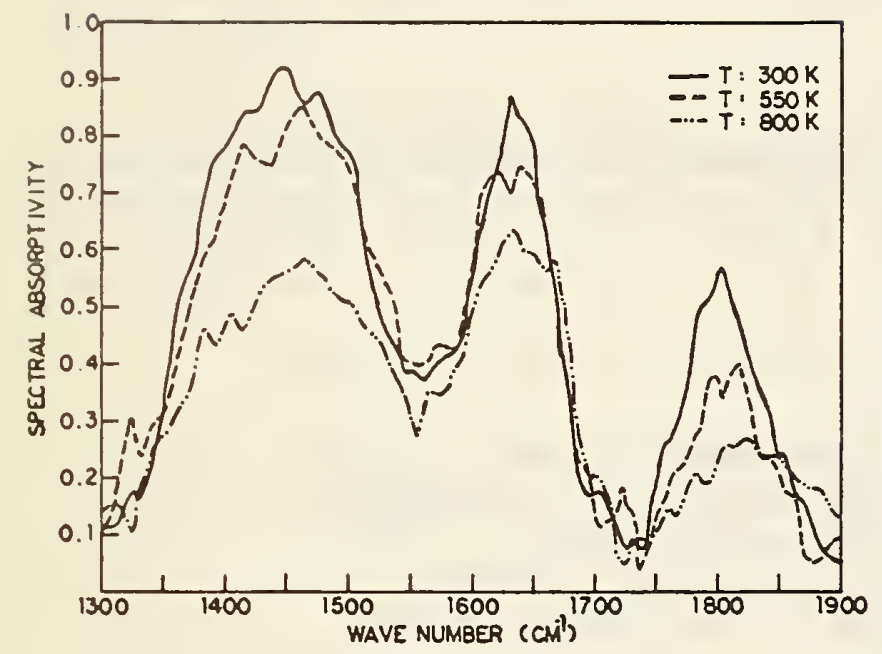

F1g. I Spectral Absorption of the $1448 \mathrm{~cm}^{-1}, 1647$ $\mathrm{cm}^{-1}$ and $1830 \mathrm{~cm}^{-1}$ Bands at $300 \mathrm{~K}, 550 \mathrm{~K}$ and $300 \mathrm{~K}$.

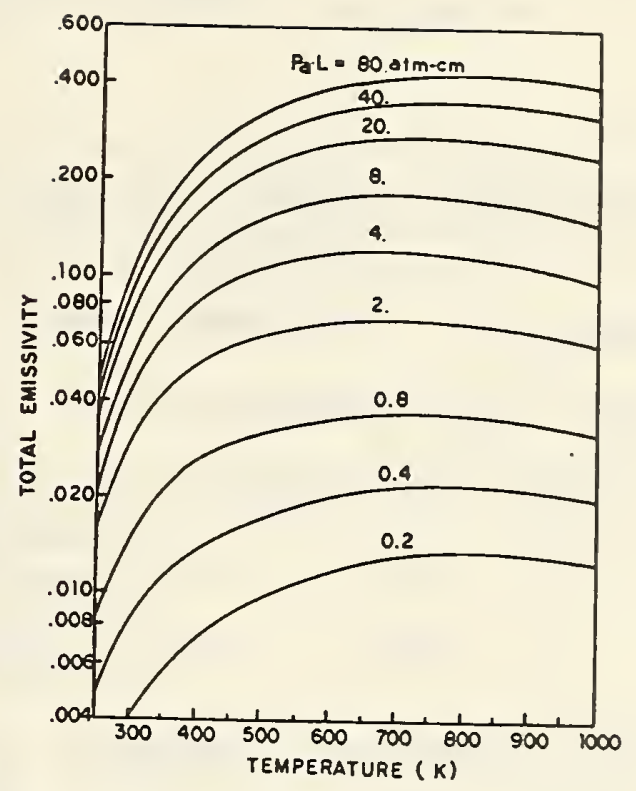

F1g. 2 Total Emlssivity of Propylene Based on the 3.4, 5.5, 6.1 and 6.9 $\mathrm{W}$ Bands with an Effective Pressure of One.

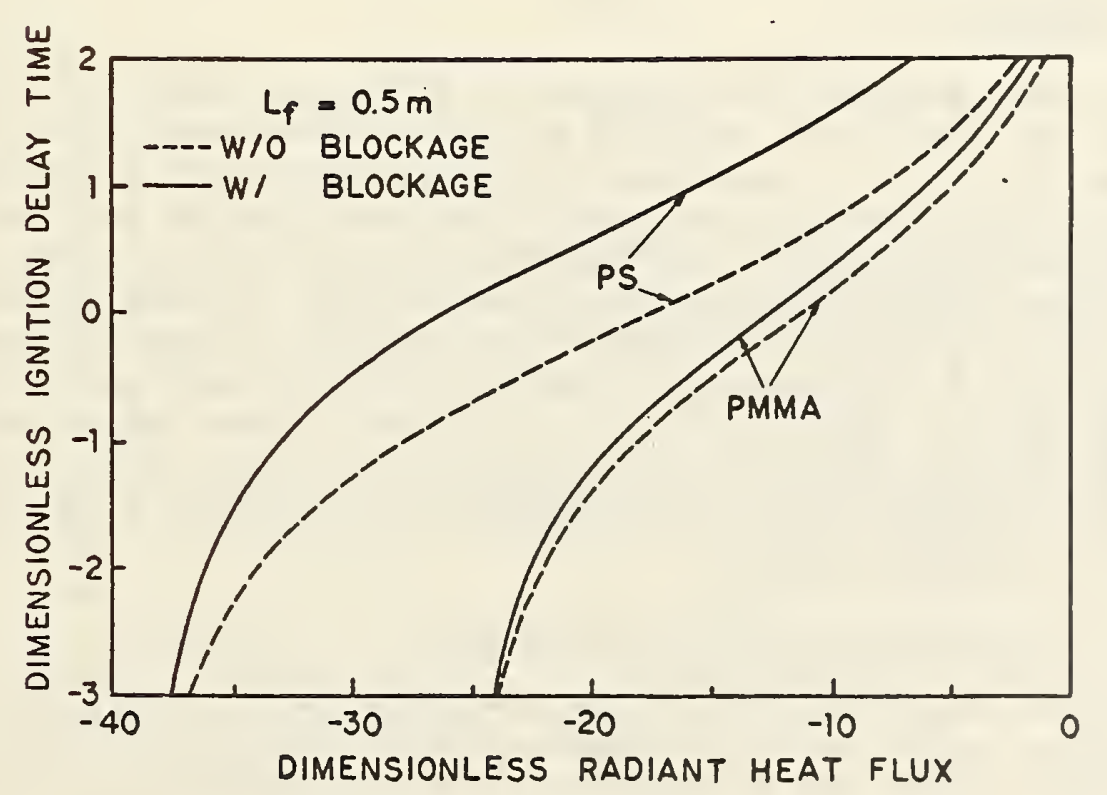

Fig. 3 Ignition Delay TIme vs. Radiative Heat Flux Displaying the Assoclated Shift due to the Blockage Effect. 
CENTER FOR FIRE RESEARCH

NATIONAL BUREAU OF STANDARDS

FY 84

Institution: Lawrence Berkeley Laboratory, University of California, Berkeley

Grant No.: $\quad$ NB 80 NAGE 6839-3

Grant Title: Fire Modeling

Principal Investigator: Professor Patrick J. Pagni

Mechanical Engineering Department

University of California

Berkeley, California 94720

Telephone: (415) 642-0729

Other Professional Personnel: Clement I. Okoh (Ph.D. Candidate)

James A. Ang (Ph.D. Candidate)

Valerie Lyons (Ph.D. Candidate)

NBS Scientific Officer: Dr. William Pitts

Technical Abstract:

The overall goal of this project is to develop physical and mathematical models of the detailed combustion phenomena which control a fire's growth within a compartment and its subsequent propagation throughout a structure. Our emphasis this grant period has been on flame radiation and its most important and least known parameter, $f_{v}$, the soot volume fraction within the flame. $f_{\mathrm{v}}$ is defined as the volume occupied by soot per unit of flame volume. Previous reports have described a multiwavelength laser extinction technique for in situ measurement of the local flame $f_{v}$. The full Mie theory, Lee and Tien optical properties and a two-parameter size distribution are assumed. Alternative simplifying assumptions have been shown to significantly overestimate $f_{\mathrm{v}}$.

The soot particles have mean diameters, d, $50 \mathrm{~nm}$ and concentrations, No, $\sim 10^{9} \mathrm{~cm}^{-3}$. The mean free path of the gas $\lambda$, is $\sim 500 \mathrm{~nm}$ so the particle Knudsen numbers are $\mathrm{Kn} \equiv \lambda / \mathrm{d} \sim 10$ and the flow field around the soot particle is free molecular. This produces strong convective coupling with the gas, i.e., the effective heat transfer coefficient, $h$, is $\sim 10^{5} \mathrm{~W} / \mathrm{m}^{2} \mathrm{~K}$. The soot temperature is locked to the gas temperature within $+0 /-5 \mathrm{~K}$, with the larger negative range due to particle radiative emission. Surface reactions 
involving $\mathrm{CO}_{2}, \mathrm{H}_{2} \mathrm{O}, \mathrm{OH}$ and $\mathrm{C}_{2} \mathrm{H}_{2}$ all appear to have insignificant effects on $\mathrm{T}_{S}$. A separate consequence of the high Knudsen number is the need to include thermophoretic forces in particle trajectory calculations.

Since the particle temperature is the gas temperature, the sooty gas can be treated as a single radiating medium and the free flow boundary layer equations can be solved including radiation explicitly. The nonadiabatic flame temperatures ( $K$ ) from these calculations at 4 $\mathrm{cm}$ downstream of the leading edge are shown in Table $\mathrm{I}$.

\section{Table I. Flame Temperatures and Soot Parameters}

$\begin{array}{lrrrrrr} & \text { Toluene } & \text { Cyclohexene } & \text { Octane } & \text { Cyclohexane } & \text { Heptane } & \text { PMMA } \\ \mathrm{T}_{\text {fl }} & 2266 & 2287 & 2225 & 2242 & 2203 & 2075 \\ \mathrm{~T}_{\text {ad }} & 2343 & 2307 & 2233 & 2249 & 2208 & 2131 \\ \text { \%C to soot } & 15 & 3.3 & 1.5 & 1.0 & 0.5 & 1.0 \\ \mathrm{~T}_{\text {exper }} & 2077 & 2077 & 2047 & 2044 & 2009 & 1943 \\ \mathrm{~T}_{\text {bead }} & 1972 & 1972 & 1946 & 1943 & 1913 & 1856 \\ \quad \mathrm{E} & - & 50.2 & 52.9 & 54.8 & 59.4 & 53.5 \\ \begin{array}{l}\text { (kcal/mole) } \\ \text { A(GHz) }\end{array} & - & 0.15 & 0.26 & 0.37 & 1.1 & 0.8\end{array}$

Only toluene, cyclohexene and PMMA show significant nonadiabatic effects on the flame temperature at these small scales. The $60 \mathrm{~K}$ drop for PMMA is due to radiant emission from the pyrolyzing fuel surface, while the $80 \mathrm{~K}$ drop for toluene and the $20 \mathrm{~K}$ drop for cyclohexene are due to soot emission. The remaining fuels show less than $10 \mathrm{~K}$ drops due to radiation, indicating that at this scale in air, radiative effects can be neglected in calculating these flow fields. This is supported by the small amount of carbon converted to soot for these fuels as shown in the third row of Table I. A comparison of measured and calculated temperature profiles across the boundary layer is shown in Fig. 1. The experimental temperatures have been corrected for radiation losses from the bead. The peak measured temperatures, $\mathrm{T}_{\text {bead, }}$ and the corrected values, $\mathrm{T}_{\text {exper}}$, are also given in Table $I$.

In addition, calculated velocity fields were used to estimate the time rate of change of the soot volume fraction along particle trajectories, $f_{v}$. The data were fit with 
Corrected Experimental and Theoretical Profile for n-Heptane at $4 \mathrm{~cm}$ ndownstream

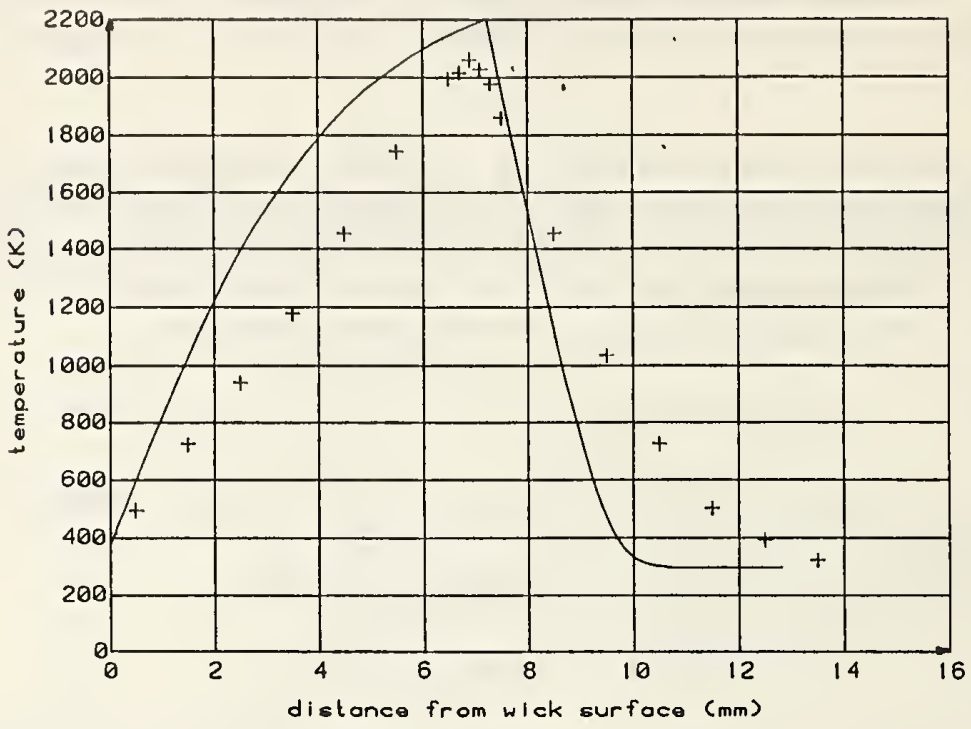

Figure 1

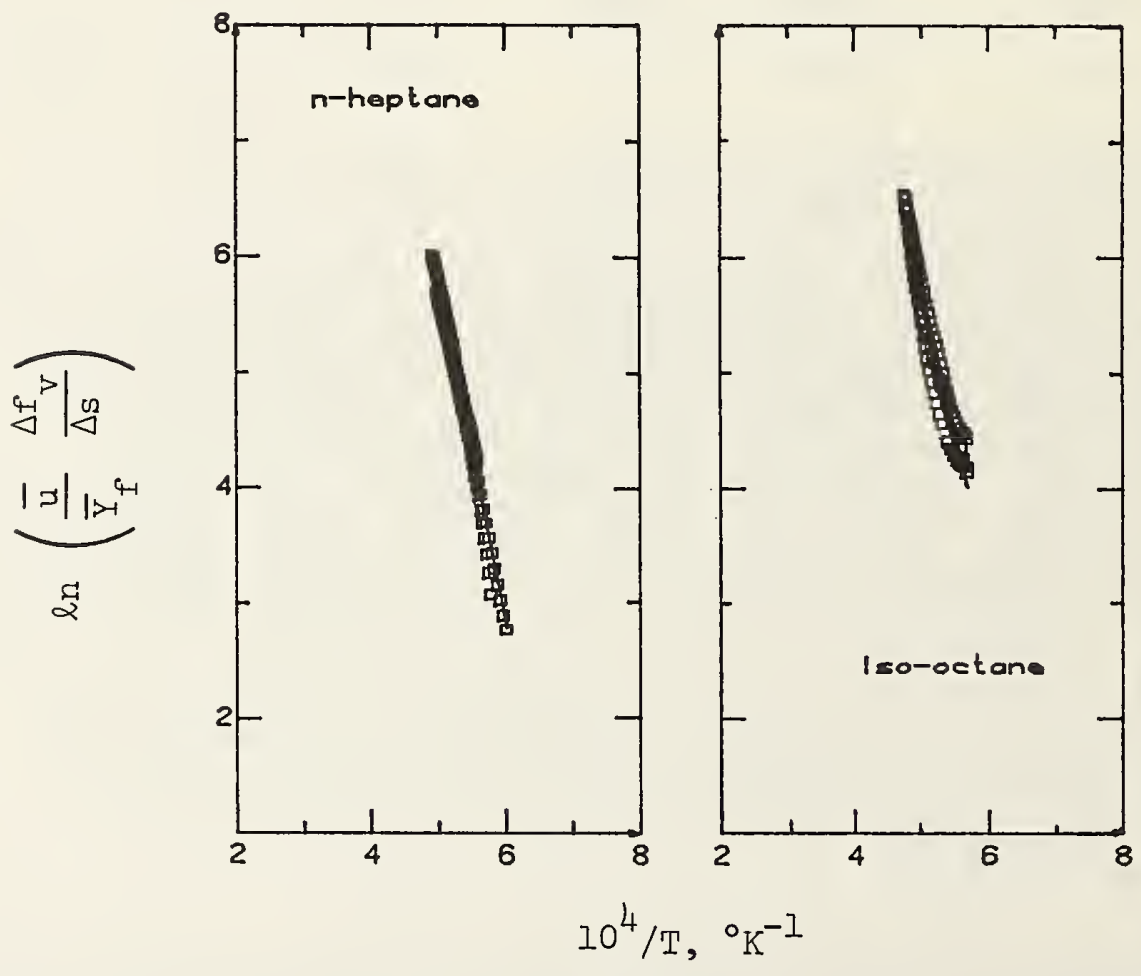

Figure 2 


$$
\dot{f}_{v \approx} \bar{u} \frac{\Delta f_{v}}{\Delta s}=A \exp (-E / R T) \bar{Y}_{f}^{a} \bar{f}_{v}^{b}
$$

where $\mathrm{s}$ is the displacement on a trajectory, $\mathrm{u}$ is velocity, $\mathrm{Y}_{\mathrm{f}}$ is fuel mass fraction, the bar indicates mean values on $\Delta s$ and $E$ and $A$ are parameters, given in Table $I$. Toluene was so sooty that complete attenuation occurred and data were limited to a short region too close to the leading edge to permit determination of $E$ and $A$. Good linearity for $a=1$ and $b=0$ is shown for two sample fuels in Fig. 2 .

In the next grant period, existing forced flow $f_{V}$ data will be analyzed. We will explore perturbation methods incorporating radiation, finite chemical kinetics and Le $\neq 1$ effects in combusting boundary layer calculations during Dr. Howard Baum's stay in our department as Springer Professor of Mechanical Engineering during the Spring Semester, 1985.

\section{Reports and Papers:}

1. P.J. Pagni, "Materials Fire Properties and Test Methods," in Proceedings of the Seventh Joint Meeting, United States-Japan Natural Resources Panel on Fire Research and Safety, 24-28 0ctober 1983, Washington, D.C., National Bureau of Standards, 1984 .

2. C-P. Mao, A.C. Fernandez-Pello and P.J. Pagni, Mixed Convective Burning of a Fuel Surface with Arbitrary Inclination," Journal of Heat Transfer, Trans. ASME, Series C, 106, 304-309, 1984.

3. R.A. Beier, P.J. Pagni and C.I. Okoh, "Soot and Radiation in Combusting Boundary Layers," to be published in the Emmons Special Issue of Combustion Science and Technology (September 1984).

4. N. Alvares, K. Foote and P.J. Pagni, "Forced Ventilation Enclosure Fires," to be published in the Emmons Special Issue of Combustion Science and Technology (September 1984).

5. P.J. Pagni and C.I. Okoh, "Soot Generation within Radiating Diffusion Flames," presented at the Twentieth Symposium

(International) on Combustion, Ann Arbor, MI., August 12-17, 1984. Also Report LBL-17391, February 1984. 
CENTER FOR FIRE RESEARCH

NATIONAL BUREAU OF STANDARDS

FY 84

Institution: University of Dayton Research Institute, Dayton, Ohio

Grant No.: $\quad$ NB83NADA4056

Grant Title: Mathematical Modeling of Furniture Fires

Principal Investigator: Nicholas A. Engler

Senior Research Physicist

University of Dayton Research Institute

300 College Park - JPC 200

Dayton, Ohio 45469

(513) 229-3921

Other Professional Personnel:

Mark A. Dietenberger,

Associate Research Physicist and Ph.D. student

NBS Scientific Officer: Dr. Vytenis Babrauskas

Technical Abstract:

The current objective of this effort is to formulate a practical mathematical model of furniture fires. The aim is to develop a method that will predict the growth and decay of a furniture fire based upon data obtained from bench scale testing of various construction materials. These bench scale tests utilize fire test devices such as the National Bureau of Standards (NBS) Cone Calorimeter, and the NBS lateral flame spread apparatus. The present research is focused on two analytical developments: (1) The structure analysis of the furniture fire model consisting of three main modules--the Flame Structure and Radiation Module (FSRM), the Ignition and Flame Spread Module (IFSM), and, the Local Burning Rate Module (LBRM), which provides the heat release rate of the burning furniture; and (2) The calculation of net radiative heat fluxes from $3-D$ gray flames to surrounding 3-D gray objects achieved with a practical zonal radiation analysis which evaluates the exchange factors among finite flame volumes and finite object surface elements.

Structure Analysis of the Furniture Fire Model. The IFSM and LBRM modules were analytically developed in a straight-forward

fashion. The IFSM module begins with a surface temperature model of a virgin furniture surface element given the input of local radiative heat flux and the material properties. The next step is to determine if the surface element has ignited, and, if so, to identify a region 
of the surface element as ignited. The flame spread rate equations for both thermally thin and thick materials and an input of the adjacent flame radiative heat flux distribution near the flame front are used to model a growing burning (or pyrolysis) region. In the LBRM module for a burning surface element, a model for the surface temperature and emissivity, and for the local pyrolysate rate, is utilized and uses as input the local radiative heat flux. The burning material thickness and the burning rate of the surface element is obtained from the pyrolysate rate. The models contained in the above two modules were available in the literature and the numerical methods were developed in this work.

The FSRM module, however, proved to be much more difficult to develop. In attacking the FSRM problem, the module was divided into two submodules, one describing four different types of fire structures and merging them into an overall furniture flame shape, and the other describing the furniture thermal radiation. These submodules are designated the "Fire Structure submodule" and the "Furniture Thermal Radiation Submodule."

This work has examined criteria for fire structure identification of four basic fire types: tall pool, short pool, wall, and corner fires. The various fire structure models available in the literature were reviewed, and the final selection of these models will be contingent upon the development of the furniture thermal radiation model. The flame merging model, a part of the fire structure submodule, was adapted to geometry other than flames from the two separate horizontal slabs. The furniture thermal radiation model that was selected, was chosen because of its modularity feature and for its ability to incorporate exchange factors already obtained for compartment fires.

Practical Thermal Radiation Model for 3-D Gray Flames and objects. The rationale behind this model selection and development is that the modeling of a furniture fire, and the modeling of compartment fires which are being generalized into more zonal divisions, will require a three-dimensional representation of thermal radiation. Typical values of furniture surface emissivities and of the flame absorptivities imply gray body assumptions. The net radiative heat fluxes need to be as accurate as possible, because they directly determine the flame spread rate and surface burning rate. The calculations of net radiative heat fluxes, however, must be practical if they are to be used in modeling time-dependent fire growth.

The zonal radiation analysis begins with the exchange factor method described by Larsen, which is similar to Hottel's zone method, for an enclosure with isothermal, optically thin, and elemental gas volumes. The exchange factor method was extended to isothermal, moderately optically thick, and finite gas volumes by the following procedures. The gas volume was treated as being moderately optically 
thick by using the mean beam length theory in deriving the flame emissivity. Orloff's procedure to multiply the flame emissivity by the configuration factors of optically thick gas volumes was used in the exchange factors evaluation. Although orloff only described the configuration factors for a target surface far from a radiating gas volume, which is the sooty flame, in this work the configuration factors were extended to distances close to the radiating gas volume. The flame emissivity as a function of total flame absorptivity, flame volume, and a reference flame projected area was also modified for agreement with theoretical and experimental results for radiation from the cylinder and conical gas volume at different distances and at different optical thicknesses. The resulting zonal radiation analysis is being used to demonstrate a simple cylinder flame on the seat of a simple chair. The enclosure of a room is being taken into account by using the radiation conservation laws derived by Larsen.

In conclusion, the NBS at present uses expensive full-scale experiments to assess the fire hazards of various types of furniture. This mathematical modeling of furniture fires will be a useful, analytical complement to these full-scale tests, and will hopefully aid engineers in designing rooms and furniture to reduce fire loss.

Reports and Papers: none 
CENTER FOR FIRE RESEARCH

NATIONAL BUREAU OF STANDARDS

FY 84

Institution: University of Florida

Grant No.: $\quad$ NB81NADA2057

Grant Title: Network Models of Building Evacuation:

Development of Software System - Year Three

Principal Investigator(s): Thomas M. Kisko and Richard L. Francis, Ph.D.

NBS Scientific Officer: Bud Nelson

Technical Abstract:

This abstract summarizes the efforts of the third year of a project to develop user friendly software for the network modeling of building evacuation.

When the evacuation of a building involves the flow of people through well defined passageways, it is natural to consider the evacuation problem to be a network flow problem. EVACNET+ is a user friendly interactive computer program that accepts a user defined network model of a building, converts that model to a time expanded dynamic "transshipment" network, and solves the dynamic network using a capacitated minimum cost network flow algorithm. The solved dynamic network gives a time-dependent plan to evacuate the building in a minimum time, and identifies building evacuation bottlenecks.

The user defined network representation of a building is called a static model. A static model consists of a set of static nodes connected by static arcs. The nodes represent building components such as rooms, halls, landings, stairs and lobbies. The arcs represent the passageways between the building components. Nodes have two attributes, capacity and initial contents. The attributes of arcs are traversal time and capacity per unit time.

A static model is constructed by relating the building components and passageways of a building to nodes and arcs of a static model. The attributes of the nodes and arcs estimated by utilizing the dimensions of the building and the distribution of people in the building at the time of the evacuation.

When EVACNET+ is run, the static model is converted to a time expanded network called a dynamic model. A dynamic model is a representation of the building where each node of the static model 
is expanded into a series of dynamic nodes. Each dynamic node represents a building component at the end of a time period. Dynamic nodes associated with a specific static node are connected with hold-over arcs. The hold-over arc flows represent people staying in a room for the unit time period associated with the specific hold-over arc.

The dynamic nodes are also interconnected by movement arcs. Flows in these arcs represent, for a specific time period, the movement of people from one building component to another building component. There are a series of movement arcs for each individual static arc. Movement arcs proceed from a dynamic node at one time period and to a dynamic node for a later time period; the later period is determined by the traversal time of the associated static arc.

The dynamic model is solved using NETFLO as a subroutine to EVACNET+. NETFLO is a primal network code for the solution of capacitated network flow problems. The principal limitations of the model are as follows: (1) it is a linear model; (2) it does not represent behavioral aspects.

EVACNET+ is an interactive computer package that is user friendly. The input is free format. Static nodes and arcs are referred to using a special form. For example, WP2.3, refers to the second workplace on the third floor. WP2.3-HA4.3 refers to a static arc from the workplace to a hall on the same floor.

A user running EVACNET+ sits at a computer terminal and first enters the static nodes and arcs representing the building or interest. The process is totally "menu driven", in the sense that all the user has to do is select options and answer associated questions. The model is also run interactively. Results can be displayed on a terminal or printed. If the user wishes, the static model may be modified and rerun.

Figure 1 is the master option list of EVACNET+. When the option list is displayed, the user has twelve alternatives to select from. Upon entering a valid option code, the system will display a suboption list. From the suboption list the user may select any of the desired actions presented, including returning to the master option 1 ist. 


\section{EVACNET+ \\ BUILDING EVACUATION ANALYSIS PROGRAM \\ MASTER OPTION LIST}

CODE - REQUESTED ACTION

EN - ENTER NODE DEFINITIONS

EA - ENTER ARC DEFINITIONS

LN - LIST NODES

LA - LIST ARCS

DN - DELETE NODES

DA - DELETE ARCS

SYS - DEFINE OR REDEFINE SYSTEM ATTRIBUTES

RM - RETRIEVE DEFINED MODEL

RUM - RUN MODEL

EXAM - TERMINATE EXECUTION OF EVACNET

HELP - WHENEVER YOU HAVE QUESTIONS

ENTER CODE OF REQUESTED ACTION

\section{FIGURE 1 - EVACNET+ MASTER OPTION LIST}

The first year's effort of the EVACNET+ project involved the development of the majority of the EVACNET+ computer program. The second year's effort involved coding a post-processing routine, implementing and testing EVACNET+ on several types of computers, writing a user's guide, and testing the system with a sample of potential users.

The current year of the project involves research on extensions to EVACNET+. The list below summarizes some of the areas that are being investigated.

(a) Interface with other fire models.

(b) Ability to model the effects of smoke and fire spread.

(c) A model-controlled adjustment option.

(d) Heuristics for determining an upper bound on evacuation time.

(e) Heuristics for approximate solutions

(f) A simulation based solution procedure.

(g) Expanded model input and editing procedures.

(h) A results data base analysis system.

We are also implementing EVACNET+ on a personal computer. An MS-DOS machine was selected as the development microcomputer. The resulting micro version of EVACNET+ will be able to be run on an IBM $P C$ or any of it's clones. 


\section{Reports and Papers:}

1. Thomas M. Kisko and Richard L. Francis, "EVACNET+: A Computer Program to Determine Optimal Building Evacuation Plans," SFPE Symposium, Computer Applications in Fire Protection: Analys is, Modeling, and Design, March, 1984. 


\author{
CENTER FOR FIRE RESEARCH \\ NATIONAL BUREAU OF STANDARDS
}

FY 84

Institution: University of Minnesota, Minneapolis, Minnesota

Grant No.:

NB83NADA4057

Grant Title:

Method and Apparatus for Quantitative Fit Test of Respirators

Principal Investigator: Benjamin Y. H. Liu

Professor and Director

Particle Technology Laboratory

Mechanical Engineering Department

University of Minnesota

Minneapolis, MN 55455

Telephone: (612) 373-3043

Other Scientific Personnel: W. Szymanski (Research Associate)

NBS Scientific Officer George Mulholland

Technical Abstract:

The objectives of this research are to investigate the use of low-cost ionization or light-scattering smoke detectors for quantitative fit-test of respirators, and to develop a quantitative fit-test apparatus based on the use of such smoke detectors. The apparatus would include an aerosol generator to produce an aerosol for testing the face-seal leakage around a respirator and a modified smoke detector to detect the presence of particles within the face mask of a respirator. The availability of such a low-cost quantitative fittest apparatus would greatly enhance the effectiveness of respirators.

The research is divided into two parts with Part I focusing on measuring the concentration and size distribution of aerosol particles produced by various nebulizers and Part II, on determining the sensitivity and response characteristics of smoke detectors to such particles.

The focus of the research so far has been on determining the output characteristics of various commercially available nebulizers. To-date a total of seven commercial nebulizers have been tested. The characteristics of the nebulizers measured include the output flow rate, droplet generation rate, mass median diameter and the geometrical standard deviation of the output aerosol. The nebulizers were tested at a series of operating pressures and oleic acid was used as the test material. 
The concentration and size distribution of the aerosol was measured with a laser optical particle counter, Model ASAS-300X, manufactured by PMS, Inc. of Boulder, Colorado. The measured mass median diameter of the droplets ranged from 1.2 to 1.4 and the geometrical standard deviation, 1.3 to 1.4 .

Some preliminary studies were made using the nebulizers along with a smoke detector as a prototype quantitative fit test apparatus. The results are encouraging, but further studies are necessary before definitive results can be reported. 


\section{CENTER FOR FIRE RESEARCH \\ NATIONAL BUREAU OF STANDARDS \\ FY 1984}

Institution: Wood Chemistry Laboratory, University of Montana

Grant No. NB81NADA2066

Grant Title: Chemistry of Smoldering Combustion

Principal Investigators: Fred Shafizadeh (deceased)

R. Keith Osterheld and Edward E. Waali

Department of Chemistry

University of Montana

Missoula, Montana 59812

Other Professional Personnel: G. Stuart Petch (Post-doctoral fellow) William F. DeGroot (Research Assistant)

NBS Scientific Officer: Dr. Thomas J. Ohlemiller

Technical Abstract:

Objective. The objective of this research is to develop a molecular understanding of the smoldering combustion of cellulose and wood fibers in order to develop methods for controlling it. In the current studies we have primarily used cross-polarization magic angle spinning solid phase ${ }^{13} \mathrm{C}$ nuclear magnetic resonance spectroscopy (CP/MAS ${ }^{13} \mathrm{C}-\mathrm{NMR}$ ) and combined thermogravimetry and Fourier transform infrared spectroscopy (TG/FTIR) to describe the chemistry of char structure and reactivity.

Results. The CP/MAS ${ }^{13} \mathrm{C}$-NMR spectra of untreated cellulose and chars prepared from celluiose at various temperatures are shown in Fig. 7. The ${ }^{13} \mathrm{C}$-NMR spectrum of unpyrolyzed cellulose shows distinct peaks for the resonances corresponding to carbons 1,4 and 6 and overlapping peaks for carbons 2,3 , and 5 . Heating to $325^{\circ} \mathrm{C}$ results in a slight reduction in the intensities of the carbohydrate peaks and the appearance of broad resonances at either side of the carbohydrate region. At $350^{\circ} \mathrm{C}$ ( $67 \%$ weight 1 oss) the carbohydrate peaks are significantly reduced and the spectrum shows resonances at 14 and $34 \mathrm{ppm}$ for methy? and other paraffinic carbons, $132 \mathrm{ppm}$ for $\mathrm{C}=\mathrm{C}$ carbons adjacent to $\mathrm{C}$ or $\mathrm{H}, 154 \mathrm{ppm}$ for $\mathrm{C}=\mathrm{C}$ adjacent to oxygen, $173 \mathrm{ppm}$ for carboxylic acid and ester groups, and $211 \mathrm{ppm}$ for aldehydo-and keto-groups. Heating beyond $400^{\circ} \mathrm{C}$ results in additional weight loss and complete loss of carbohydrate structure. The peak at $132 \mathrm{ppm}$ predominates and becomes sharper at these temperatures and the paraffinic resonances become more heavily weighted toward the methyl peak at $14 \mathrm{ppm}$. It is difficult to distinguish between the aromatic and olefinic carbon by NMR alone, but the presence of strong resonances for methyl and other paraffinic carbons indicates that a large fraction of the 3-4 hydrogen atoms present per 6 -carbon unit (based on elemental analysis) must be associated with paraffinic structures. This strongly suggests that the remaining carbon is associated with a fused aromatic system. The permanganate oxidation studies reported previously, which confirm the presence of highly sub- 


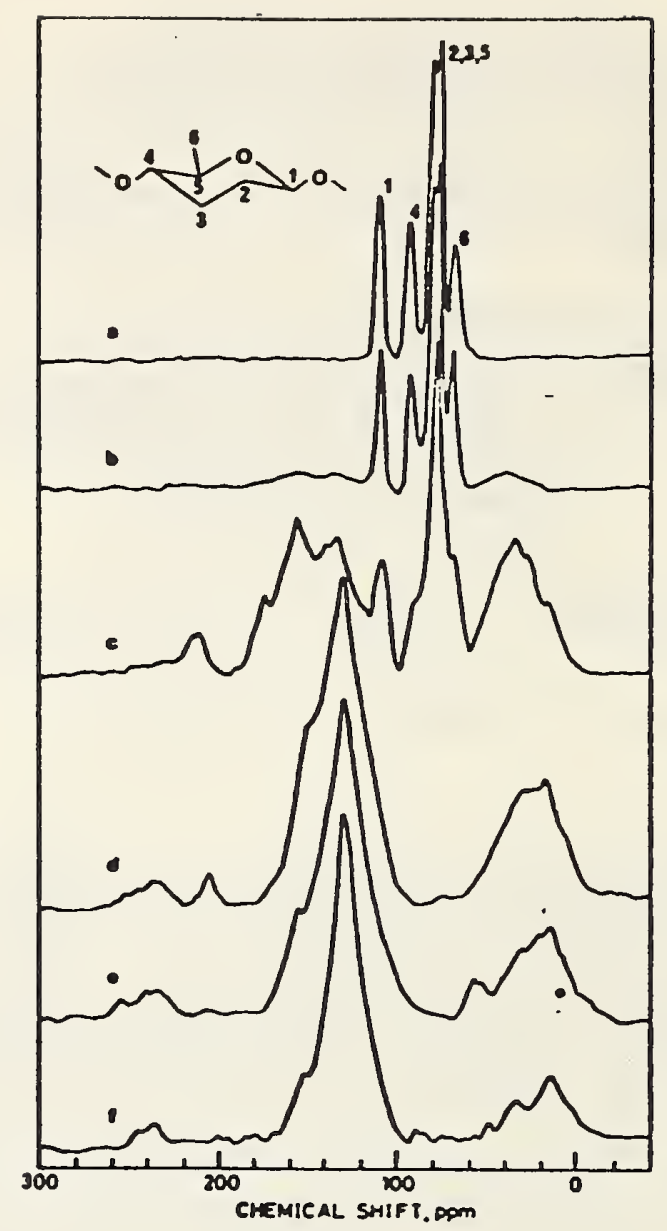

F1gure 1. CP/MAS 13C-MMR spectra of cellulose chars prepared by heating for 5 nin at different temperatures: (a) no treatment; (b) $325^{\circ} \mathrm{C}_{i}$ (c) $350^{\circ} \mathrm{C}$; (d) $400^{\circ} \mathrm{C} ;$ (e) $450^{\circ} \mathrm{C} ;$ (f) $500^{\circ} \mathrm{C}$. (The small peaks located in the 240 ppo regions are spining sidebands.)

stituted aromatic structures in chars prepared at these temperatures, lend further evidence for a fused aromatic structure of char.

CP/MAS ${ }^{13} \mathrm{C}$-NMR of chars prepared from wood and 1 ignin showed substantially the same trends with the exception that the wood and lignin chars had a more pronounced peak at $148 \mathrm{ppm}$ corresponding to aromatic carbon bearing methoxyl substituents $\left(\phi-0-\mathrm{CH}_{3}\right)$, which arise from the guaiacyl (4-hydroxy-3-methoxyphenylpropane) subunits of softwood lignins. The structure of wood char was otherwise found to be nearly identical with that of cellulose. Similarly, chars prepared from cellulose heated with inorganic additives such as $\left(\mathrm{NH}_{4}\right)_{2} \mathrm{HPO}_{4}$ and $\mathrm{NaCl}$ were very similar to those prepared from untreated cellulose, even though the char yields and temperatures of decomposition varied substantially between treatments. 
A major emphasis of this research is to relate chemical structure of the char to observed reactivity. An important aspect of the reactivity of cellulosic chars which was previously unexplained was the presence of two distinct exothermic peaks observed by differential scanning calorimetry during combustion. The first exotherm occurs at $360^{\circ} \mathrm{C}$ and the second at $520^{\circ} \mathrm{C}$ in untreated cellulose. In order to relate these two separate stages of reaction to chemical structure, a cellulose char was heated to $40 \%$ weight loss in air and the original and oxidized char samples were analyzed by CP/MAS ${ }^{13} \mathrm{C}$-NMR. The results shown in Figure 2 show that the low temperature oxidation corresponding to the first exotherm removed only the aliphatic fraction of the char and the aromatic fraction remains unchanged except for enhanced absorption corresponding to phenoxy groups $\left(\phi-0-\mathrm{CH}_{3}\right)$ due to partial oxidation of aromatic carbon. The evidence therefore suggests that the two exothermic transitions indicated by DSC are due to two separate combustion processes involving chemically distinct char fractions.

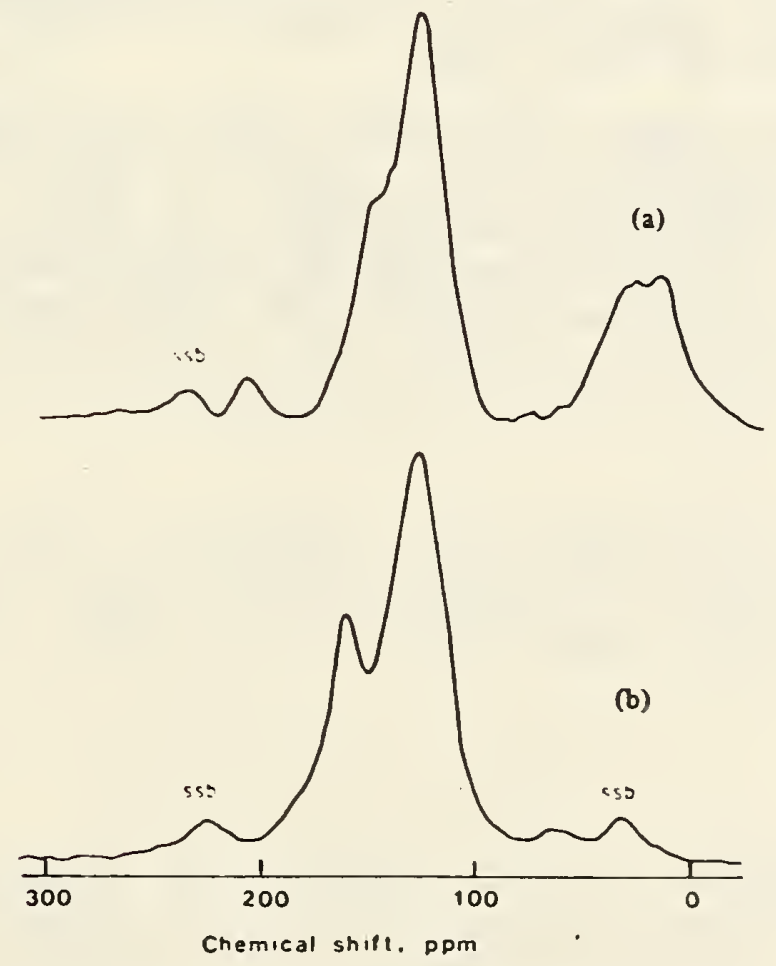

F1gure 2. CP/MAS ${ }^{13} \mathrm{C}-\mathrm{N}$ - 2 spectra of the char sample (CPT $4 \mathrm{CO}^{\circ} \mathrm{C}$ ) before (a) and after (b) $40 \%$ weight loss on oxidation in air (swall peaks at about 30 and 225 ppm are spinning sidebands). 
Combustion catalysts such as sodium chloride catalyzed the combustion of the aromatic fraction, but did not affect the combustion of the aliphatic fraction. The results of TG/FTIR studies showed that the combustion of the aliphatic and aromatic fractions gave similar $\mathrm{CO} / \mathrm{CO}_{2}$ ratios, although the ratios varied substantially between treatments.

Publications:

The following papers have been published or submitted for publication in the current fiscal year:

1. F. Shafizadeh and Y. Sekiguchi, "Development of Aromaticity in Cellulosic Chars," Carbon, 21, (1983) 511-516.

2. Y. Sekiguchi, J.S. Frye and F. Shafizadeh, "Structure and Formation of Cellulosic Chars," J. Appl. Poly. Sci. Vol. 28, 3513-3525 (1983).

3. F. Shafizadeh and Y. Sekiguchi, "Oxidation of Chars During Smoldering Combustion of Cellulosic Materials," Combust. and Flame, 55: 171-179 (1984).

4. Y. Sekiguchi and F. Shafizadeh, "The Effect of Inorganic Additives on the Formation, Composition and Combustion of Char," $\mathrm{J}$. Appl. Polym. Sci., 29, 1267-1286 (1984).

5. R.M. Rowel1, R.A. Susott, W.F. DeGroot and F. Shafizadeh, "Bonding Fire Retardants to Wood. Part I. Thermal Behavior of Chemical Bonding Agents," Wood and Fiber Science, 16, 214-223 (1984).

6. F. Shafizadeh, "The Chemistry of Pyrolysis and Fire Retardants," The Chemistry of Solid Wood, R.M. Rowe11, ed; Academic Press, New York, (1984). 


\section{CENTER FOR FIRE RESEARCH \\ NATIONAL BUREAU OF STANDARDS \\ FY 84}

Institution: University of Notre Dame

Grant No: $\quad$ NBS Grant NB 83 NADA 4018

Grant Title: Scaling Correlations of Flashover Experiments.

Principal Investigator: Professor A. M. Kanury

Department of Aerospace and Mechanical Engr.

University of Notre Dame

Notre Dame, IN 46556

Other Professional Personnel: Mr. M. S. Riepenhoff, Graduate Research Assistant.

NBS Scientific Officer: Mr. B. T. Lee

Technical Abstract:

The objective of this continuation project is to develop an understanding of the relation and correspondence between the observations and measurements made on the fire growth process to flashover in compartments of different scales. Based on this understanding, experimerits on different scales are sought to be correlated to logically infer (i) whether or not flashover would occur under a given set of circumstances and (ii) the time to flashover, if it does occur.

Based on mass and energy conservation laws, the following functional relation is deduced, in the preceeding grant period (NBS Grant NB 81 NADA 2021), for the dependency of nondimensional ceiling surface $(j=w)$ and ceiling-layer gas $(j=g)$ temperatures on nondimensional time $\tau$.

$$
\theta_{j}=\theta_{j}\left(\tau ; \phi_{0}, \beta, \psi, \Omega, \gamma\right)
$$

Detailed definitions of the parameters $\phi_{0}, \beta, \ldots$ can be found in Refs. [1] and [2]. Suffice it to point here the significance of these nondimensional parameters of the room-fire problem. कo characterizes the initial fire source (e.g.: a gas burner, a waste-basket fire, an upholstered chair, ...), by being defined as the normalized fuel input rate. The parameter $\beta$ accounts for the ability of the wall-linings, draperies, etc. which are first exposed to the fire source and which serve in the initial fire growth; it is defined heuristically at present in terms of the area covered by a gas flame per unit energy input in the gas flow, heat transfer from the flame to the lining, and measured heat release rate (per unit exposure irradiance). $\psi$ is the aspect ratio of the opening to the room. $\gamma$ is a geometric parameter, the ratio of the 
area of ceiling and upper portions of the walls to the window area. Finally, $\Omega$ is the ratio of (characteristic) energy retained within the room to heat the surfaces to the energy drained out of the room by the convective flow through the opening. As such $\Omega$ is a sort of a stanton number, the numerator of which is the heat transfer coefficient. Thermal radiation is taken at present by augmenting this coefficient in a manner cognizant of the expected radiating smoke-layer thickness.

If the event of flashover is based on any criterion involving the attainment of a minimum of either the temperature $\theta_{j}$ or any direct function of it (such as the radiant flux to the floor), the preceeding functional relation gives $\tau^{*}$ as dependent on the parameters $\phi_{0}, \beta, \psi, \Omega$

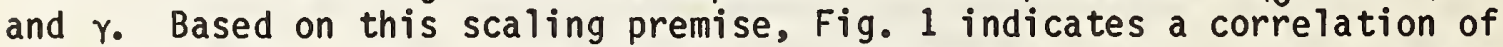
the NBS mobile home fire tests (42 quarter-scale and 46 full-scale tests) in which a variety of fire sources, wall and ceiling linings and room/opening configurations are involved. No systematic variations in $\Omega, \gamma$ and $\psi$ are prescribed so that this figure can be construed as a preliminary test of the role played by $\phi_{0}$ and $\beta_{0}$. When $\phi_{0}(1+\beta)$ is less than about 2, flashover appears not to be possible. However, when both the walls and the ceiling are lined with gypsum board, flashover will not occur even if $\phi_{0}$ and $\beta$ are large. At least a part of the scatter could be reduced if experiments are available with a systematic variation in the parameters $\Omega, \gamma$ and $\psi$.

In the continuation project, three issues are being studied. These are: (a) the contribution of the first involved combustibles (viz: the parameter $\beta$ ); (b) thermal radiation from the ceiling-layer gas in augmenting the heat transfer coefficient appearing in the definition of $\Omega$ and in culminating in a radiant flux to the floor; and (c) the gypsum board anamoly of Fig. 1. Related to the first of these issues, the role played by two-dimensional transient heat conduction within the wall-lining slab has been studied (Ref. [3]) to predict the upward fire spread on a vertical wall. Simplifying the gas-phase problem to the prescription of a height-wise variant heat transfer coefficient, and solving the 2-d transient conduction equation to obtain the temporal march of the solid surface location where the temperature is equal to a prescribed pyrolysis temperature, the flame height (assumed to be $\lambda$ times the pyrolysis height) history is predicted as shown in Fig. 2 . The most fascinating aspect of this result is that the fire growth versus time follows an exponential relation.

The implications of this result in room fire scaling are being examined currentiy.

Reports and Papers:

[1] Kanury, A.M., "Scaling Correlations of Flashover Experiments," Final Report Submitted to the National Bureau of Standards, Center for Fire Research, Grant No. NB 81 NADA 2021, University of Notre Dame, Notre Dame, IN, 46556, (August 1983).

[2] Kanury, A.M., "Scaling Correlations of Flashover Experiments," Paper 
presented at the ASTM/SFPE Symposium on Application of Fire Science to Fire Engineering, Denver, CO. To appear in an ASTM Special Technical Publication edited by T.Z. Harma thy.

[3] Riepenhoff, M.S., "An Investigation of Two-Dimensional Transient Conduction as Related to Fire Spread on a Vertical Wall," M.S. Thesis Submitted to Department of Aerospace and Mechanical Engineering, University of Notre Dame, Notre Dame, IN 46556, (July 1984).

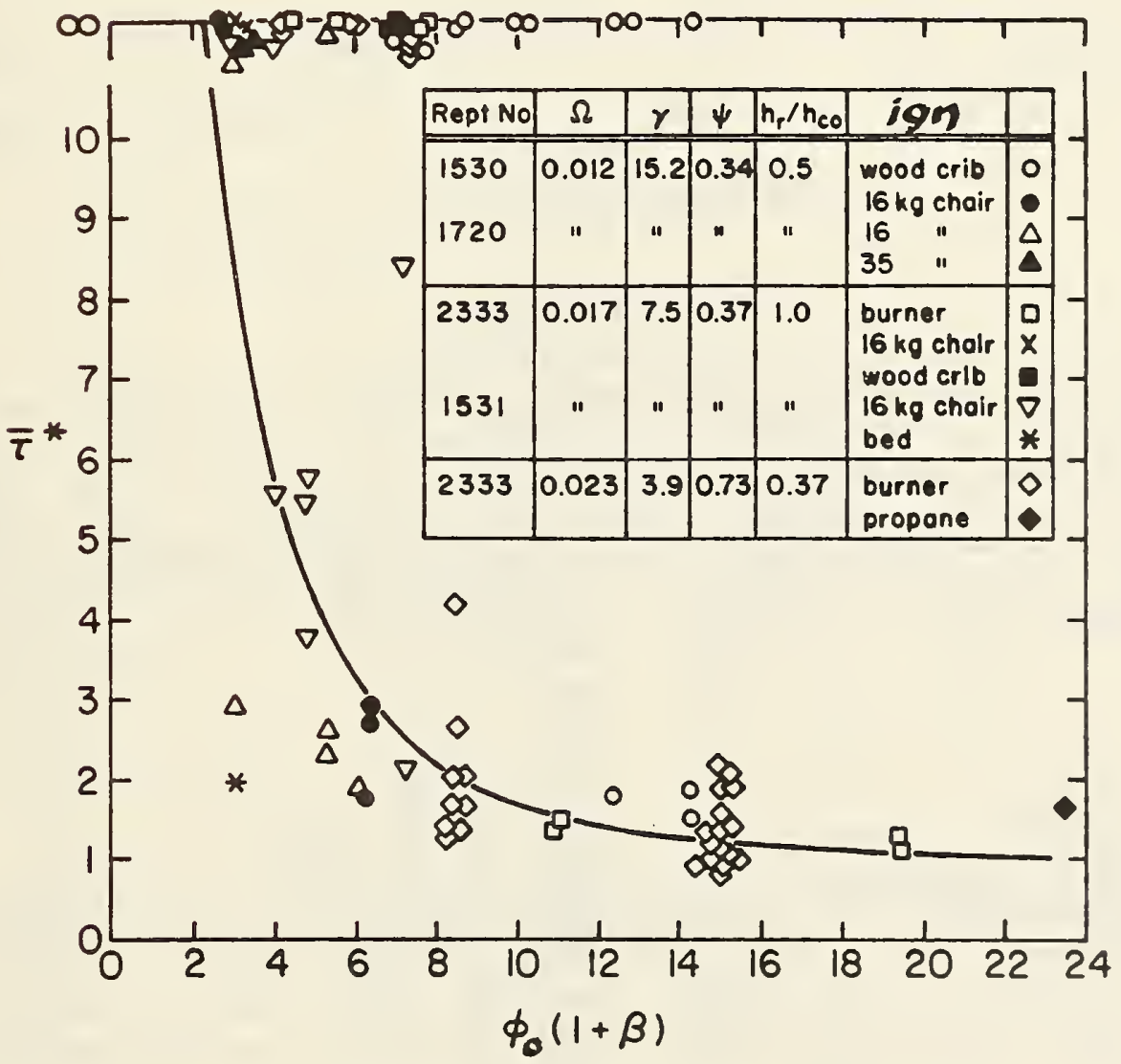

Figure 1: Correlation of Mobile Home Fire Tests [1], [2]. 

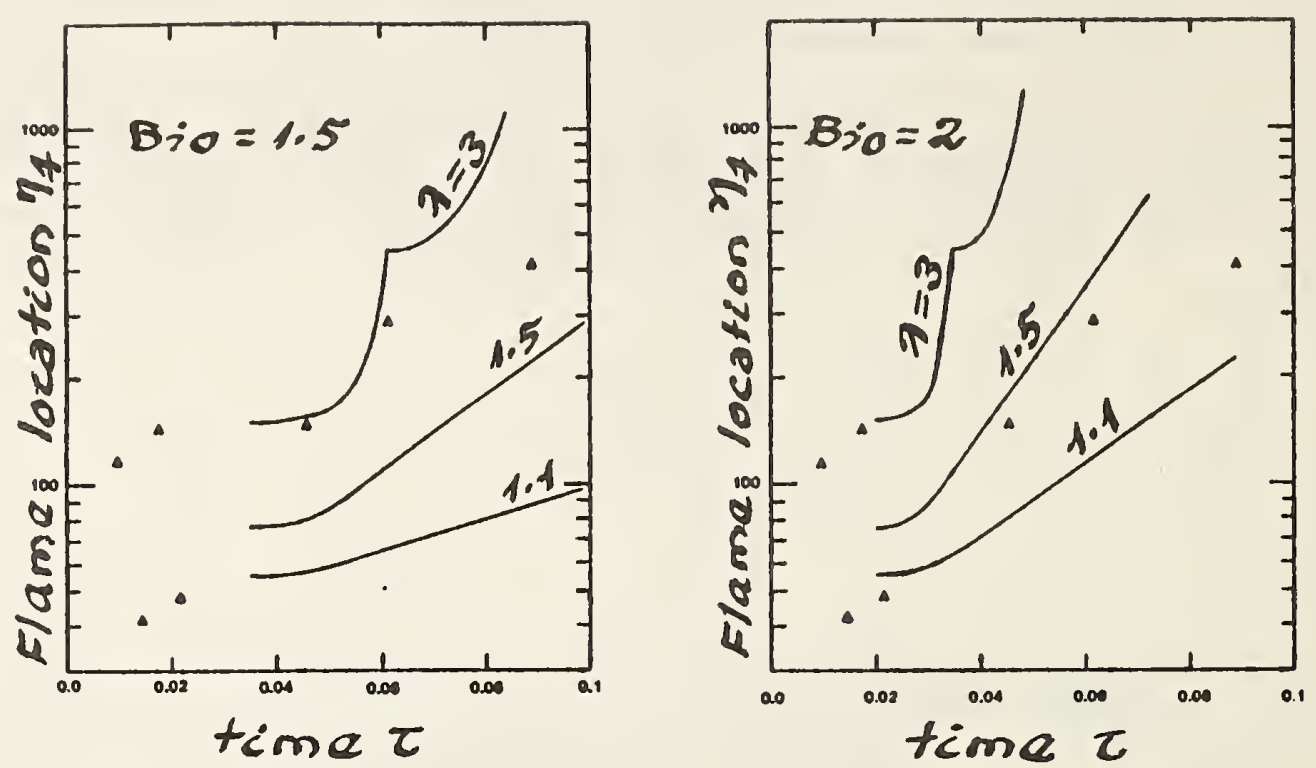

$\mathrm{Bi}=\frac{\mathrm{Bi}_{0}}{\left(\eta-\eta_{1}\right)^{0.26}}$

- Present Prediction

$\Delta$ Data of Fang
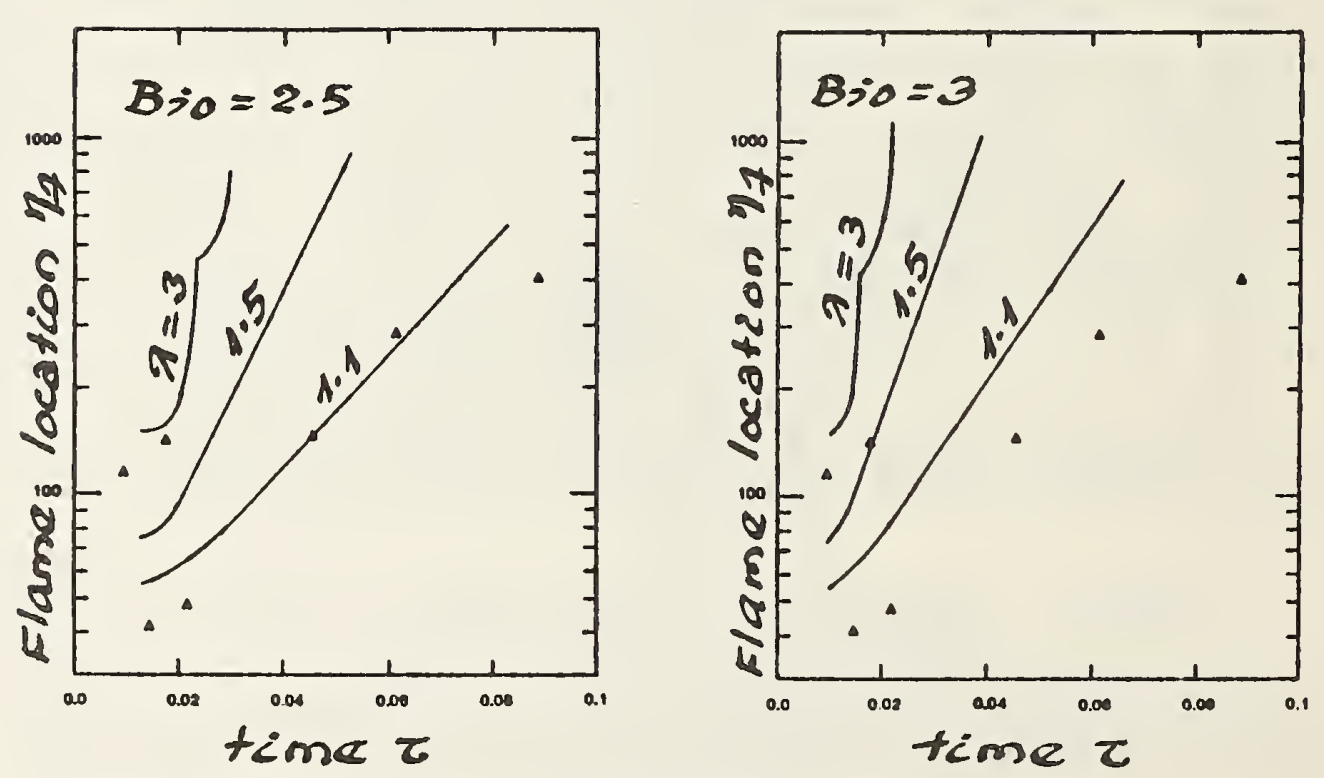

Figure 2: 2-d Transient Conduction Predictions of Upward Fire Spread on a Vertical Wall [2]. 


\section{CENTER FOR FIRE RESEARCH \\ NATIONAL BUREAU OF STANDARDS \\ FY 84}

Institution: University of Pittsburgh

Contract Number: 60NANB4D0001

Contract Title: Toxicity of Plastic Combustion Products

Principal Investigator: Yves Alarie, Ph.D.

Professor of Respiratory

Physiology and Toxicology

University of Pittsburgh

Pittsburgh, PA 15261

NBS Scientific Officer: Barbara C. Levin, Ph.D.

Technical Abstract

Several areas of research are being pursued.

1. Composite Materials

Most of the work conducted on toxicity of plastic decomposition products has been done using single materials such as wood, polyvinylchloride, polyurethane, etc. We have now completed the work on six materials. These were non-commercial materials commonly used in buildings for floor covering, ceiling tiles and display boards. The work completed indicated that the method used at the University of Pittsburgh to evaluate toxicity of smoke is well suited to test composite materials as well as single materials.

\section{Visibility}

Part of the hazard in a fire is impairment of visibility due to smoke. This measurement has never been made during thermal decomposition of materials simultaneously with assessment of the toxicity. We have developed a nephelometer. This nephelometer is attached to the animal exposure chamber and permits continuous monitoring of smoke density during toxicological evaluation.

3. Japanese Samples

Three samples were submitted last October by Japanese investigators for evaluation at the University of Pittsburgh so that comparisons could be made between our method and theirs. The samples are polyvinylchloride, polymethylmethacrylate and a fiber insulation board. Evaluation is about 50\% completed. 


\section{New Model for Toxic Hazard Analysis}

We have started a new effort in an attempt to obtain data in a realistic situation of humans escaping smoke from a fire in a corridor. We have developed a "corridor" for mice which consists of a glass tube of an appropriate diameter so that the mice can run into it only forward or backward and cannot turn around. This glass tube is 150 feet long and is continuously ventilated with fresh air. Provisions are made to add contaminants such as $\mathrm{CO}$, HCN, formaldehyde or smoke so that their effect on the traveling speed of the animals can be evaluated.

The results obtained so far indicate that the traveling speed of mice with fresh air ventilation is very reproducible and, therefore, the study of the effects of toxicants can be evaluated. Preliminary results with $\mathrm{CO}$ indicate that the traveling speed is reduced in proportion to the $\mathrm{CO}$ concentration and that the total distance covered before complete incapacitation occurs is also reduced as the $\mathrm{CO}$ concentration increases. Thus two key elements, distance to be covered for escape and time available to travel this distance, can be used in a hazard analysis. We can also change the speed at which the toxicant (or smoke) reaches the animals as they are traveling into the corridor and take this factor into consideration.

\section{Reports and Papers (This Year)}

Alarie, Y., Stock, M.F., Matijak-Schaper, M. and Birky, M.M. Toxicity of smoke during chair smoldering tests and small scale tests using the same materials. Fund. App1. Toxicol. 3, 619-621, 1983.

Wong, K.L., Stock, M.F. and Alarie, Y. Evaluation of the pulmonary toxicity of plasticized polyvinylchloride thermal decomposition products in guinea pigs by repeated $\mathrm{CO}_{2}$ challenges. Toxico1. App 1. Pharmraco1. 70, 236-238, 1983.

Wong, K.L., Stock, M.F., Malek, D.E. and Alarie, Y. Evaluation of the pulmonary toxicity of wood smoke in guinea pigs by repeated $\mathrm{CO}_{2}$ challenges. Toxicol. App 1. Pharmacol., in press.

Alarie, $Y$. Toxicity of smoke from polymeric materials during thermal decomposition. Annual Review of Pharmacology and Toxicology, in press. 
AGENDA

Annual Conference on Fire Research

National Engineering Laboratory

National Bureau of Standards

October $17,18,19,1984$

Wednesday, October 17,1984
$8: 15$ a.m.
Registration, Green Auditorium Lobby
9:00 a.m.
Welcome - J. Snell, Director, CFR/NBS
$9: 10 \mathrm{a} \cdot \mathrm{m}$.
Opening Remarks - C. Bragdon, Administrator, United States Fire Administration
$9: 15 \mathrm{a} \cdot \mathrm{m}$.
J. deRis, 1984 Emmons Lecturer: Flammability and Radiation

SESSION I: Growth of Fire in a Compartment

9:55 a.m.

$10: 00 \mathrm{a} \cdot \mathrm{m}$.

$10: 30 \mathrm{a} \cdot \mathrm{m}$.

$11: 00 \mathrm{a} \cdot \mathrm{m}$.

$11: 30 \mathrm{a} \cdot \mathrm{m}$

$12: 00$ p.m.

$12: 30 \mathrm{p} \cdot \mathrm{m}$.

$1: 00 \mathrm{p} \cdot \mathrm{m}$.
Session Chairman (Introduction) - P. Pagni, University of California, Berkeley

Internal Flows and Combustion in Two Layer Room-Fire Models - E. Zukoski, California Institute of Technology

Difficulties in Finding a Correct Solution to Conservation Equation Used in Multi-Compartment Transport - W. Jones, CFR/NBS

Coffee Break

Thermal Response of Unconfined Ceilings Above Growing Fires and the Importance of Convective Heat Transfer - L. Cooper, CFR/NBS

Effects of Ventilation and Panel Properties on Temperature Rise from Aircraft Fires -

T. Eklund, FAA

Slide-Rule Estimates of Fire Growth J. Quintiere, R. Lawson, CFR/NBS

Lunch 
SESSION II: Use of Models in Hazard Analysis
$2: 00$ p.m.
Session Chairman (Introduction) -
A. Fowe11, CFR/NBS
2:05 P.m.
CFR Toxic Hazard Assessment: Development and Application - R. Bukowski, CFR/NBS
$2: 35$ p.m.
Use of Mathematical Models in Hazard Assessment - F. Clarke, I. Benjamin, and P. DiNenno, Benjamin/ Clarke Associates, Inc.
3:05 p.m.
Coffee Break

SESSION III: Use, Development, and Validation of Models

$3: 35 \mathrm{p} \cdot \mathrm{m}$.

$3: 40$ P.m.

4:10 p.m.

$4: 40 \mathrm{p} \cdot \mathrm{m}$.

$5: 10$ p.m.

$6: 30$ p.m.

Thursday, October 18,1984

a.m. Session IV

p.m. Session V

all day Session VI
Session Chairman (Introduction) -

A. Fowe11, CFR/NBS

Experience with the Harvard Mark VI Program H. Mitler, CFR/NBS

A Study of Compartment Fires and the Validation of Computer Models - K. Charter, Owens-Corning Fiberglas Technical Center

Microcomputer Based Stochastic Fire Spread Analysis - R.B. Williamson, University of California

Ad journ

Crab Feast at Cracked $\mathrm{Claw}$

\section{PARALLEL SESSIONS}

Alerting, Reactions and Movement of People in Buildings when Threatened by Fire - Lecture Room B

Fire Risk Analysis and Fire Risk Data - Lecture Room B

Data and Subprograms Required for Calculations Green Auditorium 
SESSION IV: Alerting, Movement and Reactions of People

in Buildings when Threatened by Fire

$9: 00 \mathrm{a} \cdot \mathrm{m}$.

$9: 05 \mathrm{a} \cdot \mathrm{m}$.

$9: 35$ a.m.

10:05 a.m.

$10: 35$ a.m.

11:05 a.m.

$11: 35$ a.m.

12:05 p.m.

$12: 35$ p.m.

1:05 p.m.
Lecture Room B

Session Chairman (Introduction) -

H. Nelson, CFR/NBS

Sound Transmission Loss from Corridors to

Rooms: Implications for Locating Fire Alarm Sounders - D. Robinson, University of

Massachusetts

Response Latencies of the Handicapped and Elderly to Simulated Residential Fire Egress Scenarios - R. Pearson, North Carolina State University

Evacuation Technology: An Update on the Effective Width Model for Crowd Flow Capacity and Related Changes to Egress Standards J. Pauls, National Research Council, Canada

Coffee Break

Assessment of Escape Routes in Buildings Discussion of a Design Method for Calculating Pedestrian Movement - E. Kendik, Institut für Hochbau für Architekten, Austria

Modeling Emergency Evacuation - D. Alvord, American Institute of Architects Foundation

Transit Station Evacuation Evaluation G. Berlin, Modeling Systems, Inc.; and W. Hathaway, DoT, Transportation Systems Center

Early Actions in Fire Emergencies - B.M. Levin, CFR/NBS; and J. Keating, University of Washington

Lunch 
SESSION V: Fire Risk Analysis and Fire Experience Data

Lecture Room B

2:00 p.m.

2:05 p.m.

$2: 35 \mathrm{p} \cdot \mathrm{m}$.

3:05 p.m.

$3: 35 \mathrm{p} \cdot \mathrm{m}$.

4:05 P.m.

4:35 P.m.

5:05 p.m.

$5: 35$ p.m.

\section{SESSION VI: Data and Subprograms Required for Calculations}

Session Chairman (Introduction) - J. Hall, National Fire Protection Association

Ignition Risk Analysis - Cigaret te Ignition of Upholstered Furniture - K-N Yeh, University of Maryland

Fire Protection of Flammable Work Stations in the Clean Room Environment of a Microelectric Fabrication Facility - D. Crinnion, F. Fisher, G. Toms, R.B. Williamson, University of California at Berkeley

Coffee Break

Relationships Between Worker Casualties, Other Fire Loss Indicators, and Fire Protection Strategies - J. Moran, Department of Health and Human Services

Suppression and Extinguishment of Fire - 98 Years of Experience with Automatic Sprinkler Systems in Australia - H. Marryatt, Australia

Development of a Fire Safety Code for Buildings for Saudi Arabia - K. Basham, Saudi Arabian Standards Organization

International Concepts in Fire Protection: Japan and Hong Kong - P. Schaenman, TriData Corporation

Ad journ
$9: 00$ a.m.

9:05 a.m.

$9: 35$ a.m.
Session Chairman (Introduction) - J. deRis, Factory Mutual Research Corporation

Heat Release Rate of Wood - W. Parker, CFR/NBS

The Behavior of Furniture Frames During Fire G. Springer, Stanford University 
10:05 a.m.

$10: 35$ a.m.

11:05 a.m.

$11: 35 \mathrm{a} \cdot \mathrm{m} \cdot$

12:05 p.m.

$12: 35$ p.m.

1:05 p.m.

2:00 p.m.

$2: 35 \mathrm{p} . \mathrm{m}$.

3:05 p.m.

$3: 35 \mathrm{p} . \mathrm{m}$.

4:05 p.m.

$4: 35 \mathrm{p} \cdot \mathrm{m}$.

5:05 p.m.

$6: 30 \mathrm{p} \cdot \mathrm{m}$.
A Simplified Characterization for Upholstered Furniture Heat Release Rates - V. Babrauskas, CFR/NBS

Coffee Break

Flammability Testing of Thermoplastic Films for Aircraft Interior Applications - D. Kourtides, National Aeronautics and Space Administration

Heat Release from Wall Assemblies Containing Fire Retardant Treated Wood - J. Brenden, Forest Products Laboratory

Combustion Chemistry in Fires - A. Tewarson, Factory Mutual Research Corporation

Simulation of Negatively Buoyant Flows Arising in Enclosure Fires - D. Boldman, Y. Jaluria, Rutgers University

Lunch

Practical Thermal Radiation Model for 3-D Gray Flames and Objects - M. Dietenberger, University of Dayton

Use of Computer Fire Models in Corner Burn Tests - E. Dickens, Jr., G. Smith, B.F. Goodrich

Coffee Break, Employees Lounge

Smoke Control in Hospitals/Bedroom Buildings 0 . Meland, River and Harbour Laboratory, SINTFF, ; and E. Skaret, Norwegian Institute of Technology

The Acute Toxicological Effects from the Inhalation of Single and Multiple Fire Gases B. Levin, CFR/NBS

How to Report the Results from the University of Pittsburgh Toxicity Test - Y. Alarie, University of Pittsburgh

Ad journ

International Reception at the Quality Inn 
SESSION VII: Fire Suppression and Detection

\begin{tabular}{|c|c|c|}
\hline $9: 00$ & a.m. & $\begin{array}{l}\text { Session Chairman (Introduction) - } \\
\text { G. Heskested, Factory Mutual Research } \\
\text { Corporation }\end{array}$ \\
\hline $9: 05$ & a.m. & $\begin{array}{l}\text { Direction for Improving Manual Fire Suppression } \\
\text { Using Physically Based Computer Simulations - } \\
\text { L. Pietrzak, G. Johanson, Mission Research } \\
\text { Corporation }\end{array}$ \\
\hline $9: 35$ & a.m. & $\begin{array}{l}\text { Water Spray Suppression of Gas-Well Blowout } \\
\text { Fires - D. Evans, B. McCaffrey, CFR/NBS }\end{array}$ \\
\hline $10: 05$ & $\mathrm{a} \cdot \mathrm{m}$. & $\begin{array}{l}\text { Modes of Fire Suppression - R. Sheinson, } \\
\text { J. Hahn, D. Indritz, National Research. } \\
\text { Laboratory }\end{array}$ \\
\hline $10: 35$ & a.m. & Coffee Break \\
\hline $11: 05$ & $\mathrm{a} \cdot \mathrm{m}$. & $\begin{array}{l}\text { Effectiveness of Fire Control Agents on Hexane } \\
\text { Fires - J. Welker, University of Arkansas }\end{array}$ \\
\hline $11: 35$ & $\mathrm{a} \cdot \mathrm{m}$. & $\begin{array}{l}\text { Metal Fire Extinguishment - T. Sharma, B. Lal, } \\
\text { J. Singh, Central Building Research Institute, } \\
\text { Roorkee, India }\end{array}$ \\
\hline $12: 05$ & $\mathrm{p} \cdot \mathrm{m}$. & $\begin{array}{l}\text { Comparative Effectiveness of Solid, Liquid and } \\
\text { Gaseous Inhibitors in Adiabatic and Non- } \\
\text { Adiabatic Premixed Flames - H. Kim, P. Taylor, } \\
\text { J. Reuther, Pennsylvania State University }\end{array}$ \\
\hline $12: 35$ & p.m. & $\begin{array}{l}\text { Principles for Fire Detection - J. Newman, } \\
\text { Factory Mutual Research Corporation }\end{array}$ \\
\hline $1: 05$ & $p \cdot m$. & $\begin{array}{l}\text { Experimental and Analytical Study of Fire } \\
\text { Sprinkler Scaling Laws - J. Prahl, Case } \\
\text { Western Reserve University }\end{array}$ \\
\hline $1: 35$ & $\mathrm{p} \cdot \mathrm{m}$. & Closing Remarks \\
\hline $1: 45$ & $p \cdot m$. & Ad journ \\
\hline
\end{tabular}


1984 CONFERENCE ON FIRE RESEARCH

October $17,18,19$

\section{LIST OF PARTICIPANTS}

ADAMS, Pat, Man Made Fiber Producers Association, 1150 17th Street, N.W., Washington, D.C. 20036

ALAHDADI, Firooz, University of New Mexico Civil Engineering Institute, Campus P.O. Box 25

ALARIE, Yves, Graduate School of Public Health, University of Pittsburgh, 130 DeSoto Street, Pittsburgh, Pennsylvania 15261

ALMAND, Charles W., U.S. Gypsum Co., 1050 17th Street, Suite 1150, Washington, D.C. 20036

ALVARES, Norman, Lawrence Livermore National Laboratory, P.0. Box 808, L442, Livermore, California 94550

ALVORD, Danial, American Institute of Architects Foundation, 1735 New York Avenue, N.W., Washington, D.C. 20006

AMED, Earle B., Bureau of Mines, 2401 E. Street, N.W., Washington, D.C.

ANSON, Bruce D., Rohm and Haas Company, P.0. Box 219, Bristol, Pennsylvania 19007

BAS'HAM, Khaled S., Construction and Building Materials Section - SASO, P.0. Box 3437, Riyadh 11471, Saudi Arabia

BEAN, J. Michael, Lord Bissell, and Brook, 115 South LaSalle Street, Chicago, Illinois 60603

BEITEL, Jesse J., Southwest Research Institute, 6220 Culebra Road, San Antonio, Texas 78216

BERLIN, Geoffrey, Modeling Systems, Iner, Boston, Massachusetts

BLAIR, John A., E.I. du Pont de Nemours \& Co., Polymer Products Dept., Chestnut Run, Building 713, Wilmington, DE 19898

BORING, Delbert F., American Iron \& Steel Institute, 4937 West Broad Street, Columbus, Ohio 43228

BOVERMAN, David Asher, EG\&G, Florida, P.0. Box 21267, Kennedy Space Center, Florida 32815

BRAGDON, Clyde, United States Fire Administration, 16825 S. Seton Avenue, Emmitsburg, Maryland 21727

BRENDEN, John J., USDA, Forest Service, Forest Products Laboratory, fifford Pinchot Drive, Madison, Wisconsin 
BRYAN, John L., University of Maryland, Department of Fire Protectior Engineering, College Park, Maryland 20742

BUCHANAN, Michael, W.T. Burnett Company, 1500 Bush St., Baltimore, Maryland 21230

CHARTER, Ken, Owens Corning Fiberglas Corporation, Technical Center, Granville, Ohio 43023

CHIDESTER, Joyce, Foundation for Fire Safety, 1700 North Moore Street, Rosslyn, Virginia 22209

CUSTER, Richard, Worcester Polytechnic Institute, Center for Fire Safety Studies, Worcester Polytechnic Institute, Worcester, Massachusetts 01609

DALY, Thomas, Hilton Hotels Corporation, 9880 Wilshire Boulevard, Beverly Hills, California 90210

DAVIS, Sanford, Center for Fire Research, National Bureau of Standards, Gaithersburg, Maryland 20899

DENNIS, Cornelius F., Department of Buildings, City of New York, 120 Wall Street, New York, N.Y. 10005

DeRIS, John, Factory Mutual Research, Norwood, Massachusetts 02062

DICKENS, E. Douglas Jr., B. F. Goodrich R\&D Center, 9921 Brecksville Road, Brecksville, Ohio 44141

DIETENBERGER, Mark A., Univeresity of Dayton Research Institute, 300 College Park, Dayton, OH 45469

DiNENNO, Philip J., Benjamin/Clarke Associates, Inc., 10605 Concord Street, Suite \#501, Kensington, Maryland 20895

DUNLAP, W.A., Dow Chemical USA, P.O. Box 515, Granville, Ohio 43023

ECHTERNACHT, John E., Wormald U.S., Inc., 180 Grand Avenue, Suite 900, Oakland, California 94612

EKLUND, Thor, FAA Technical Center, ACT 350, Building 204, Tilton Road, Atlantic City, New Jersey 08405

ENGLER, Nicholas A., University of Dayton Research Institute, 300 College Park, Dayton, Ohio 45469

FAETH, G.M., Pennsylvania State University, 315 M.E. Building, University Park, Pennsylvania 16802

FESMAN, Gerald, Stauffer Chemical Company, Grasslands Road, Elmsford, NY 10523

FOOTE, Kenneth L., Lawrence Livermore National Laboratory, P.0. Box 808, L-442, Livermore, California 94550 
FOWELL, Andrew, Center for Fire Research, National Bureau of Standards, Gaithersburg, Maryland 20899

FRIEDMAN, R., Factory Mutural Research, Norwood, Massachusetts 02060

GANDHI, Pravinray, Unverwriters Laboratories, Inc., 333 Pfingsten Road, Northbrook, Illinois 60062

GARN, Paul D., Center for Fire and Hazardous Materials Research University of Akron, Akron, Ohio 44325

GEWAIN, Richard G., American Iron and Steel Institute, 1000 16th Street, N.W., Washington, D.C. 20036

GLOWINSKI, Robert W., National Forest Products Association, 1619 Massachusetts Avenue, N.W., Washington, D.C. 20036

GOREN, Simon L., Department of Chemical Engineering, University of California, Berkeley, California 94720

GREENAUGH, Kevin C., NRC, Washington, D.C. 20555

HALL, John, National Fire Protection Association, Batterymarch Park, Quincy, Massachusetts 02269

HARRIS, Carl, Department of Systems Engineering, University of Virginia, Charlottesville, Virginia 22901

HARTZELL, Gordon E., Southwest Research Institute, 6220 Culebra Road, San Antonio, Texas 78284

HASEGAWA, Harry K., Lawrence Livermore National Laboratory, P.0. Box 55501, L-442, Livermore, California 94550

HATHAWAY, C. E., Monsanto Company, 800 North Lindbergh

HAWKINS, W. Frank, Watts Bar Nuclear Plant, P.0. Box 800, Spring City, Tennessee 37381

HEIMANN, David, DTS6-65, U.S. DoT, Transportation System Center,

55 Broadway, Cambridge, Massachusetts 02142

HESKESTAD, Gunnar, Factory Mutual Research Corporation, 1151 Boston-Providence Highway, Norwood, Massachusetts 02062

HIRSCHLER, F.F. Goodrich Chemical Group, Avan Lake Technical Center, Avon Lake, Ohio 44012 
HoLMES, Wayne D., American Nuclear Insurers, 270 Farmington Avenue, Farmington, Connecticut 06032

HOPPER, Richard Ned, Carpet and Rug Institute, Suite 1000, 1100 17th Street, N.W., Washington, D.C. 20036

HUGGETT, Clayton, Center for Fire Research, National Bureau of Standards, Gaithersburg, Maryland 20899

INDRITZ, Doren, Exxon Research and Engineering Company

JALURIA, Yogesh, Mechanical Engineering. Department, Rutgers University, New Brunswick, New Jersey 08903

JONES, Walter, Center for Fire Research, National Bureau of Standards, Gaithersburg, Maryland 20899

JONSSON, Robert, Division of Building Fire Safety and Technology, Lund Institute of Technology, P.0. Box 118, S-221 00, Lund, Sweden

KAMINSKI, Andrzej, DTS 6-65, U.S. DoT, Transportation System Center, 55 Broadway, Cambridge, Massachusetts 02142

KELLEY, Ronald, Dow Corning Corporation

KENDIK, Ezel, Argentiniestr 28/10, 1040 Vienna, Austria

KISKO, Tom, University of Florida, 303 Weil Hall, Gainesville, Florida 32611

KOFFEL, William E. Jr., Gage-Babcock \& Associates, Inc., 301 Maple Avenue, West, Suite 2-F, Vienna, Virginia 22180

KOURTIDES, Demetrius A., National Aeronautics and Space Administration, Ames Research Center, N223-6, Moffett Field, California 94035

KUBU, Edward T., Allied Corporation, Fibers Division, P.O. Box 3l, Petersburg, Virginia 23804

LABES, Willis G., Prof. Emeritus, IIT, 1000 Allendale Drive, Charlottseville, Virginia 22901

LANGE, Bob, MobiI Research and Development

LAWSON, Randy, Center for Fire Research, National Bureau of Standards Gaithersburg, Maryland 20899

LEVINE, Robert S., Center for Fire Research, National Bureau of Standards, Gaithersburg, Maryland 20899

LEVY, Arthur, Battelle, Columbus Laboratories, 505 King Avenue, Columbus Ohio 43201 
LUND, Peter D., Society of Fire Protection Engineers, 60 Batterymarch Street, Boston, Massachusetts 02110

MALHOTRA, H.L., Consultant, 44, Goodyers Avenue, Radclift Hurts, U.K.

MITLER, Henri, Center for Fire Research, National Bureau of Standards, Gaithersburg, Maryland 20899

MODY, Mahesh J., City of New York, Department of Buildings, 120 Wall Street, New York, New York 10005

MOREHART, Jonas L., National Institutes of Health, Rm. Cl02, Building 31 , 9000 Rockville Pike Bethesda, Maryland 20205

MULHAUPT, Rick, NFPA Research Foundation, Batterymarch Park, Quincy, Massachusetts 02269

NEWMAN, Jeffrey S., Factory Mutual Research Corporation, 1151 Providence Highway, Norwood, Massachusetts 02062

NORTHCOTT, Julian, Kling Lindquist, Inc., 2301 Chestnut Street, Philadelphia, Pennsylvania

PACKHAM, Steven, 996 South 1500 East, Salt Lake City, Utah 84105

PADDEN, Noes B., United States Fire Administration, 16825 S. Seton Avenue, Emmitsburg, Maryland 21727

PAULS, Jake, National Research Council Canada, Rm. 178, Building M-50, NRC Canada, Ottawa, Canada KIAOR8

PEARSON, Richard, North Carolina State University, School of Engineering Department of Industrial Engineering, Box 5511, Raleigh, North Carolina 27650

PEDLOW, J. Watson, Quelcor Division, Thomas and Betts Corporation, P.0. Box 33, Medio, Pennsylvania 19863

PIETRZAK, Larry, Mission Research Corporation, P.0. Drawer 719, Santa Barbara, California 93102

PLATTS, Francis H., Westinghouse Electric Corporation, P.0. Box 248, Hampton, South Carolina 29924

PRAHL, Joseph M., Department of Mechnical and Aerospace Engineering, Case Western Reserve University, Cleveland, Ohio 44106

PRZYBYLA, Underwriters Laboratories Inc., 333 Pfingsten Road, Northbrook, Illinois 60062 
REMMERS, Gene M., David Taylar Naval Ship R\&D Center, Code 1202, Bethesda, Maryland 20084

REUTHER, James J., Battelle Columbus Laboratories, 505 King Avenue, Columbus, Ohio 43201

ROBINSON, Donald, Envirormental Health and Safety, University of Massachusetts, $N 414$ Morrill Science Center, Amher'st, Massachusetts 01003

ROUX, H.J., Armstrong Worla Industries, Inc., Lancaster, Pennsylvania 17604

SCHAENMAN, Philip, TRIData Corporation, 1500 Wilson Boulevard, Arlington, Virginia 22209

SHAw, W.A., Hoechst Fibers Industries, P.0. Box 5807, Spartanburg, South Carolina 29304

SHOUMAN, Alımad, University of New Mexico Engineering Institute, Campus P.0. Box 25

SKAARET, Eimund, Norwegian Institute of Technicology, Divisior of Heating and Ventilating, N-7034 Trondhelm - NTH, NORWAY

SMITH, Gregory F., B.F. Goodrich Technical Center, P.0. Box 122, Avon Lake .Ohio 44012

SNELL, Jack E., Center for Fire Research, National Bureau of Standards, Gaithersburg, Maryland 20899

SPRINGER, George S., Stanford, University, Department of Aero/Astro, Stanford, Connecticut 94305

STIEFEL, Wayne, Center for Fire Research, National Bureau of Standards, Gaithersburg, Maryland 20899

SULTAN, M.A., National Research Council of Canada, Ottawa, Ontario KlA OR6 (Building M-59)

TEWARSON, A., Factory Mutual Research Corporation, 1151 Boston-Providence Turnpike, Norwood, Massachusetts 02062

T'IEN, James S., Case Western Reserve University, Department of Mechanical and Aerospace Engineering, Cleveland, Ohio 44106

THOMAS, Emory, Brunswick Defense, 3333 Harbor Blvd, Costa Mesa, California 92626

TUCKER, Richard B.C. Jr., STX, Inc., 8989 Yellowbrick Road, Baltimore Maryland 
WATTS, Jack, Fire Safety Institute, P.0. Box 674, Middlebury, Vermont 05753

WECKMAN, Beth, Department of Mechanical Engineering, University of Waterloo, Waterloo, Ontario, Canada N2L 3G!

WEINTRAUB, Arnold A., U.S. Department of Energy, 5112 Russett Road, Rockville, Maryland 20853

WELKER, J. Reed, University of Arkansas, 227 Engineering Building, Fyetteville, Arkansas 72701

WENDT, Bruce, Department of Mechanical and Aerospace Engineering, Case Western Reserve University, Cleveland, Ohio 44106

WHITE, James A. Jr., Weyerhaeuser Company, P.0. Box 188, Longview, WA 98632

WLLLIAMSON, R. Brady; Department of Civil Engineering, University of California, Berkeley, California 94720

WINGER, James, Center for Fire Research, National Bureau of Standards, Gaithersburg, Maryland 20899

YEH, K., University of Maryland, 2100 Marie Mount, College, Park, Maryland 20742

YING, Shuh-Jing, University of South Florida, Fowler, Avenue, Tampa, Florida 33620

YOU, Hong-Zeng, Factory Mutual Research Corporation, 1151 Boston-Providence Turnpike, Norwood, Massachusetts 02062

ZUKOSKI, Edward E., California Institute of Technology, Pasadena, California 91125 


\begin{tabular}{|c|c|c|c|c|}
\hline U.S. DEPT. OF COMM. & 1. PUBLICATION OR & 2. Performing Organ. Report No 3. Publication Date \\
BIBLIOGRAPHIC DATA & $\begin{array}{c}\text { REPORT NO. } \\
\text { NHET (See instructions) }\end{array}$ & NBSIR 85-3136 & & Apr 11985 \\
\hline
\end{tabular}

4. TITLE AND SUBTITLE

SUMMARIES OF CENTER FOR FIRE RESEARCH GRANTS AND IN-HOUSE PROGRAMS - 1984

5. $\operatorname{AUTHOR}(S)$

Sonya M. Cherry

6. PERFORMING ORGANIZATION (If jolnt or other than NBS, see instructions)

7. Contract/Grant No.

NATIONAL BUREAU OF STANDARDS

DEPARTMENT OF COMMERCE

WASHINGTON, D.C. 20234

9. SFONSORING ORGANIZATION NAME AND COMPLETE ADDRESS (Street Clly, $_{\text {StOL, ZIP) }}$

8. Type of Report \& Period Covered

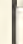

10. SUPPLEMENTARY NOTES

Document describes a computer program; SF-185, FIPS Software Summary, is attached.

11. ABSTRACT (A 200-word or less factual summary of most significant information. If document includes a significant bibliography or literature survey, mention it here)

This report was prepared for distribution at the 1984 Annual Conference on Fire Research, October 17-19, 1984. It contains extended abstracts of grants and contracts for fire research sponsored by the Center for Fire Research, National Bureau of Standards, as well as descriptions of the internal programs of the Center for Fire Research.

12. KEY WORDS (Six to twelve entries; alphabetical order; capitalize only proper names; and separate key words by semicolons)

Evacuation; combustion; extinction; fire models; flame spread; ignition; polymers; smoke; soot; toxictty.

13. AVAILABILITY

[.] Unlimited

$\square$ For Official Distribution. Do Not Release to NTIS

Order From Superintendent of Documents, U.S. Government Printing Office, Washington, D.C. 20402.

Xrder From National Technical Information Service (NTIS), Springfield, VA. 2216I
14. NO. OF

PRINTED PAGES

161

15. Price

$\$ 16.00$ 

